\title{
Survey of Response-to-Intervention's Challenges for School-Based Speech-Language Pathologists
}

Jane D. Simmerman

West Virginia University

Follow this and additional works at: https://researchrepository.wvu.edu/etd

\section{Recommended Citation}

Simmerman, Jane D., "Survey of Response-to-Intervention's Challenges for School-Based SpeechLanguage Pathologists" (2011). Graduate Theses, Dissertations, and Problem Reports. 3105.

https://researchrepository.wvu.edu/etd/3105

This Dissertation is protected by copyright and/or related rights. It has been brought to you by the The Research Repository @ WVU with permission from the rights-holder(s). You are free to use this Dissertation in any way that is permitted by the copyright and related rights legislation that applies to your use. For other uses you must obtain permission from the rights-holder(s) directly, unless additional rights are indicated by a Creative Commons license in the record and/ or on the work itself. This Dissertation has been accepted for inclusion in WVU Graduate Theses, Dissertations, and Problem Reports collection by an authorized administrator of The Research Repository @ WVU.

For more information, please contact researchrepository@mail.wvu.edu. 
Survey of Response-to-Intervention's Challenges for

School-Based Speech-Language Pathologists

Jane D. Simmerman

Dissertation submitted to the

College of Human Resources and Education

at West Virginia University

in partial fulfillment of the requirements

for the degree of

Doctor of Education

in

Curriculum and Instruction

Allison Swan Dagen, Ph.D., Chair

Aimee Morewood, Ph. D.

Mary Ellen Tekieli Koay, Ph.D.

Sebastían R. Diaz, Ph.D.

Jane Cardi, Ed.D.

Department of Curriculum and Instruction

Morgantown, WV

2011

Keywords: No Child Left Behind; Response-to-Intervention; Speech-language pathologist;

Caseload; Workload

Copyright 2011 Jane D. Simmerman 


\section{ABSTRACT \\ Survey of Response-to-Intervention's Challenges for School-Based Speech-Language Pathologists}

\section{Jane D. Simmerman}

With the introduction of the No Child Left Behind Act (NCLB), speech-language pathologists (SLPs) have experienced a new focus on language and literacy within their roles and responsibilities to provide services to students. The American Speech and Hearing Association (ASHA) support the role of SLPs in literacy efforts through their policies regarding expanded roles and responsibilities for school-based SLPs. ASHA notes that school-based SLPs have a clearly defined role in Response to Intervention (RTI) based on their expertise, knowledge and training to provide services as a resource and an interventionist when appropriate. The effect of the redefined roles and responsibilities of school-based SLPs for children who are experiencing literacy difficulties has been largely unstudied in the state of West Virginia. This study was an attempt to begin to investigate the challenges that SLPs in the state of West Virginia feel they face within the RTI model. While an effective research based framework such as RTI is essential to the success of students, the perceptions of the challenges that SLPs feel they face in their role in the RTI process directly impacts the effectiveness of participation in the RTI model in delivery of services on a day-to-day basis. SLPs' perceptions of the challenges they face in the RTI process, adequacy of training, willingness to participate in the documentation required within the RTI model, and the willingness to adopt collaboration techniques with other professionals within the RTI model are examined in the study. The sample population for the survey consisted of SLPs $(n=227)$ from across the state of West Virginia. The study was conducted through a three phase process. Phase One involved a pilot study of two counties in the state of West Virginia, Phase Two involved the use of a paper survey that was distributed at the 2011 annual West Virginia Speech and Hearing Association (WVSHA) Convention, and Phase Three involved the distribution of the survey via SurveyMonkey.com. Demographic information was collected and participants were asked to state their agreement on 26 perception statements using a 5-point Likert scale.

This quantitative study gathered data on the challenges SLPs from across the state of West Virginia feel they are currently facing within the RTI model. Results of the study indicate that the majority of school-based SLPs in West Virginia do not currently participate in the delivery of RTI services to students. In addition, the study indicated that the majority of school-based SLPs who participated in the study provide direct services to students through a caseload only model, which includes students who have a current Individualized Education Plan (IEP) in place and have not embraced a new framework called RTI to meet the challenges of appropriately offering interventions to students struggling with literacy issues. Based on statistical analysis of this survey utilizing both descriptive statistics and ANOVA, recommendations were made to help guide future professional development and training for school-based SLPs in the implementation of the RTI model. The current study confirms the need for school-based SLPs in West Virginia to consider adapting their service delivery model to address the unique needs of the children who struggle with literacy issues. 


\section{Acknowledgements}

The journey through my doctorate degree has been an invaluable learning experience. Along the way I have made many new friends and explored the world of Curriculum and Instruction. I also feel that I have had the opportunity to deepen my love of education as I followed the path of learning. My sincerest thanks and appreciation is extended to all who have assisted in any way with the completion of my journey through the dissertation process.

I extend a heartfelt thanks to Dr. Allison Swan-Dagen who graciously agreed to serve as my advisor and dissertation chair. She has strengthened the foundations of my learning through her encouragement and support. In addition, she has helped me to achieve a life long goal.

I wish to also thank the members of my dissertation committee, Dr. Aimee Morewood, Dr. Mary Ellen Tekieli Koay, Dr. Sebastián R. Díaz, and Dr. Jane Cardi, for their guidance and input. I truly appreciate their time and expertise.

Last, but definitely not least, I would like to thank my family. I am ever so grateful for the support that my husband, Frank, has given me throughout the many hours I have dedicated to the completion of this degree. I am also extremely thankful for my two children, Trey and Rebecca, who have continually provided encouragement throughout this endeavor. 


\section{Table of Contents}

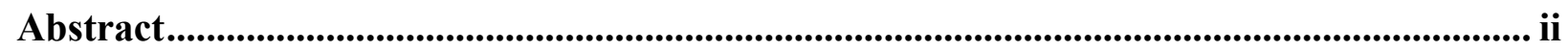

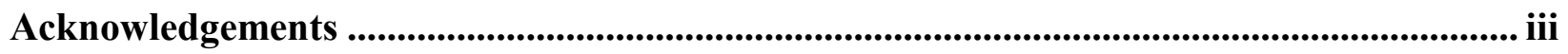

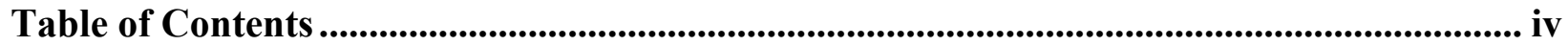

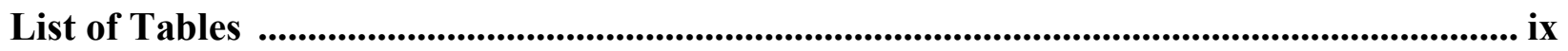

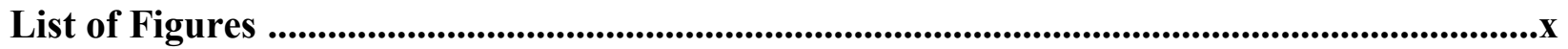

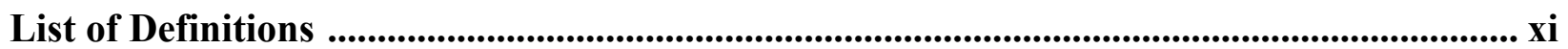

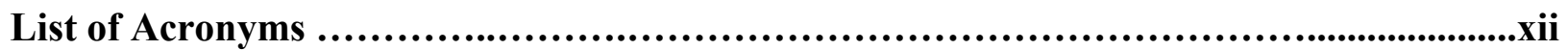

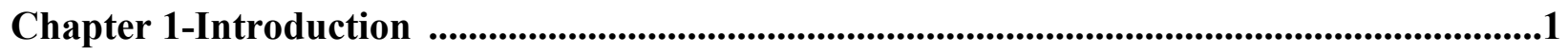

Evolution of Speech Therapy ........................................................................................................4

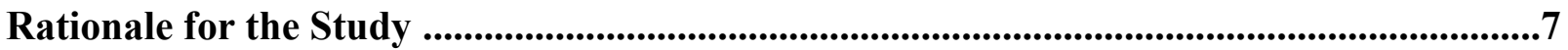

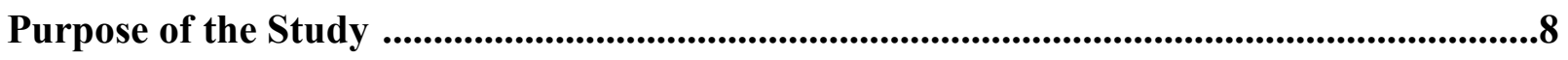

Research Questions and Hypotheses ..............................................................................................9

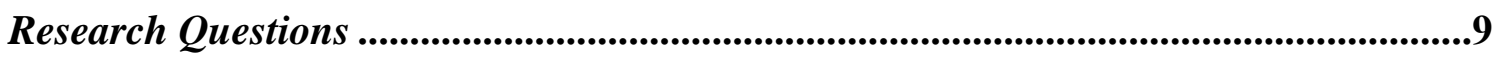

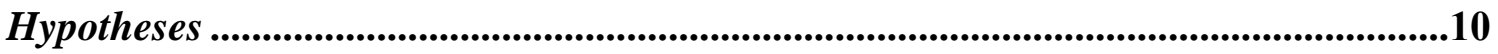

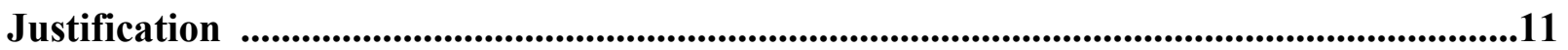

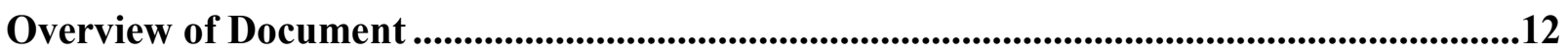

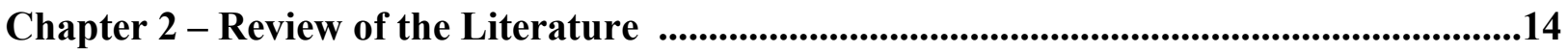

A Brief Overview of ASHA Position Statements ........................................................16

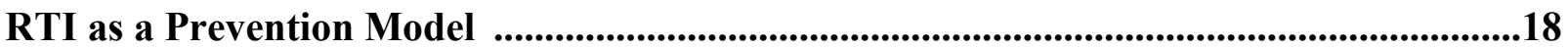

Where Do SLPs "Fit" in the Tiers of Intervention? ...................................................25

Tier 1 ......................................................................................................................................................2

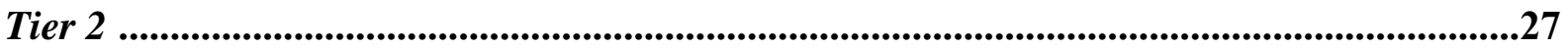


Tier 3

Are SLPs Engaging in RTI Practices?

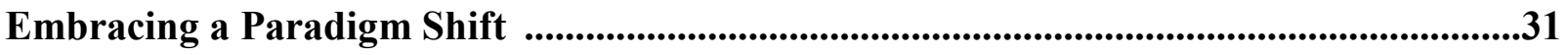

Examining the Issue of Caseload versus Workload for SLPs ............................................35

Professional Development - Bridging the Gap between Research and Practice ................38

Opportunities and Challenges for SLPs - How Will They Be Perceived? ..........................41

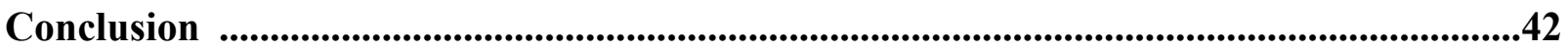

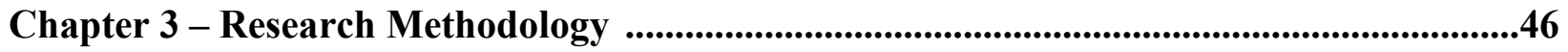

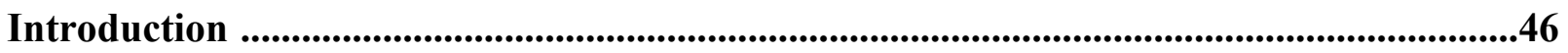

Design of the Study $\quad$.........................................................................................................................46

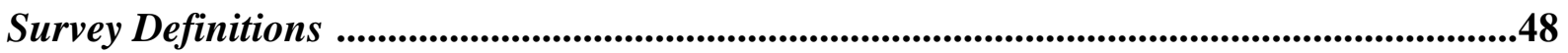

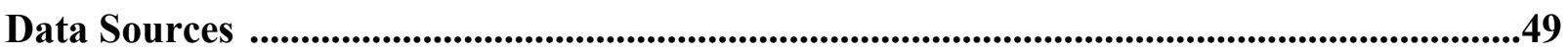

Population and Sample

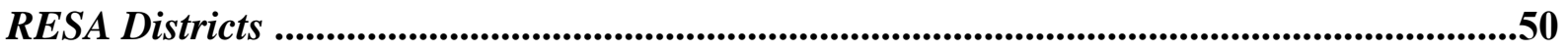

Data Collection Procedures ............................................................................................52

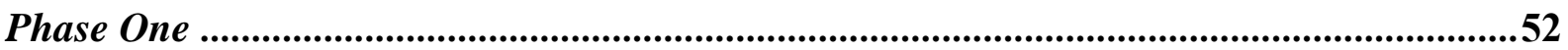

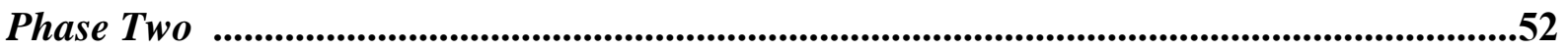

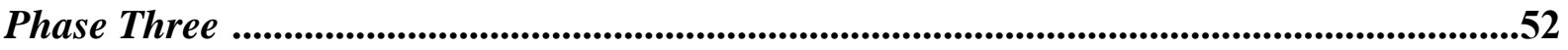

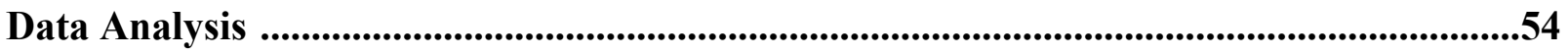

Establishment of Content Validity and Reliability ................................................................56

Validity in Relation to Research Questions ..................................................................58

Research Question One (RQ1) ..............................................................................................59

Research Question Two (RQ2) .......................................................................................................60 
Research Question Three (RQ3) ..........................................................................................62

Research Question Four (RQ4) ...............................................................................................................63

Research Question Five (RQ5) ............................................................................................................64

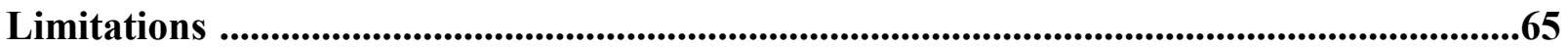

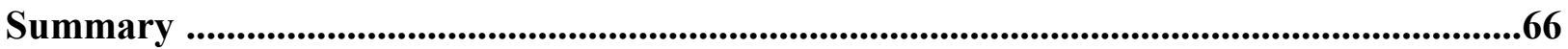

Chapter 4 - Results .............................................................................................................................68

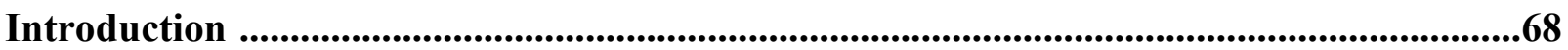

Demographic and Descriptive Statistics ............................................................................69

Current Caseload Configuration ............................................................................................................69

Years of Experience ..........................................................................................................................70

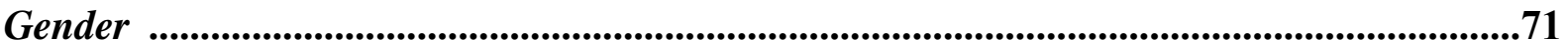

Highest Degree Earned ..................................................................................................................................71

Breakdown of Respondents by RESA District ............................................................................72

Data Analysis for Research Questions .................................................................................73

Research Question One (RQ1) ........................................................................................................73

Research Question Two (RQ2) ...............................................................................................74

Research Question Three (RQ3) .....................................................................................76

Research Question Four (RQ4) .......................................................................................................77

Research Question Five (RQ5) ................................................................................................78

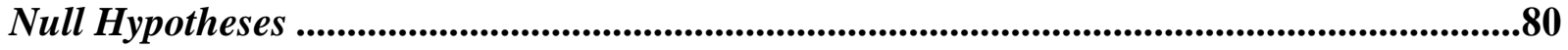

Analysis of Variance (AVOVA .........................................................................................................81

Current Caseload Configuration ..........................................................................................................82

Years of Experience ..................................................................................................................................88 
Highest Degree Earned .................................................................................................82

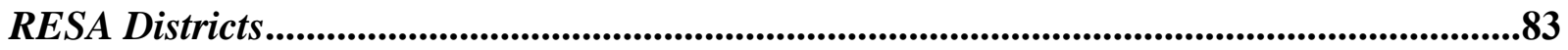

Ranking of Major Issues for SLPs in the RTI Process ..........................................................83

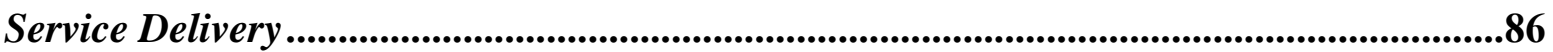

Additional Information by RESA District Regarding Participation in RTI.......................87

Internal Reliability .....................................................................................................................88

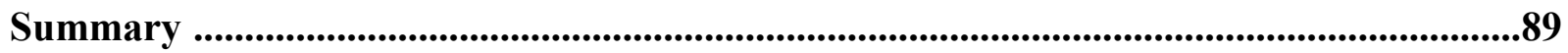

Chapter 5 - Discussion .....................................................................................................................91

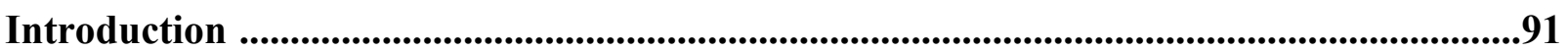

Emergent Themes $\quad$....................................................................................................................92

Difficulty Embracing Collaboration within the RTI Model.............................................92

Difficulty Embracing Changes within Service Delivery Models........................................93

Difficulty Embracing Ownership of the RTI Model .................................................................95

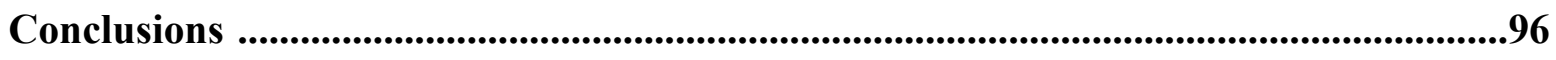

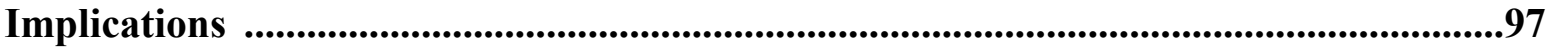

Recommendations for Future Research

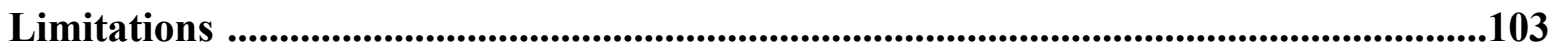

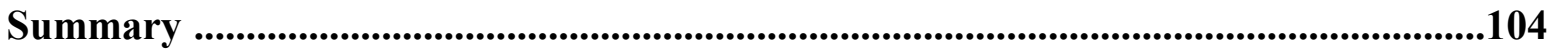

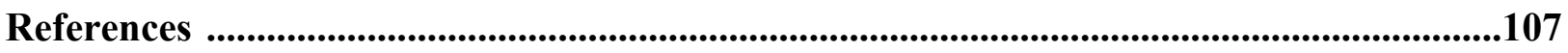

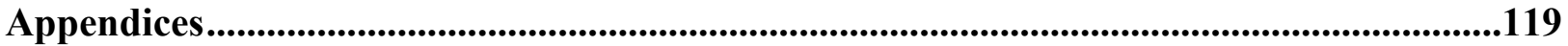

Appendix A - Survey of School-Based SLPs and the RTI Process ................................119 
Appendix B - Example of the Invitation Letter for the Paper Survey-

Phase 1 \& Phase 2

Appendix C - Example of the Invitation Letter for SurveyMonkey.com-Phase 3

Appendix D - West Virginia University Internal Review Board - Permission to Conduct a Pilot Study.

Appendix E - West Virginia University Internal Review Board - Permission to Include

Pre-existing Data.

Appendix F - West Virginia University Internal Review Board - Permission to Collect

Data from Survey Monkey.com 


\section{List of Tables}

Table 3.1 Summary of the Number of Completed Surveys by Phase

Table 4.1. Frequency and Percent of the Caseload Configuration Reported by School-Based SLPs in the State of West Virginia Who Responded to the Survey .70

Table 4.2. Frequency and Percent of the Years of Experience Breakdown of School-Based SLPs in the State of West Virginia Who Responded to the Survey

Table 4.3. Frequency and Percent by Gender of School-Based SLPs in the State of West Virginia Who Responded to the Survey

Table 4.4. Frequency and Percent by Highest Degree Earned of School-Based in the State of West Virginia Who Responded to the Survey

Table 4.5. Frequency and Percent by RESA District of School-based SLPs in the State of West Virginia Who Responded to the Survey.

Table 4.6. Reported Frequency and Percent for Questions \#1 through \#6 .74

Table 4.7. Reported Frequency and Percent for Questions \#18 through \#23 .......................75

Table 4.8. Reported Frequency and Percent for Questions \#24 through \#26 .........................76

Table 4.9. Reported Frequency and Percent for Questions \#7 through \#12 ..........................77

Table 4.10 Reported Frequency and Percent for Questions \#13 through \#17 .....................79

Table 4.11. Reported Service Delivery by SLPs in West Virginia......................................86

Table 4.12. Frequency and Percent of Respondents Who Reported Participation in RTI by RESA District. 


\section{List of Figures}

Figure 2.1. Description of the Three Tiered Reading Model ..................................................20

Figure 3.1. Regional Educational Service Agencies in West Virginia

(RESA Districts).

Figure 3.2. Research Question One (RQ1) Survey Statements ................................................60

Figure 3.3. Research Question Two (RQ2) Survey Statements ................................................61

Figure 3.4. Research Question Three (RQ3) Survey Statements .............................................62

Figure 3.5. Research Question Four (RQ4) Survey Statements .........................................63

Figure 3.6. Research Question 5 ((RQ5) Survey Statements ...................................................65

Figure 4.1. Results of the Reported Frequency Responses to the Rank Order Question for the Category of Most Challenging..........................................................................88

Figure 4.2. Results of the Reported Frequency Responses to the Rank Order Question for the Category of Least Challenging

Figure 4.3. Percentages of Reported Participation by RESA Districts ................................88 


\section{List of Definitions}

American Speech-Language-Hearing Association (ASHA). The American SpeechLanguage-Hearing Association is the professional credentialing association for speech-language pathologists and audiologists.

Caseload. The term caseload typically refers to the number of students with Individualized Education Programs (IEPs) who school SLPs serve through direct and/or indirect service delivery options (ASHA, 2002).

Classroom/Push-In Model of Service Delivery. The classroom/push-in model of service delivery involves SLPs who provide speech, language services to students on their caseloads in the classroom setting in order to problem solve and design appropriately individualized and differentiated lessons.

Consultation/Collaboration Model of Service Delivery. This type of indirect service delivery is employed when a group of individuals (e.g., the SLP and teacher) collaboratively solve problems related to the students needs. Collaborative consultation can be described as an interactive process that enables groups of people with diverse expertise to generate creative solutions to mutually defined problems (Idol, Nevin \& Paolucci-Whitcomb, 1994). It can be the medium that supports interactions between teachers and SLPs in order to address the student's speech and language weaknesses (Merritt \& Culatta, 1998).

Direct Therapy/Pull-Out/Traditional Model of Service Delivery. By definition, pullout speech language services occur whenever the SLP works independently and provides smallgroup or individual services in a setting that is separate from the student's classroom (e.g., speech therapy room, hallway, etc.). 
Education of All Handicapped Children Act. The Act passed by Congress in 1975 that orders all public schools to provide an education to all disabled children.

Evidence-Based Practice. Evidence-based practice is the use of the best available evidence in research and individual expertise in making decision about interventions for individual students.

Free Appropriate Public Education (FAPE). FAPE includes special education and related services which are provided at public expense, under public supervision and direction, and without charge to the parent. Services meet the standards of the state education agency and include preschool, elementary, and secondary education and are provided to fulfill the Individualized Education Plan (IEP).

Individualized Education Plan (IEP). A written plan/program developed by the school's special education team with input from the parents and specifies the student's academic goals and the method to obtain these goals.

Interventionist. Member of a school team to identify students at risk for poor learning outcomes, monitor student progress, provide evidence-based interventions and adjust the intensity and nature of those interventions depending on a student’s responsiveness.

Individuals with Disabilities Education Act 2004 (IDEA). This is the Act that outlines rights and regulations for students with disabilities in the U.S. who require special education. Under the IDEA, all children with disabilities are entitled to a Free Appropriate Public Education (FAPE) in the Least-Restrictive Environment (LRE).

Least Restrictive Environment (LRE). LRE refers to the educational placement which provides the services necessary to meet the unique educational needs of the student, while 
providing the student with integration to the maximum extent appropriate with peers without exceptionalities.

No Child Left Behind (NCLB). The Act passed by Congress on January 8, 2002, which was the largest reform of ESEA since it began in 1965. The goal of this Act was to ensure accountability, flexibility, and equitable support for the education of all of the children in America.

President's Commission on Excellence in Special Education (PCESE). President George Bush ordered the creation of the 24-member President's Commission on Excellence in Special Education on Oct. 2, 2001 (Executive Order 13227). The President charged the Commission with studying issues related to federal, state, and local special education programs in order to improve the educational performance of students with disabilities. The Commission's effort represents the most expansive review of special education in the 27-year history of the Individuals with Disabilities Education Act. The Commission submitted the report titled A New Era: Revitalizing Special Education for Children and their Families to The White House on July 1 as required by the Executive Order.

Professional Development. According to the thesaurus of the Educational Resources Information Center (ERIC) database, professional development refers to activities to enhance professional career growth. Such activities may include individual development, continuing education, and in-service education, as well as curriculum writing, peer collaboration, study groups, and peer coaching or mentoring. ASHA's 2007 Scope of Practice in Speech-Language Pathology Position Statement defines professional development as any activity that relates to the science and contemporary practice of speech-language pathology, and results in the acquisition of new knowledge and skills or the enhancement of current knowledge and skills. 
Response to Intervention (RTI). This is a process by which early preventative assistance is provided to students exhibiting the first signs of academic difficulty.

Workload. Workload refers to all activities required and performed by school-based SLPs. SLP workloads include considerable time for face-to-face direct services to students. Workloads also include many other activities necessary to support students' education programs, implement best practices for school speech-language services, and ensure compliance with IDEA and other mandates (ASHA, 2002). 


\section{List of Acronyms}

The field of speech-language pathology often uses a unique set of acronyms to describe various aspects of the profession. The following list identifies the acronyms used in this paper. The list includes the following:

ASHA: American Speech and Hearing Association

IDEA: Individuals with Disabilities Education Act

IEP: Individualized Educational Plan

LEA: Local Education Agency

NCLB: No Child Left Behind

RESA: Regional Education Service Agency

RTI: Response-to-Intervention

SLP: Speech-language pathologist

WVSHA: West Virginia Speech and Hearing Association 


\section{CHAPTER 1}

\section{Introduction}

It is September and time for school to swing into full gear. It is also time for interventionists to begin benchmark assessments. Mrs. Smith, a speech-language pathologist (SLP) is approached by the administrator at her school and asked to participate as an interventionist for the upcoming school year. Mrs. Smith has overheard the teachers in her building talking about a "new” program called Response to Intervention (RTI), which is designed to keep students from falling farther and farther behind in reading-related tasks. Last year, the SLPs in Mrs. Smith's district attended an all day professional development session on RTI that was considered an "overview” of the RTI model. However, Mrs. Smith and the other SLPs whom Mrs. Smith has talked to in her district lately, have many unanswered questions about the challenges of assuming the role of an interventionist ...

Mrs. Smith begins to question where she fits in the RTI process ... What are some of the challenges that I face as an interventionist? How do my perceptions of tiered intervention practices affect the delivery of RTI to my students? Where does RTI fit in the roles and responsibilities of an SLP? When will I receive more professional development on the RTI model? How does this impact my caseload on a day-to-day basis? Has anyone bothered to address any of these questions with Mrs. Smith? Since 1975 when Public Law 94-142 Education Act mandated speech and language services in the schools, the scope of practice has continually changed for SLPs. As a result of the Individuals with Disabilities Education Improvement Act (IDEA, 2004), emphasis has been placed on a systematic approach that integrates general and special education into a unified 
system. The opportunity for schools to expand their use of alternative service delivery models represents a significant paradigm shift for SLPs' day-to-day practices. Presently, SLPs now have unique contributions to make in the learning environment such as:

- focusing on language and related cognitive underpinning;

- using a language lens to employ a linguistic perspective in viewing curriculum, instruction, and assessment components and student's responses to them; and

- taking a diagnostic-prescriptive approach (Ehren, 2007).

Historically, federal legislation has influenced the roles of educators of exceptional students. In 1975, Congress passed Public Law 94-142, the Education of All Handicapped Children Act. This legislation led to requirements for school systems to actively search and identify students with disabilities that were educationally handicapping. In order to comply with Public Law 94-142, most states adopted a version of an IQ-achievement discrepancy model to diagnose learning disabilities (Fuchs, Mock, Morgan, \& Young, 2003). Through the years, the IQ-achievement discrepancy model has received repeated criticism. Gresham (2001) declared, "The process by which public schools identify students as Learning Disabled often appears to be confusing, unfair, and logically inconsistent” (p. 2).

In 1997, Public Law 94-142 was amended and renamed the Individuals with Disabilities Education Act (IDEA). This amendment called for students with disabilities to be included in state and district-wide assessments. At this time, regular education teachers became required members of the Individual Education Plan (IEP) team meeting.

In 2001, President George W. Bush established the President's Commission on Excellence in Special Education (PCESE), which set the standards and made 
recommendations on what changes should be made to the present special education services for children (Batsche, Elliot, Graden, Grimes, Kovaleski \& Prasse, 2006). The PCESE published their findings on July 1, 2002, which consisted of three main recommendations, which served to influence change in regard to the Individuals with Disabilities Education Act. They are as follows:

- focus on results - not on process;

- embrace a model of prevention, not a model of failure; and

- consider children with disabilities as general education children first (U. S. Department of Education Office of Special Education and Rehabilitative Services, 2002, p. 8-9).

These efforts led to the enactment of the No Child Left Behind Act of 2001, which called for all students, including students with disabilities to be proficient in math and reading by the year 2014 .

Presently in our schools, two federal government mandates, the No Child Left Behind Act (NCLB, 2002) and the Individuals with Disabilities Education Improvement Act (IDEA, 2004), have acted as catalysts to change the rigor in the implementation of classroom interventions. Over the past ten years, educators have become increasingly aware of the need to make educational decisions based on data that inform curriculum, the needs of their students, and the implementation of programs that are effective. Under the current mandates, interventionists in schools across America are expected to identify and implement empirically-based, student-specific instructional interventions with an increased focus on precision and at higher levels of accountability in regard to their students (Gersten \& Hitchcock, 2008). Both of these mandates have far-reaching 
implications for the policies and practices that are currently taking place in our schools (O’Connor, Harty, \& Fulmer, 2005). The general education initiative that resulted from NCLB and IDEA (2004) is referred to as Response to Intervention (RTI). According to Brown-Chidsey and Steege (2005), RTI affords "great promise for increasing the likelihood that all students will be successful in school” (p. 160).

\section{Evolution of Speech Therapy}

According to Means (2006), the field of speech language pathology began at the turn of the century when a school superintendent identified a need for speech training in the schools. However at that time instructors were deemed speech correctionists and assisted only those students who demonstrated stammering. Later, SLPs began to identify and treat articulation errors and voice disorders (Means, 2006). By 1923, legislation in the state of Wisconsin was established for speech correctionists in the public school and by 1940, eight additional states adopted the legislation. It was not until the mid 1960s when 45 states passed legislation for speech improvement programs in schools that speech and language disorders became part of service delivery (Blosser and Neidecker, 2002). In addition, Means (2006) noted when Public Law 94-142 was mandated in 1975, speech and language services in the schools became available to children with speech and language impairments. Throughout this time period the scope of practice for SLPs continued to change.

Blosser and Kratcoski (2002) declared that the role of the SLP is a reflection of the emerging issues in each decade. In addition, Blosser and Kratcoski (2002) noted the transition from a "medical model” to an "educational model”. The following is a 
summary from Blosser and Kratcoski's (2002) chart, The Evolution of SLP Service Delivery Models:

- in the 1970s, the focus was on a mechanistic view to language and the concepts of syntax, semantics and phonology were viewed as necessary components of learning;

- in the 1980s, pragmatics were emphasized and language and learning became linked by the SLP;

- in the 1990s, the introduction of inclusion, collaboration, and consultation resulted in a paradigm shift that many SLPs were not prepared to embrace within their service delivery model; and

- currently, this paradigm shift of location of service and provider in special education continues through the 2000s in which the SLPs' role is the facilitator of service delivery within various contexts. The focus for the SLP now becomes one of standards, quality of outcomes, and evidence-based practice. The SLP becomes a facilitator within a framework that involves knowledge of the curriculum.

In 2001, the American Speech-Language and Hearing Association (ASHA) developed guidelines to clarify the roles and responsibilities for SLPs in all practice settings related to the development of reading and writing among children and adolescents. The Roles and Responsibilities of Speech-Language Pathologists (2001) noted that SLPs play a "critical and direct role in the development of literacy for children and adolescents based on the connections between spoken and written language” (ASHA, 2001, p. 2). According to ASHA (2001), school-based SLPs can play a number of important roles in 
the utilization of RTI to identify children with disabilities and provide needed instruction to struggling students in both general education and special education settings. Moreover, ASHA (2001) reported SLPs may also make contributions to literacy efforts on behalf of other children and adolescents in collaboration with other academic professionals. Rigney (2004) noted that SLPs need to become familiar with the state content standards and curriculum. Through collaboration with regular educators, SLPs may make a move toward an educational model rather than provide services through a medical model. Rigney (2004) also suggested SLPs possess knowledge in instructional strategies in reading, reasoning, problem solving, and communicating which puts them in a critical leadership role in designing and delivering professional development activities to improve instruction. The American Speech-Language-Hearing Association (ASHA) (2001) noted SLPs may be the first professionals to identify weaknesses that could impact reading and writing difficulties through a student's difficulty with language. Moreover, ASHA (2001) reported SLPs address the elements of early language and literacy development such as the following:

- building and reinforcing relationships between early spoken language and early pre-literacy abilities;

- addressing difficulties involving phonological awareness memory and retrieval;

- teaching children to use tactile, kinesthetic, and auditory cues; and

- analyzing how the language demands of curriculum may stress a student's capabilities at different age and grade levels.

In 2010, the Ad Hoc Committee on the Roles and Responsibilities of SpeechLanguage Pathologists in Schools issued an updated position statement for school-based 
SLPs, which outlined the integral roles in the learning environment that are currently driven by educational reform and legal mandates. The 2010 position statement noted that the early years of school practice for SLPs included services focused on fluency, voice, language, and articulation disorders; however, now, an expanded scope of practice calls for a redefinition of work in the schools. Moreover, the 2010 position statement specifically addressed reading, writing, curriculum, and RTI as areas of evolving professional practice for the school-based SLP. Specifically, the 2010 position statement noted that RTI is a "framework for addressing the diverse learning needs of all students at a school to prevent failure” (p. 10).

\section{Rationale for the Study}

As a school-based SLP, I have had the opportunity to interact with school-based SLPs from counties throughout the state of West Virginia at various state meetings, a state coordinator in the Office of Special Programs at the West Virginia Department of Education, and the current president of ASHA. Feelings among these school-based SLPs are mixed on the delivery of RTI practices. The rationale for this study is based on a paradigm shift due to changes in roles and responsibilities for school-based SLPs (Ehren, Montgomery, Rudebusch, \& Whitmire, 2006).

In order to consider the adoption of tiered intervention practices, SLPs may need to alter various aspects of their delivery of service to students, such as the caseload versus workload model and the implementation of evidence-based practices. Matzke and Neumiller (2008) suggested "Together, a collaborative team of educators with a variety of expertise gather and analyze data regularly to identify struggling students, offer appropriate classroom-based and, if needed, supplemental interventions, and monitor 
student response to these interventions.” (p. 1). Regarding intervention and instructional support, SLPs may assume new and expanded roles that incorporate prevention and identification of at-risk students as well as more traditional roles of intervention (Ehren, Montgomery, Rudebusch, \& Whitmire, 2006; Justice, 2006; Ehren, 2007; ASHA, 2010).

In March of 2011, the West Virginia Department of Education revealed updated guidelines for best practices for speech-language pathology services in West Virginia schools. The West Virginia Department of Education (2011) noted “traditional approaches to speech therapy often result in students being enrolled in programs for long periods of time without making significant progress” (p. 45). The West Virginia Department of Education (2011) further noted "RTI has unique implications for students with speech-language impairments and has been adapted for implementation in speech therapy programs throughout the country” (p. 45).

\section{Purpose of the Study}

The background information collected for the introduction and from the experiences of the researcher comprised the many reasons for continuing research in this area. The purpose of this study was to investigate the various challenges that school-based SLPs face and how these challenges affect their participation rate in the RTI process. In addition, the following variables, which may provide challenges on a day-to-day basis for SLPs’ who are involved in tiered intervention practices, were considered:

- $\quad$ knowledge of the RTI process;

- $\quad$ workload versus caseload issues;

- professional development;

- feelings toward government mandated programs; and 
- accountability for the data involved with the RTI process

Considering the changes in the roles and responsibilities of SLPs' delivery of service to students in relation to tiered intervention practices, it is hypothesized that SLPs will feel that they have many challenges to address in order to assume successful implementation and active participation in the RTI process. In addition, it is also hypothesized that increased knowledge about the role of SLPs in the RTI process may lead to more positive perceptions in terms of the utility of RTI and the perceptions of benefit to students. It is likely that the more SLPs learn about how to confront the challenges associated with RTI, the more they will feel that SLPs can make a meaningful difference for students.

\section{Research Questions and Hypotheses}

Research Questions. This study was based on the belief that the challenges schoolbased SLPs feel they face in the RTI model serve as influences in whether or not schoolbased SLPs choose to participate in the RTI model. Insight into SLPs' challenges was sought using the following research questions:

The following research questions were used to guide the investigations of this examiner:

- Research Question One (RQ1). What do school-based SLPs in West Virginia perceive as challenges in the RTI process?;

- Research Question Two (RQ2). How do school-based SLPs in West Virginia feel about their present levels of training for implementation of tiered intervention practices?;

- Research Question Three (RQ3). What are the challenges of RTI within the service delivery on a day-to-day basis for school-based SLPs in West Virginia?; 
- Research Question Four (RQ4). How willing are SLPs in West Virginia to participate in the documentation process within the RTI model?

- Research Question Five (RQ5). How willing are SLPs in West Virginia to adopt collaboration techniques with other professionals in order to participate within the RTI model?

Hypotheses. Research questions one through five were addressed in the 26 statement Likert survey as SLPs selected their responses to statements about the challenges in the RTI process. The following statements include the null hypotheses:

- Null Hypothesis One (NH1). There will be no difference in the perceptions of the challenges of the RTI model for school-based SLPs;

- Null Hypothesis Two (NH2). There will be no difference in the challenges associated with the levels of professional development for the implementation of the RTI model for school-based SLPs from the eight Regional Education Service Agency (RESA) Districts in West Virginia.

- Null Hypothesis Three (NH3). There will be no difference in the challenges associated with service delivery of the RTI model on a day-to-day basis for schoolbased SLPs from the eight Regional Education Service Agency (RESA) Districts in West Virginia.

- Null Hypothesis Four (NH4). There will be no difference in the willingness of SLPs in West Virginia to participate in the documentation process within the RTI model.

- Null Hypothesis Five (NH5). There will be no difference in the willingness of SLPs in West Virginia to adopt collaboration techniques with other professionals in order to participate within the RTI model. 


\section{Justification}

These research questions emerged from an analysis of the various ASHA documents such as the Roles and Responsibilities of Speech-Language Pathologists (2001) and the Roles and Responsibilities of Speech-Language Pathologists (2010). In addition, comments that have been made by SLPs at various meetings and workshops I have attended have led me to question how the various attitudes toward RTI have been formed by SLPs throughout West Virginia. In a Position Statement released in 2001, ASHA noted SLPs offer expertise in the language basis of literacy and learning, experience with collaborative approaches to instruction/intervention, and an understanding of the use of student outcomes data when making instructional decisions. These research questions serve as only a guide to gain further knowledge of the challenges that SLPs face in the RTI process. Throughout this process, my goal is to seek an understanding of the impact these challenges have on the day-to-day delivery of services to children within the schools. Successful implementation of tiered intervention practices by SLPs requires active participation in the RTI process. The Roles and Responsibilities of SpeechLanguage Pathologists (2001) noted “The critical contributions of literacy competence to academic and social success and lifetime opportunities make it not only appropriate but essential that SLPs assume these roles and responsibilities” (ASHA, 2001, p. 34).

Certainly, if traditional roles continue, it will be difficult for SLPs to embrace the RTI process. SLPs must begin to investigate a paradigm shift in their thinking of the way that they serve students who demonstrate learning difficulties. RTI requires the collaborative preparation of school personnel who will need to work together to assist the general education of all students. The point of RTI, however, is not to add more tasks but to 
reallocate time to better address prevention and early intervention, and in the long run serve more students up front rather than at the point of special education evaluation and service On many occasions, it has been suggested that it takes a village to raise a child. I feel that SLPs can assume a very important role in the "village" to promote awareness of literacy in students.

The focus of my study and investigation is to find information in regard to West Virginia school-based SLPs' challenges of their roles and responsibilities within the RTI process. I maintain the belief that school-based SLPs in West Virginia are interested in making a significant difference in the lives of our students. Moreover, I feel that West Virginia school-based SLPs have a unique contribution to make in efforts to facilitate literacy development in children. Ehren (2007) noted that either SLPs will respond by asserting the essential nature of their roles in student success and deliver valued services, or they will run the risk of becoming a critical-shortage profession that other educators are not motivated to support.

\section{Overview of Document}

This study follows the typical protocol for the dissertation or other standard research. Chapter One is an overview of the study and states the current problem. Chapter Two focuses on the RTI literature regarding professional roles in RTI implementation for school-based SLPs. Chapter Three summarizes the methodological process implemented to answer the research questions. Chapter Four provides a summary of the data collected. Chapter Five contains a discussion of the findings of the study, implications, future research needs and limitations of the study. 
The information reported in this introductory chapter is provided in order to give the reader a better understanding of how recent mandates have impacted the scope of practice for school-based SLPs. The brief overview of the evolution of speech and language services serves to set the stage for further study of the challenges school-based SLPs now face. The information in Chapter Two has been provided to show some of the research that addresses the issues school-based SLPs face in the RTI process plus support further study of the challenges driven by educational reform, legal mandates, and evolving professional practices SLPs may encounter in their day-to-day service delivery models. 


\section{CHAPTER 2}

\section{Review of the Literature}

Two federal government mandates, the No Child Left Behind Act (NCLB, 2002) and the Individuals with Disabilities Education Act (IDEA, 2004), have acted as catalysts to change the rigor in the implementation of classroom interventions. Currently, the use of scientifically based practices to recognize and respond to individual needs for students and the advancement of professional competencies to foster learning in the least restrictive environment (LRE) have taken center stage in the field of education (Bender \& Shore, 2007).

Walker (2004) reported general education teachers may not always see themselves as interventionists and indeed may resist the expectation that they will provide individualized interventions as a routine part of their classroom practice. Speechlanguage pathologists (SLPs) may possibly adopt the same mindset in relation to their role in the Response to Intervention (RTI) process. In this literature review, resources were investigated that address the changing roles and responsibilities for school-based SLPs in regard to the RTI process and how the changing roles and responsibilities impact service delivery. In addition, a review of the literature was used as a guide to understand how SLPs feel about the challenges of their roles and responsibilities in RTI as well as address the possible challenges that may impact SLPs while assuming the role of an interventionist.

School-based SLPs are expected to be proficient in a wide range of clinical diagnosis and treatment areas. Research has suggested that very large workloads have negative effects on the satisfaction of school-based professionals (Blood, Ridenour, Thomas, \& 
Qualls, 2002). In the past, SLPs have provided service delivery within a very defined and specific role as compared to other educators. Since the 1970s, the description of language has dramatically expanded. Presently, reading and writing proficiency of all school age students are the concern of SLPs (Ukrainetz \& Frequenz, 2003). In recent years, the field of speech-language pathology has seen major changes. In the past two decades, SLPs have increased their focus on the identification, assessment, and treatment of reading disabilities in children (Catts, Fey, Zhang, \& Tomblin, 2001; Justice \& Ezell, 2004). Ritter (2009) suggested that SLPs encounter young children with reading problems on a regular basis, and often, a child's language impairment reflects a deficiency that may impact the child's reading ability.

In this review of the literature I will first provide a brief overview of the 2001 ASHA Position Statement, the 2010 ASHA Position Statement, and Knowledge and Skills Needed by Speech-Language Pathologists with Respect to Reading and Writing in Children and Adolescents (2002). These position statements address the roles and responsibilities of SLPs with respect to reading and writing in children and adolescents. Other areas that will be addressed include the following: examination of RTI as a prevention model; overview of studies that examine the level of engagement of SLPs in RTI practices; investigation of how embracing a paradigm shift affects SLP participation in RTI practices; discussion of where SLPs "fit" in the RTI model; examination of caseload versus workload issues for SLP involvement in the RTI model; examination of the importance of professional development for SLPs in the RTI process; and SLPs perceptions of opportunities and challenges within the RTI model. 


\section{A Brief Overview of ASHA Position Statements}

The focus on RTI among SLPs prompted the release of a Position Statement from ASHA (2001). In 2001, ASHA issued a Position Statement that was intended to serve as an official policy statement with guidelines for best practices. (Ehren, Montgomery, Rudebusch, \& Whitmire, 2007). The 2001 ASHA Position Statement included guidance for SLPs in the following areas:

- preventing written language problems by fostering language acquisition and emergent literacy;

- identifying children at risk for reading and writing problems;

- assessing reading and writing;

- providing intervention and documenting outcomes for reading and writing;

- assuming other roles, such as providing assistance to general education teachers, parents, and students;

- advocating for effective literacy practices; and

- advancing the knowledge base.

The 2001 ASHA Position Statement also indicated that these roles are dynamic in relation to the evolving knowledge base and have implications for research and professional education. All of these areas are to be implemented in collaboration with others who have expertise in the development of written language and vary with settings and experience of those involved.

Guidelines for the roles of SLPs are provided in the 2002 ASHA publication Knowledge and Skills Needed by Speech-Language Pathologists with Respect to Reading and Writing in Children and Adolescents. Knowledge and Skills (2002) addressed the 
Response to Intervention (RTI) model of service delivery to struggling learners. The ASHA guidelines in the 2002 Knowledge and Skills report recommended that more time be allotted to activities that focus on addressing the language foundation of literacy and learning. In addition, collaboration, leadership, and research principles are included as skills that are related to the roles for SLPs (Knowledge and Skills, ASHA, 2002). In 2010 the American Speech-Language Hearing Association (ASHA) issued a new professional issues statement which replaced the previous position statement. The 2010 ASHA Position Statement, which was developed by the Ad Hoc Committee, specifically addressed the roles and responsibilities of school-based SLPs. In order to help students meet the performance standards of a particular school district and state, the ASHA 2010 Position Statement listed the roles and responsibilities "as a basis for speech-language services in schools to promote efficient and effective outcomes for students”, which include the following critical roles:

- providing appropriate speech-language services across all levels (Pre-K through high school);

- serving a full range of communication disorders;

- ensuring educational relevance;

- providing unique contributions to curriculum through a focus on addressing linguistic foundations of curriculum for all students who struggle in school settings;

- highlighting language/literacy across the language processes of listening, speaking, reading, and writing; and

- providing culturally competent services. 
Moreover, the 2010 ASHA Position Statement of the Roles and Responsibilities anticipated that a realignment of existing roles and responsibilities in the context of a reasonable workload with appropriate professional preparation and lifelong learning may become necessary for all school-based SLPs.

The 2010 Position Statement also suggested changes in the traditional roles of schoolbased SLPs. This 2010 Position Statement instructed SLPs to play a critical and direct role in the literacy development of students with communication disorders, and also make contributions to literacy efforts on behalf of other children and adolescents through collaboration with other academic professionals.

Most SLPs are in agreement that collaboration between themselves and classroom teachers can be beneficial since both parties have knowledge that can increase successfulness (Elksnin \& Capilouto, 1994). With increased collaboration, a stronger commitment to involvement in literacy and curriculum becomes possible. Any change in practice needs to be studied in order to better understand the SLPs' role in the schools. Studies should focus on obtaining data on everyday realistic practices as well as the idyllic and preferred practices of the therapist (Ukrainetz \& Fresquez, 2003). Ukrainetz (2006) noted RTI has the "potential to fundamentally change regular education and its interface with special education” (p. 298). In addition, the educational changes brought about by RTI provide an opportunity as well as a challenge for SLPs to make fundamental changes in service delivery (Fresquenz, 2003).

\section{RTI as a Prevention Model}

According to the National Association of State Directors of Special Education (NASDSE), RTI is the practice of providing high-quality instruction and intervention 
matched to student need (National Association of State Directors of Special Education, 2005). Ehren (2007) further added that RTI is a prevention model that affords a mechanism to make sure that students who need more explicit instruction are able to receive intervention services without being identified as a student with a disability. Another aspect of RTI involves monitoring progress frequently to make decisions about changes in instruction and goals, in conjunction with applying the child's response data to important educational decisions.

Fuchs, Compton, Bouton, Caffrey, and Hill (2007) noted that RTI is a way to provide early intervention to students who are at-risk for academic and behavioral failure as well as an alternative way to identify students with learning disabilities. The purpose behind the RTI model is to reorganize the service delivery system, break down the divisions between regular and special education, and provide research-based interventions to all students. Justice (2006) proposed SLPs fit within the RTI model to provide evidencebased interventions to struggling students. The typical RTI model involves a tiered approach in which Tier 1 involves intervention within the general education classroom; Tier 2 is either a problem-solving approach or intense intervention (specialized remediation); Tier 3 may include assessment to determine eligibility for placement within special education (Kovaleski, 2003). Figure 2.1 below describes the three tiered model. 
Figure 2.1. Description of the Three Tiered Reading Model

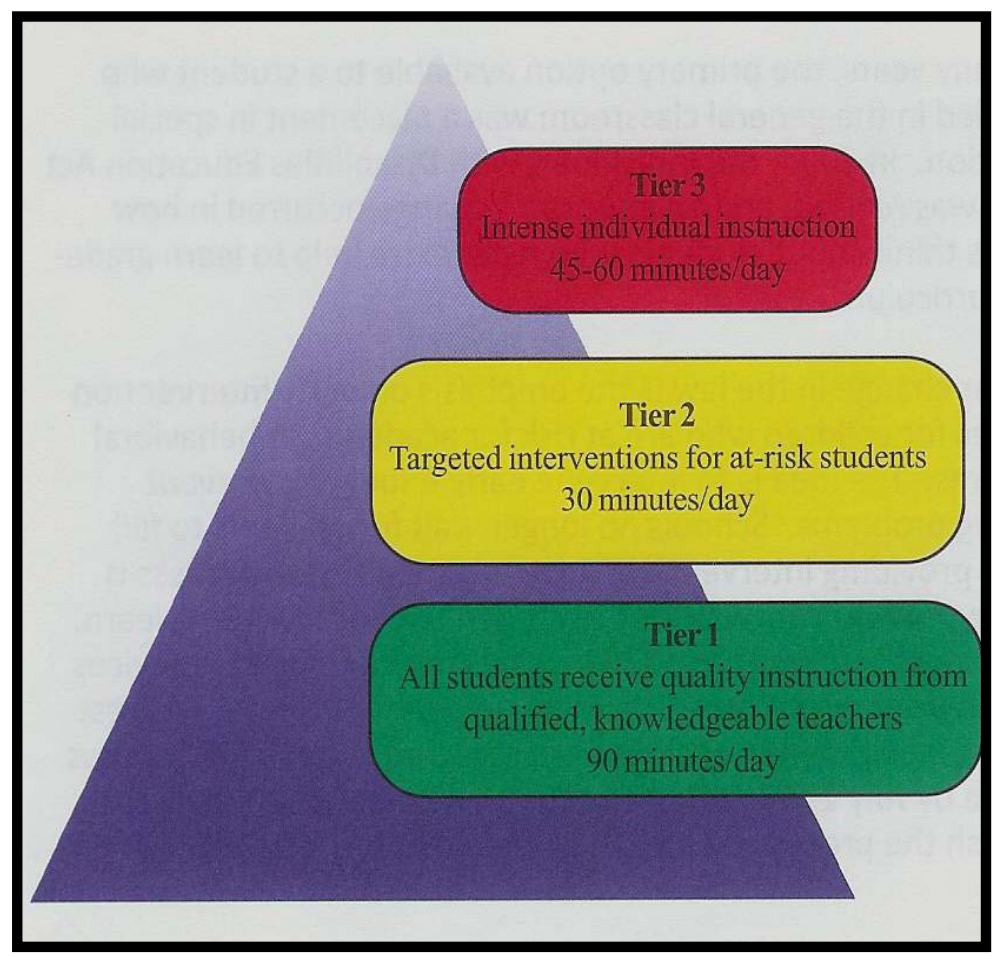

Figure 2.1. Layers of intervention responding to student's needs are noted, which show how each tier provides more intensive and supportive intervention. In addition, this figure depicts how each tier is aimed at preventing reading disabilities. Adapted from "Understanding the Response to Intervention Process" by the West Virginia Department of Education, 2008, Office of Special Programs, Extended and Early Learning, p.2.

RTI is by definition data-driven, so no decisions are made without evidence to support the decisions that are made (Brown-Chidsey \& Steege, 2005). Brown-Chidsey and Steege (2005) claimed RTI is simply not one intervention or method but... "a set of scientifically based procedures that can be used to make decisions about educational programs.” (p. 5). 
Werts, Lambert, and Carpenter (2009) suggested that groups involved in research of the efficacy of instruction associated with RTI encouraged legislators to include language in the reauthorization of IDEA (2004) that would guard against students receiving the label of having a learning disability. Consequently, IDEA (2004) gave states and local schools the authority to implement a process of research-based interventions. Barnes and Harlacher (2008) reported RTI has emerged as a multitiered model to provide instruction based on student needs. The team, which typically consists of people from various disciplines such as regular education teachers, special education teachers, and related school personnel must use a problem-solving approach and make data-based decisions in order to meet the principles of RTI (Barnes \& Harlacher, 2008). The hypothesis associated with RTI addresses early identification of struggling students, which will result in the likelihood that a student will not be referred to specialized services since he or she would receive appropriate instruction both in class and through supplemental interventions.

To date, there is no prescribed process or set of procedures for RTI. Werts et al. (2009) reported regardless of the fact that a universal model is not in place, the RTI process "begins with delivery of high-quality instruction in the general education classroom” (p. 246). Bender and Shores (2007) pointed out that most researchers in the RTI literature supported the standard treatment protocol, which utilizes a set of standard research-based interventions, usually implemented in two, three, or four tiers or levels. According to Bender and Shores (2007), the standard treatment protocol, "involves several separate educational interventions, progressing in intensity over time, prior to classification as learning disabled" (p. 21). The standard treatment protocol is in contrast 
to the previous discrepancy procedure, which involved a "one time” assessment of academic achievement. Bender and Shores (2007) also noted students who are involved in the standard treatment protocol are exposed to educational interventions and monitoring to assess the student's response to the interventions. While some details for implementation of RTI are still being debated, there is a broad consensus on certain core elements, such as organizing intervention resources into levels of increasing intensity. Students who are identified as being at-risk for school failure receive individualized academic support and are closely monitored to make sure goals are achieved (Kovaleski, 2003).

Even though the literature has noted consensus with certain elements of RTI, many questions remain concerning the implementation of the RTI model, such as addressing foundational concepts of implementation of RTI practices (Hollenbeck, 2007). Hollenbeck (2007) emphasized:

Organizational issues center on the fit between RTI and the current school model, as well as the type and level of school-wide restructuring necessary for implementation. Such issues range from minor-allocating time resources, providing space for pull-out activities-to more significant-determining research-based and competencies across professionals (p. 142).

In order to address the lack of consensus on issues pertaining to RTI, Werts et al. (2009) conducted a survey of district-level special education administrators in North Carolina to determine their perceptions on the use of personnel to implement the RTI model. Survey questions addressed three categories: roles of personnel, time needed for instruction, and considerations for implementation (Werts et al., 2009). Werts et al. 
(2009) reported, “General opinion with regard to collection of data and judgment of responsiveness was that this should be the responsibility of multiple people” (p. 251). Werts et al. (2009) suggested that several implications for the implementation of the RTI model were evident from their data. These implications include the following:

- school personnel who should be involved in the implementation of RTI practices included: school psychologists, general education teachers, special education teachers, and related service personnel (speech pathologists, program specialists/instructional coaches);

- length of time spent on instruction should be at least 30 minutes for each session;

- the frequency of RTI instruction should take place once a day;

- a focus should be on the differentiating instruction in the learning environment to meet the child's needs; and

- professional development should focus on how to implement RTI in the learning environment and not just on what the RTI process involves.

Regardless of the lack of consensus on RTI practices, Barnes and Harlacher (2008) noted the importance of identifying who is responsible for implementation of RTI.

Some researchers have expressed concerns about the implementation process involved with RTI (Fuchs, Mock, Morgan, \& Young, 2003; Kavale, Holdnack, \& Mostert, 2005). Fuchs et al. (2003) believed that despite RTI’s lofty aims, many teachers fail to implement interventions with fidelity. One factor that may impact the implementation of RTI is the teachers' perspectives of their roles and responsibilities in the RTI model. This may hold true for SLPs as well. However, the foundation for SLPs' involvement in RTI has been established through the profession's policies on literacy, workload, and 
expanded roles and responsibilities. Despite the fact that policies are in place that address RTI, the responsibility to implement RTI begins at the school level through professional development opportunities and collaboration with other professionals. Another consideration is the impact an administrator has on the RTI process through restructuring staff assignments, changing schedules, and approaching reading instruction as a school wide responsibility.

Shortly after discussions began to appear in the literature associated with implementation of RTI practices, K-12 administrators, general educators, and related service providers began to examine the implications of RTI relative to their professions (Boscardin, 2007; National Association of State Directors of Special Education, 2005). Brown-Chidsey and Steege (2005) reported that general education personnel were challenged to combine efforts with special education personnel to better meet the increasingly diverse learning needs of students, and to ensure access and participation within the general curriculum. Related service providers, particularly SLPs, started to participate in professional dialogue that resulted in publications focused on new service delivery models and organization of workloads that emphasize the SLPs role in prevention activities, which target curriculum and literacy issues. In addition, revised and expanded notions of roles and responsibilities and new perspectives on identifying and supporting students with language impairments began to be investigated (Justice, 2006; Moore-Brown, Montgomery, Bielinski, \& Shubin, 2005; Staskowski \& Riveria, 2005; Troia, 2005). Boswell (2005) suggested that changes in IDEA 2004 have prompted many local education agencies (LEAs) across the nation to consider the adoption of prevention models such as RTI that may reduce the number of students who 
need special education services or provide an alternate method of identifying students as having a specific learning disability.

\section{Where do SLPs "Fit" in the Tiers of Intervention?}

Presently, the traditional role of the SLP as identified within IDEA (2004) provides speech therapy services for school-age children with communication disorders that adversely affect the children's educational performance. This traditional role results in referral for a speech-language evaluation and placement in speech therapy if state guidelines for eligibility are met. However, Means (2006) suggested SLPs should consider accountability for student progress is not only mandatory, but it is an ethical responsibility as well. In addition, The SLP must review the school district's performance in academic areas and become part of the district wide program improvement plans (Moore-Brown, 2004). Additionally, the SLP must be familiar with the state and district curriculum and utilize the curriculum for intervention. The West Virginia Department of Education Guidelines for Best Practices (2011) suggested SLPs engage in ongoing professional development in order to provide interventions for students that encourage students to become effective communicators within the education environment. In addition, Dana and Yendol-Hoppey (2008) suggested the prominent model of professional development has taken the form of workshops delivered on "inservice” days when instructional staff works, but students have a holiday. Dana and Yendol-Hoppey (2008) refer to these workshops as "sit and get” professional development that provides instructional staff with "new pedagogy from an outside expert” (p. 2). 
The professional role of SLPs in addressing the literacy needs of children includes efforts of prevention, assessment, and intervention (ASHA, 2001, ASHA, 2002). Schuele and Boudreau (2008) suggested "SLPs have distinct and extensive content knowledge related to phonological awareness that differs from teachers' knowledge base; this knowledge can be a critical asset for educational teams.” (p. 4). Schuele and Boudreau (2008) further noted the SLPs can contribute to their school teams' efforts to enhance children's phonological awareness acquisition in four ways: first, SLPs can share their content knowledge; second, SLPs can provide their perspective in assessment decisions; third, SLPs can collaborate with classroom teachers to enhance phonological awareness instruction within the general education curriculum; and fourth, SLPs may be the school team member who is most suited to provide small-group phonological awareness intervention to struggling students.

In addition, Troia (2005) reported that RTI presents a chance for SLPs to consider and weigh in on the potential benefits and limitations of RTI. Troia (2005) emphasized "as members of the education vanguard, SLPs must remain cautiously optimistic about their role in reform efforts, such as those embodied by the 2004 reauthorization of IDEA” (p. 116). Ehren (2007) noted that as far as SLPs' implementation of RTI practices, there are few examples of involvement or leadership in RTI models. Ehren (2007) feels that this "omission is unfortunate, as SLPs have much to offer in their efforts to provide effective, scientifically based instruction and intervention, especially to literacy.” (para. 6). If RTI is viewed as a way to help all students, then RTI may be more likely to be implemented effectively by all professionals in the school setting. 
Justice (2006) provided an important and timely article with evidence-based perspectives on practice that SLPs might implement in providing intervention. Justice (2006) suggested three organizational principles that SLPs might follow to deliver RTI interventions, which include the following: attention should be directed first toward ensuring the adequacy of children's primary reading instruction environments, children's literacy achievements in the first-tier instructional environment should be monitored carefully to identify when and if additional tiers of support are needed, and additional tiers of support should duplicate and extend the instruction of the first-tier environment, and children's performance in these tiers should be monitored carefully (pp. 287-289).

Tier I. SLPs can contribute in many ways to address the instructional needs of the majority of a school's students and to prevent students from becoming at-risk for further problems. With this in mind, Tier I can be considered a prevention step. Moreover, SLPs can make contributions through formal and informal speech and/or language screening, which can be either norm-referenced or curriculum-based measurements. In Tier I, consultation with the classroom teacher in the areas of literacy and language skills would also be appropriate. Troia (2005) suggested that SLPs can contribute at Tier I by offering information concerning the structures and functions of language that influence teaching and learning in all academic domains, especially literacy. In addition, Troia (2005) noted, as a key resource in an RTI framework, "SLPs have the capacity to ensure the diffusion of greater recognition and understanding of the role of language in curriculum, instruction, and student success.” (p. 114).

Tier 2. In Tier II, SLPs can collaborate with other professionals to monitor and assess speech and language skills. In addition, SLPS can provide small-group intervention. At 
Tier II, the SLPs could assess students with any number of formal assessment tools to address language and literacy issues for students who are having difficulty. Troia (2005) noted the primary role of SLPs in Tier II may involve consulting with teams delivering targeted interventions to "make supplemental instruction most advantageous for struggling readers with language-learning difficulties.” (p. 114).

The literature revealed that there is research to support the effectiveness of SLP involvement in Tier II intervention to promote emergent literacy in preschoolers. A study conducted by Koutsoftas, Harmon, and Gray (2009) assessed the effectiveness of a Tier II intervention in a study of 34 preschool students who received intervention over a sixweek period delivered by trained teachers and SLPs. Koutsoftas et al. (2009) found that in a relatively short period of time, small-group Tier II intervention improved the phonemic awareness skills of $71 \%$ of the children in the targeted group. Nancollis, Lawrie, and Dodd (2005) studied the effects of a nine-week intervention conducted by SLPs in low-income preschool classrooms that involved 99 children. Results from the study conducted by Nancollis et al. (2005) indicated that children in the intervention group performed significantly higher on rhyme awareness than children in the control group. In addition, Olsen (2008) reported a successful pilot program utilizing the RTI model, which was conducted in conjunction with classroom teachers that was referred to as the Speech Sound Intervention (RTI-SSI) at the Tier II level. Olsen (2008) noted that the pilot program provided a foundation to begin additional RTI programs plus an opportunity to meet specific needs within a classroom setting by using resources that were available without significant expense. 
Tier III. It has been suggested that SLP involvement in Tier III could incorporate collaboration with other professionals. Collaboration at Tier III between SLPs and other professionals in the school may determine a need for intensive intervention and eligibility for special education based on the lack of responsiveness to prior intervention. Troia (2005) noted that SLP roles in Tier III treatments may address two main responsibilities: providing specialized treatments for those poor readers with language deficits who have not benefited from universal instruction and targeted interventions and consulting with special educators to help them maximize their services. This tier requires identification of students who did not respond successfully to intervention provided in Tier II. The students in Tier III may be referred for a battery of formal assessments. Based on the results of the formal assessments, the student may be determined eligible for special education services. At this tier, the SLP may become involved in the development of an Individualized Education Plan (IEP) and develop appropriate goals for the student.

\section{Are SLPs engaging in RTI practices?}

A survey conducted by Daniel and Reynolds (2007) revealed that more than half of the 33 SLPs who responded to their survey reported no involvement in phonological awareness instruction in the regular curriculum or collaboration with classroom teachers, with $29 \%$ reporting that they did not provide phonological awareness instruction to children on their caseloads who may be at risk for reading failure. In addition, Daniel and Reynolds (2007) noted SLPs felt that the classroom teacher was the professional most important in providing phonological awareness instruction. According to ASHA's 2002 publication, Knowledge and Skills Needed by Speech-Language Pathologists with Respect to Reading and Writing in Children and Adolescents, the findings from the 
previous study may be considered problematic in the fact that a number of SLPs are not in tune with the scope of practice established by ASHA, which includes assisting children to acquire the necessary prerequisite skills such as phonological awareness. In addition, Daniel and Reynolds' (2007) survey results indicated that of the SLPs surveyed who reported providing phonological awareness instruction to children on their caseloads, 34\% (approximately 11 SLPs) provided instruction only to children with articulation and phonological disorders. Moreover, Daniel and Reynolds (2007) reported that no SLP in their study reported collaborating with classroom teachers in the planning or implementation of phonological awareness instruction. Daniel and Reynolds (2007) noted that implications for further research included investigating how SLPs can be more effective in facilitating phonological awareness plus investigating the barriers that SLPs face in spending adequate time providing phonological awareness instruction to children who are at risk for reading failure.

Chard and Dickson (1999) noted that children with speech and language problems are at significant risk for literacy problems as well. Other researchers have echoed a similar position by suggesting that there is a link between reading problems and speech and language disorders in the areas of syntax, morphology, and semantics (Catts, 1997; Pullen \& Justice, 2003).

In the research conducted by Ukrainetz and Fresquez (2003), five SLPs were studied during their day-to-day activities in the schools. Even though this was a very small sample, the findings contribute to understanding how SLPs perceive their role in the schools and how these roles complement and overlap with other remedial educators. Ukrainetz and Fresquez (2003) focused on language as a domain of specialization in this 
qualitative constant-comparative design. Ukrainetz and Fresquez (2003) concluded that SLP service delivery was different from that of the other remedial educators by providing infrequent sessions for a large caseload sustained for many years. Moreover, Ukrainetz and Fresquez’s (2003) study noted the importance of SLPs' continuation of providing unique interventions, such as articulation therapy, but this study also emphasized that SLPs need to "continue reflection on how best they can provide services in light of the larger school context.” (p. 297). Ukrainetz and Fresquez's (2003) study contributed to further investigation into the challenges that ultimately face SLPs who are interested in participation in the RTI model in their prospective schools.

\section{Embracing a Paradigm Shift}

There is no doubt that many SLPs will be required to make a paradigm shift in order to accept the roles and responsibilities associated with participation in tiered intervention practices. Ehren, Montgomery, Rudebusch, and Whitmire (2006) noted the number of important roles that SLPs can play in the use of RTI to identify children with disabilities along with providing needed instruction to struggling students in both general education and special education settings. Ehren et al. (2006) suggested that the challenges include a shift from a "within child" deficit paradigm to a contextual perspective. School-based SLPs will need to consider fundamental changes in the ways that they engage in assessment and intervention activities. It is also essential for SLPs to work with administrators, teachers, and support personnel to meet the needs of all students. ASHA (2010) noted the importance of collaboration in reform efforts now in place in elementary and secondary schools. 
As a school-wide initiative, RTI can provide a blueprint for all school stakeholders to contribute to the academic success for students (Abbott, Walton, Tapia, \& Greenwood, 1999). According to Ehren (2007), SLPs need a new perspective in order to assume a proactive role in RTI practices. Ehren (2007) further suggested that SLPs need to not consider RTI as adding something to a plate that is already full but, "think about RTI as the impetus for getting a different plate - an opportunity for doing things differently in school settings" (para. 7). Ehren et al. (2006) further noted that the point of RTI is not to add more tasks, but to reallocate time to better serve students through addressing prevention and early intervention. This approach allows for students to receive intervention services up front rather than at the point of special education evaluation.

IDEA lists the prevention of communication disorders as one of the activities in the definition of speech-language pathology services. SLPs' could make a contribution to the success of RTI practices by using their training in the delivery of individualized intervention for children who are experiencing difficulty in the areas of speech and language. Gillam (2008) discussed the attributes SLPs bring to the table as an interventionist through the following comments:

SLPs have a wealth of knowledge about processes that underlie academic success including attention, memory, and perception processes, linguistic and metalinguistic knowledge, and learning mechanisms. SLPs are adept at creating and utilizing criterion-referenced progress monitoring tools. With the advent of RTI, our expertise is even more important to the development, implementation and evaluation of successful, intensive intervention programs for children with language learning difficulties. (p. 7) 
Spoken language provides a foundation for the development of reading and writing. SLPs can assist students who are experiencing difficulties with spoken language and help them develop the language and literacy competence that is needed to be successful in the classroom. ASHA’s Knowledge and Skills (2002) reported that IDEA has increased the roles and responsibilities of SLPs. By addressing the expanded roles and responsibilities that ASHA supports for SLPs in the areas of spoken and written language, a reciprocal relationship can be established in general language and literacy competency. In addition, SLPs can provide services in the least restrictive environment for all students while facilitating literacy for children and adolescents.

ASHA’s (2010, Position Statement) “Roles and Responsibilities of Speech-Language Pathologists in Schools” clearly stated and supported the SLP's role in prevention, identification, assessment, intervention and consultation with regard to a student's reading and writing development. Moreover, it was noted that SLPs are encouraged to work in partnership with other professionals to meet students' needs (ASHA, 2010, Position Statement). This statement served to further highlight the direction of SLPs in defining their roles and responsibilities and ensuring appropriate services to students in order to meet evolving professional practices.

Effective RTI implementation requires flexible teaching and support staff motivated to establish evidence-based strategies with high levels of treatment fidelity, or standardized methods of administering evidence-based interventions (Fuchs, D. \& Deshler, 2007). A review of the literature that addresses research in the area of fidelity of implementation of RTI by SLPs in relation to how attitudes and opinions influences the delivery of the RTI model is quite limited. However, two recent studies, Steinke who conducted a master's 
thesis and Wold who conducted a doctoral dissertation will be discussed that address issues related to attitudes and opinions of SLPs concerning the willingness to become engaged in the RTI model.

Wold (2010) explored the attitudes and opinions concerning RTI along with the training needs identified for the implementation of the RTI model. Wold (2010) used a comparison question, which attempted to determine if there were differences among Directors of Special Education, Specific Learning Disabilities (SLD) Teachers, and SLPs in the following areas: understanding of the RTI model, using teams to problem solve, selecting the "right" intervention, progress monitoring, graphing data for visual analysis, professional development training, and the effects of RTI on school districts. Fifty-two SLPs, 137 SLD teachers, and 25 Directors of Special Education were involved in the study by Wold (2010). SLPs comprised 23.4\% of this study. Wold (2010) reported that results from this study indicate SLPs in North Dakota have not fully embraced a paradigm shift and require more training in the RTI process.

Blosser and Neidecker 2002 noted that SLPs working in the schools will need to have strategies for coping with change. Moreover, Blosser and Neidecker (2002) suggested: the role of the SLP as a collaborator and consultant will be greatly expanded, as will the role as a team member in the school in diagnosis, assessment, and placement ... the school SLP will be more and more involved in the overall education, in the communicative skills of reading, writing, and spelling as well as speaking and listening. (p. 17) 
Boswell (2005) reported the ASHA Schools 2009 Conference ended with a charge from Tommie Robinson, President-elect to school-based SLPs to embrace the RTI model. Boswell (2005) reported the following message from Robinson:

Moving from the basics to beyond involves risks, and some therapists are proposing new ideas, such as starting an RTI program ... when you take the risk in going out and starting an RTI program, you are hitching your wagon to something that is larger than yourself... we have to draw on our resources to have the wisdom and knowledge about what is the right thing to do. (para. 14)

\section{Examining the Issue of Caseload versus Workload for SLPs}

Many SLPs wonder how they will be able to adjust their time to provide intervention services to general education students in addition to fulfilling their responsibility to their caseloads. The literature points to an adoption of a workload approach, which focuses on the individual needs of students while allowing SLPs to contribute to improved student performance by providing educationally relevant services. Ehren (2007) noted that because delivery of services within the RTI framework involves students other than those identified as speech-language impaired (SLI), a mechanism needs to be in place to account for the time spent on RTI activities.

Essential components of a workload approach for SLPs include flexible scheduling and a continuum of service delivery models. ASHA (2002) has noted a school SLPs' workload has been synonymous with a caseload model. The term caseload typically refers to "the number of students with Individualized Education Programs (IEPs) or Individualized Family Service Plans (IFSPs) that school SLPs serve though direct and/or indirect service delivery options” (ASHA, 2002, p. 42). ASHA (2002) reported workload 
refers to all activities required and performed by SLPs in schools which may include, “activities necessary to support students’ educational programs, implement best practices for school speech-language services, and ensure compliance with IDEA and other mandates.” (p. 42).

In May of 2010, the same month that ASHA published the 2010 position statement on Roles and Responsibilities of Speech-Language Pathologists in Schools, they released their findings of a survey of SLP caseload characteristics from school settings across the United States. According to ASHA, the 2010 Schools Survey was conducted to provide information concerning school-based service delivery in addition to updating and expanding existing information gathered during previous school surveys. The number of respondents to the survey included 2,544 SLPs, which resulted in a response rate of 64.8\%. For purposes of the ASHA 2010 Schools Survey a caseload approach for an SLP was defined as being based only on the number of students served. The same survey defined a workload approach as being based on the number of students served plus the additional duties of an SLP. Results from the ASHA 2010 School Survey included the following overall findings from 2, 196 SLPs from across America (no breakdown was available of number per state):

- more than four clinical service providers out of five (82\%), reported the use of a caseload approach to determine the number of students that they served;

- $\quad$ percentages of SLPs who incorporate a workload approach in their schedules were reported by state and varied greatly with a range of West Virginia at $0 \%$ and New Hampshire at 44\%;

- $\quad$ median caseload size was 50 students; 
- fifty-two percent of SLPs provided consultation and/or strategies to classroom teachers in their role in RTI;

- SLPs reported $71 \%$ of their time was involved in traditional pull-out service to address speech and language problems; and

- SLPs reported $6 \%$ of their time was devoted to RTI services.

In a study conducted by Katz, Maag, Fallon, Blenkarn, and Smith (2010), variables that contribute to school based SLPs' feelings about what constitutes a manageable caseload were investigated. Approximately 2,000 public school SLPS were solicited to participate in an online survey. Of the SLPs that were contacted, 634 full-time SLPs responded. Katz et al. (2010) reported that SLPs' feelings of unmanageability surfaced when caseload sizes entered the range of 41-45 students and feelings shifted to unmanageable once the number of students exceeded 55 students. Katz et al. (2010) further noted that "these data suggest that the number of students on school-based SLPs' caseloads is highly related to the SLPs' sense of their ability to manage workload responsibilities.” (p. 147).

Ehren et al. (2006) reasoned new and expanded roles for SLPs that incorporate prevention and identification of at-risk students may involve a decrease in time spent on traditional models of intervention (e.g. pull-out therapy) and increase time involved in indirect services and support activities. To meet this challenge SLPs will need to be willing to adapt to a more systemic approach of consultation and collaboration in order to effectively serve their assigned schools. IDEA 2004 does not mandate significant change, but it encourages the adoption of new approaches that promise improved student outcomes (Ehren et al., 2006). 


\section{Professional Development - Bridging the Gap between Research and Practice}

Ehren (2007) stated that considering the present challenges in education, the profession of speech, language pathology is "clearly at a crossroads in the schools” (p. 15). Effective professional development is the foundation for any initiative that is introduced to impact student achievement. Shulman (1986) noted that knowledge of content, pedagogy, and curriculum develops in teachers when they make a commitment to becoming a life-long learner. All personnel that are part of the implementation of RTI must receive ongoing training and support in order to become effective interventionists. Bean and Morewood (2007) reported that effective professional development is needed in order to provide teachers opportunities to improve. The same principle may apply to SLPs. Professional development must focus on strategies that are evidence-based. NCLB (2002), section 9101, specifically highlighted the importance of professional development plus provided the following criteria for activities associated with professional development:

- improve and increase teachers' knowledge of the academic subjects they teach;

- provide high quality, sustained, intensive, and classroom focused instruction; and

- positively impact classroom instruction and teacher performance.

In order to encourage SLPs’ participation in the RTI process, providing high quality professional development becomes the cornerstone of implementation for RTI initiatives. SLPs need to be involved in professional development that includes research-based intervention instruction. According to Ehren (2007), ASHA has provided continuing education opportunities through workshops and classes, conference presentations, and partnerships with other groups to encourage SLP participation in the RTI process. 
Professional development has also been noted as a foundational concern for the effective implementation of RTI (Danielson, Doolittle, \& Bradley, 2007; Berkley, Bender, Peaster, \& Saunders, 2009).

Results from various studies of professional development in the 1990s suggested that professional development can influence teachers' classroom practices significantly and lead to improved student achievement (American Educational Research Association, 2005). SLPs need high-quality professional development in order to expand their roles in the delivery of the RTI model. By gaining knowledge of the RTI model, SLPs will be able to develop positive perspectives in relation to RTI practices.

To help improve student performance, the critical features of high-quality professional development should be in place, including professional development structure, such as teacher networks and study groups (Kratochwill et al., 2007). In addition, the American Educational Research Association (2005) noted that effective professional development will provide practitioners with a way to directly apply what they have learned to their instruction.

In a longitudinal study by Desimone, Porter, Garet, Yoon, and Birman (2002), findings supported the idea that "professional development characterized by 'active learning' where teachers are not passive recipients of information, boosts the impact of professional development activities” (p. 101). Desimone et al. (2002) further suggested teachers must engage in active learning such as interacting with their colleagues on a regular basis to discuss their work and their student's learning in order to develop a “deeper understanding of how children think and learn” (p. 101). 
Desimone (2011) observed the importance of professional development as "one of the keys to improving the quality of U.S. schools” (p. 68). Education policy has started to reflect research consensus on the core features of professional development. Desimone (2011) noted the following:

The No Child Left Behind Act of 2001 describes high-quality professional development as activities that 'improve and increase teacher's knowledge of the academic subjects that teachers teach (content focus), that are 'sustained [and] intensive' (duration), and that are 'aligned with and directly related to state academic content standards, student academic achievement standards, and assessments. (p. 69) In addition, Desimone (2011) emphasized the importance of coherence and collective participation in professional development through the five core elements that have been identified as essential in any program of professional development. The five core elements of professional development as described by Desimone (2011) include the following:

- content focus - professional development activities that focus on subject matter content and how students learn that content;

- active learning - opportunities to become involved, such as observing and receiving feedback, analyzing student's work, or making presentations, as opposed to passively sitting through lectures;

- coherence - what teachers learn in any professional development activity should be consistent with school, district, and state reforms and policies;

- duration - professional development activities should be spread over a semester and should include 20 hours or more of contact time; and 
- collective participation - groups of teachers from the same grade, subject, or school should participate in professional development activities together to build an interactive learning community.

Professional development is a foundational concern to the effective implementation of RTI (Berkley, Bender, Peaster, \& Saunders, 2009; Danielson, Doolittle, \& Bradley, 2007). Darling-Hammond and McLaughlin (2011) noted professional development today means providing occasions for critical reflection on practice. In addition, DarlingHammond and McLaughlin (2011) suggested professional development can be considered capacity building, which allows educators to fashion new knowledge and beliefs about content, pedagogy, and learners. Capacity building policies, according to Darling-Hammond and McLaughin (2011), view knowledge as constructed by and with practitioners for use in their own contexts, rather than as something conveyed by policy makers as a single solution for top-down implementation.

\section{Opportunities and Challenges for SLPs - How Will They Be Perceived?}

The interconnectedness of literacy and oral language development has surfaced over the past two decades in the field of speech pathology (Catts, Fey, Zhang, \& Tomblin, 2001; Justice \& Ezell, 2004; Kaderavek \& Justice, 2004). Danielson, Doolittle, and Bradley (2007) posed the following question: "What outcomes can schools expect if they implement those [evidence-based] practices within the RTI framework with fidelity?” (p. 632). As RTI efforts are implemented, the notion that SLPs can participate in significant ways to assist struggling students must be considered. ASHA (2001) declared that SLPs have a unique contribution to make when treating children with language-based reading 
deficits, along with the collaboration of other professionals concerned with facilitating children's learning to be successful readers.

Kratochwill, Volpiansky, Clements, and Ball (2007), stated that successful implementation of RTI is multifaceted and involves knowledge of evidence-based interventions, multitiered intervention models, screening, assessment and progress monitoring. In addition, the administration of interventions must be met with a high degree of integrity, support and coordinated efforts across all levels of staff and leadership within the school (Kratochwill et al., 2007). In the discussions of professional development and building capacity for sustainability, Danielson, Doolittle, and Bradley (2007) suggested that the research base will need to expand greatly if educators are to be supported in improving the achievement of all students—-the ultimate goal of No Child Left Behind. Ehren (2007) declared that since RTI has become part of the fabric of education, it is incumbent upon SLPs to engage seriously in efforts of professional development.

\section{Conclusion}

Throughout current research, we are reminded that early intervention is paramount to student achievement. SLPs' involvement in the RTI process may provide services to struggling learners that will assist them with success in the educational setting. One by one struggling learners who require intensive interventions may benefit by receiving the help they deserve through the framework of the RTI model.

The educational changes brought about by RTI present an opportunity as well as a challenge for SLPs to provide fidelity in the implementation of service delivery. ASHA (2010) noted that research supports the interrelationships across the language processes 
of listening, speaking, reading, and writing. ASHA (2010) further points out SLPs have the opportunity to make a positive impact on the literacy achievement of students at the elementary level as well as the secondary level. Ehren et al. (2006) noted that SLPs need to consider an expansion of their "tool kit" to include more instructionally relevant, contextually based procedures.

NCLB and IDEA have brought to the forefront an emphasis on accountability for student outcomes. SLPs can play a large role in data collection and analysis of the RTI model. In order to address new special education laws requiring early intervention service provision for at-risk children, it becomes increasing important for all qualified school personnel to participate in providing services. The literature reviewed in this manuscript has suggested that SLPs can work collaboratively with other professionals within their scope of practice in the school environment to facilitate reading skills in all children. Moreover, Ciampaglio (2008), an SLP working at Youth's Benefit Elementary School in the Harford County (Maryland) public schools for 15 years, asserted that SLPs can contribute to school-wide language and literacy programs by using data to document the need for change plus analyze what should be changed.

SLPs who work with school-age children have the opportunity to contribute to the literacy development of specific students as well as the literacy instruction and intervention programs in their schools. The RTI model presents new opportunities and challenges for SLPs to extend curriculum-relevant practices to students. Research clearly defined that targeting students identified as "at-risk" for future literacy failure and providing appropriate, sound, and consistent interventions showed promising evidence for literacy acquisition at all skill and grade levels (Koutsoftas et al., 2009; Staskowski \& 
Rivera, 2005; Ehren, 2009). It will be important to the fidelity of implementation of RTI to ensure that SLPs have a positive understanding of their roles in tiered intervention and are motivated to participate in tiered intervention practices.

As far back as 1999, ASHA recognized the role school-based SLPS may provide to support the literacy needs of students. ASHA's definition of service delivery included the following statement: "service delivery is a dynamic concept that changes as the needs of the students change” (ASHA 1999, p. 273). Ehren (2007) suggested that students should be continually reevaluated to address their unique and changing needs. Within the RTI process, SLPs have the opportunity to become problem-solvers and address struggling students' speech and language needs through appropriately identifying and addressing RTI implementation. Early intervening and RTI may dramatically change educational speech-language pathology as a profession (Ukrainetz, 2006). School-based SLPs may begin to make a difference if they are willing to embrace changes and recognize the potential of these new roles in achieving their goals of successful communication and literacy acquisition for all children.

SLPs who work with school-age children have the opportunity to contribute to the literacy development of specific students as well as the literacy instruction and intervention programs in their schools. The RTI model presents new opportunities and challenges for SLPs to extend curriculum-relevant practices to students. Research clearly defined that targeting students identified as "at-risk” for future literacy failure and providing appropriate, sound, and consistent interventions showed promising evidence for literacy acquisition at all skill and grade levels (Koutsoftas et al., 2009; Staskowski \& Rivera, 2005; Ehren, 2009). It will be important to the fidelity of implementation of RTI 
to ensure that SLPs have a positive understanding of their roles in tiered intervention and are motivated to participate in tiered intervention practices.

My focus in pursuing further study and investigation was to find information and research that related to school-based SLPs' incorporation of RTI and the challenges that impact RTI implementation into day-to-day activities. To date, there is limited research that addresses school-based SLPs' expectations and challenges in the implementation of RTI. In order to answer the question, What are the challenges school-based SLPs face in the RTI process?, it is important to first investigate school-based SLPs' perceptions on the challenges they feel they face in the RTI process and how those challenges will affect school-based SLPs’ roles and responsibilities.

In the next chapter, I will attempt to discuss the procedures used in surveying schoolbased SLPs in West Virginia in order to gain a more comprehensive picture of the impact RTI has had on the broad scope of practice. School-based SLPs' perceptions of the challenges they feel they face on a day-to-day basis concerning RTI need to be studied in order to realistically assess changes in training and education for school-based SLPs. 


\section{CHAPTER 3}

\section{Research Methodology}

The purpose of this chapter is to describe the research design, the methodology, the data collection, and the data analysis procedures implemented in this study. Chapter Three is divided into eight sections: an introduction; the design of the study; data sources; population and sample; data collection procedures; data analysis; assurances of content validity and reliability; and limitations.

\section{Introduction}

The investigation in this study involved obtaining data about the challenges West Virginia school-based SLPs feel they face in the specific framework of their applicable roles and responsibilities within the RTI model. The categories that were examined in relation to the challenges SLPs face in the RTI process included the following:

- attitudes toward general perceptions of the challenges toward the RTI process;

- attitudes toward accountability and data collection (fidelity to treatment protocol);

- attitudes toward professional development associated with the RTI process; and

- attitudes toward caseload versus workload models

Basic demographic information was collected from each participant in addition to their opinions of the challenges that they feel are associated with SLPs' involvement in RTI.

\section{Design of the Study}

This was a quantitative study, which employed a questionnaire survey to gather descriptive data of the school-based SLPs' attitudes toward challenges in the RTI process. (Refer to Appendix A) This design was selected because there were no control groups or manipulation of independent variables. Fink (2009) suggested that a survey 
design which collects data at a single point in time is referred to as a cross-sectional survey design. This survey was designed to measure pre-existing conditions and to provide a snapshot of the challenges school-based SLPs feel they are facing in light of federal mandates such as IDEA and NCLB. Moreover, a survey method was selected in order to make generalizations from the sample to the population and allow for inferences to be drawn about the SLPs' challenges that they face in the RTI process (Babbie, 1990). It is my feeling that a survey granted an avenue to begin to understand school-based SLPs’ opinions concerning their challenges in the RTI process.

There were five demographic questions and 26 five-point Likert scale perception statements. Two other areas were included in the questionnaire, a rank order of four categories and a question that addressed the current service delivery configuration for each participant. The research instrument was named the Survey of School-Based SLPs and the RTI Process.

This survey was designed with the intention that it would take a participant approximately 10 to 15 minutes to complete. Although a longer survey produces more information, a researcher may find that the risk of completion by a respondent is directly linked to the time a respondent must invest. The twenty-six statement survey with two additional questions was chosen purposefully to encourage a higher response rate and circumvent lack of interest in participation of a lengthy survey.

In addition, construction of the questionnaire survey was simple and straightforward. Challenges school-based SLPs feel they face within the RTI process were the focus of the survey statements as well as the rank order question and the service delivery 
configuration. The statements were research derived and the five-point Likert scale questions provided a means to quantify the school-based SLPs' responses.

Survey Definitions. The respondents were also provided simple definitions of terms that relate to the RTI process on a Letter of Invitation. (Refer to Appendix B - Letter of Invitation for Paper Survey and Appendix C - Letter of Invitation for Survey Monkey). This was an attempt to limit confusion with educational jargon and/or specialized terminology for school-based SLPs in relation to the RTI model during participation in the survey. The Letter of Invitation included the following terms for purposes of consistency:

- Response to Intervention: Research-based interventions over time while progress monitoring the student's response to interventions. The state of West Virginia recommends both duration and increased intensity of interventions to meet the needs of struggling students in the general education environment in order to decide if a student needs further evaluation by a psychologist and/or individualized education plan;

- Tiered intervention: Struggling students are provided research-based interventions with graduating levels of intensity based on data collected over time;

- Caseload: For this survey, a caseload is defined as being one based only on the number of students served who have a current Individualized Educational Plan (IEP) that addresses communication issues; and

- Workload: For this survey, a workload is defined as being one based on the number of students with an IEP that addresses communication issues served plus 
additional duties performed by the school-based SLP (such as implementation of RTI practices).

Special care was taken in the construction of the statements to avoid ambiguous phrasing, inflammatory language that might elicit an emotional response, leading phrases, or loaded questions.

Respondents were assured that complete anonymity was in place to encourage candid responses. The surveys were completely confidential with demographic information that identified the respondent with one of eight Regional Educational Service Agency (RESA) districts in the state of West Virginia rather than one of the 55 counties in West Virginia.

\section{Data Sources}

For this study, the preferred method of data collection was a survey that involved demographic information and data collection from one point in time (Wiersma, 2000). The data sources included the following four sections:

- the first section of the questionnaire requested the following information: Gender; RESA District of each participant; the number of years each participant has been employed as a school-based SLP; caseload setting of each participant; and level of education of each participant;

- the second section of the questionnaire surveyed the respondents through the use of a five-point Likert-type scale (e.g., strongly agree to strongly disagree);

- the third section requested each respondent to rank order challenges SLPs face in the RTI model from most challenging to least challenging; and

- the last section of the questionnaire asked the respondents to respond to a question involving current service delivery practices by assigning a percentage. 


\section{Population and Sample}

The target population for this survey involved school-based SLPs from all 55 counties in the state of West Virginia. According to Brian Reed, 2010-2011 President of the West Virginia Speech-Language and Hearing Association (WVSHA), there are approximately 400 practicing school-based SLPs in the state of West Virginia (personal communication, March 30, 2011). At this time, an accessible data base with demographic information on the approximate 400 school-based SLPs from across the state of West Virginia is not available.

Since this study involved a number of potential respondents drawn from a defined population, the Raosoft (2004) website was employed to calculate the sample needed by using the following areas: margin of error $-5 \%$, confidence interval - 90 percent, and population size -400 . Roasoft (2004) indicated that 162 respondents would be the minimum recommended size for this survey.

Nardi (2006) indicated that survey research has shown response rates as low as 2030\%. Due to this statement an endorsement for the study was obtained from Kathryn Knighton, Office of Special Programs at the West Virginia Department of Education. Kathryn Knighton provided an endorsement for the study prior to the distribution of the paper survey (verbal endorsement given at the Public Schools Forum held on March 31, 2011 at the WVSHA Annual Convention).

RESA Districts. In order to provide confidentiality for survey respondents, RESA Districts were used to aggregate data and avoid more specific county identification. Eight RESA Districts were established by the West Virginia Legislature under West 
Virginia Code §18-2-26 in 1972 (West Virginia School Laws Annotated, 2009). West

Virginia Code §18-2-26-E-5 stated:

Dividing the State into appropriate, contiguous geographical areas and designating an agency to serve each area. The rule shall provide that each of the State's counties located within the boundaries of each agency, as determined by the state board, shall be members of that agency. (p. 41).

All eight RESA districts were represented by the respondents who completed surveys.

Figure 3.1, which is located below shows the configuration of the counties that comprise the eight RESA Districts in the state of West Virginia.

Figure 3.1 Regional Education Service Agencies in West Virginia (RESA Districts)

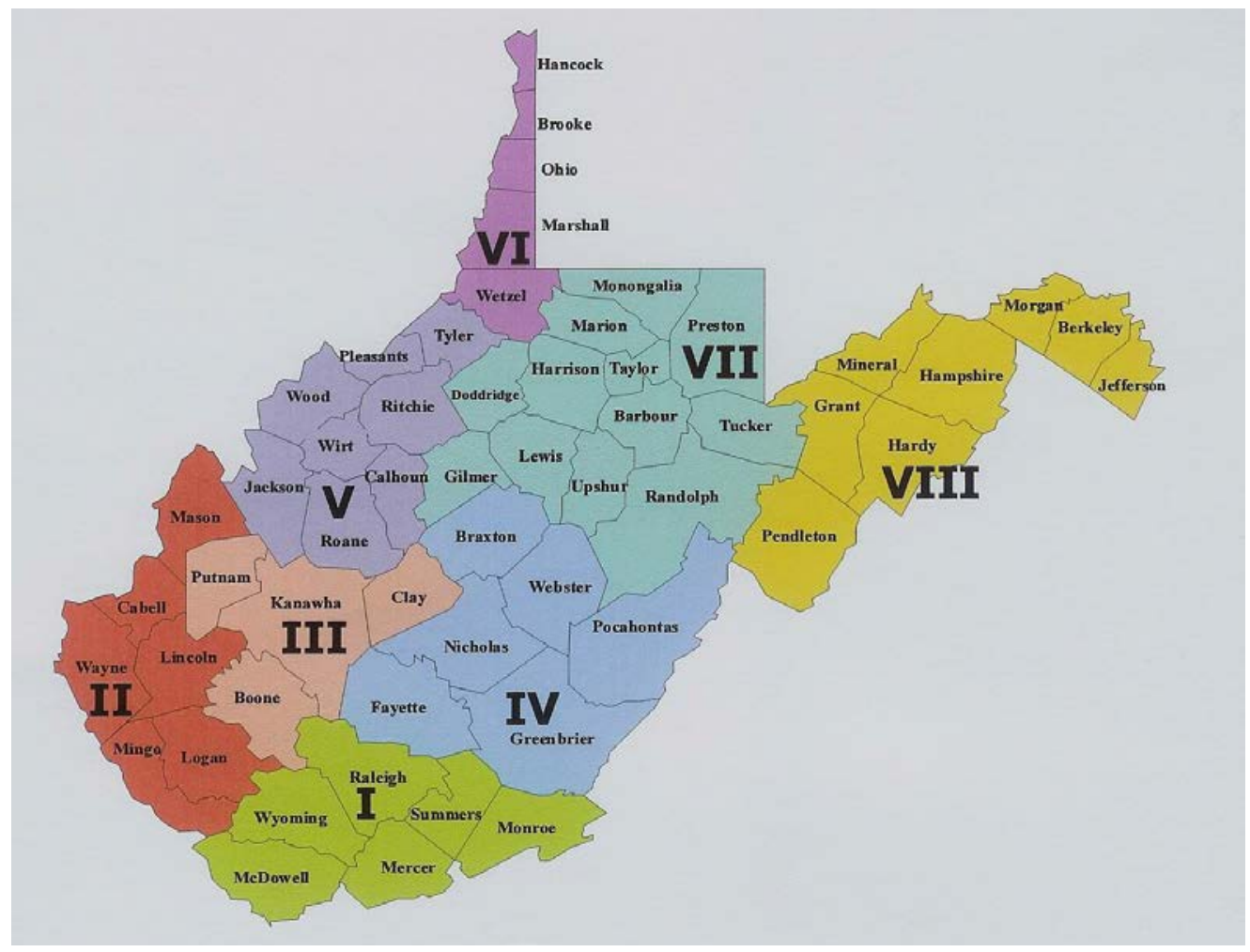

Figure 3.1. The map shows the configuration of the eight RESA Districts in West Virginia. Adapted from http://wvde.state.ev.us/ed_directory/RESAMap.pdf. 


\section{Data Collection Procedures}

A three phase process was used to collect data from school-based SLPs in the 55 counties in West Virginia in order to obtain information concerning the challenges that they feel are associated with SLPs' roles and responsibilities in the RTI process.

Phase One. Upon university level Institutional Review Board (IRB) review and granting of exempt status (refer to Appendix D), a Pilot Study was conducted. The first phase in this investigation involved a pilot study that distributed a Letter of Invitation (see Appendix E) and a paper survey to obtain information from SLPs in two counties. Twenty-eight school-based SLPs from RESA V and twenty school-based SLPs from RESA VII participated in the pilot study. The pilot study was conducted in February of 2011.

Phase Two. Phase Two involved the distribution of paper surveys at the 2011 West Virginia Speech and Hearing Association (WVSHA) Annual Convention, which was held in March of 2011. One hundred and sixty-four surveys were distributed and completed over a two-day period of time at the 2011 WVSHA Annual Convention. The same cover letter and survey utilized for the pilot study were also utilized for the second phase of the study. The IRB Exempt status letter for data collected at the 2011 WVSHA Annual Convention is located in Appendix F.

Phase Three. For Phase Three, Kathryn Knighton, Coordinator of Special Programs for the West Virginia Department of Education, distributed an e-mail via access accounts, which included the survey, a Letter of Invitation, and a link to SurveyMonkey.com (see Appendix) in order to access school-based SLPs in all 55 counties in the state of West Virginia. The same Letter of Invitation and survey were again used. This distribution 
involved contacts that consisted of either lead school-based SLPs or a school-based SLP designated as a contact in a specific county. The third phase of the study was an attempt to reach current members of WVSHA who did not attend the 2011 Annual Convention or school-based SLPs from around the state of West Virginia who did not attend the 2011 Annual Convention and are not members of WVSHA. The surveys for Phase Three were hosted by the survey website SurveyMonkey.com. The internet was employed in order to allow for a large number of school-based SLPs from the population to be accessed across a large area (e.g. school-based SLPs throughout the state of West Virginia) in an inexpensive and rapid manner (Creswell, 2003; Martella, Nelson, \& Marchand-Martella, 1999). A two-week window of time was given to potential respondents contacted via the internet. A reminder e-mail was sent out via access accounts after one week. Fifteen school-based SLPs completed the survey via SurveyMonkey.com.

Table 3.1 located below provides a summary of the number of completed surveys in each of the three phases of the study. 
Table 3.1

Summary of the Number of Completed Surveys by Phase

Total Number

Phase

Phase 1

Pilot study $\quad 48$

Phase 2

Paper survey at WVSHA 2011 Convention 164

Phase 3

$\begin{array}{ll}\text { SurveyMonkey.com survey } & 15\end{array}$

Note. $\mathrm{n}=227$. All eight RESA Districts were represented.

\section{Data Analysis}

The survey data was compiled into an Excel spreadsheet and then exported to the IBM Statistical Package for the Social Sciences (SPSS) version 19 for analysis. Analysis of Variance (ANOVA) and descriptive statistics were used to analyze the difference in means for statements from SLPs from the eight RESA districts for the Likert-type questions in order to probe the research questions outlined in this study. The results of these tests will be discussed in detail in Chapter 4 .

The items on the Likert-type questions were grouped in one of five sections to probe the research questions outlined in the study. The five point Likert scale allowed for SLPs to respond from Strongly Agree (SA) or Agree (A) or Neutral (N) or Disagree (D) or Strongly Disagree (SD). Questions 13 through 17 used the following response scale: At least once an hour during work, At least once every day, At least once a week, At least once a month, and Less than once a month. When an item was not answered by a 
respondent, no response was recorded. All data was recorded exactly as marked by the 227 respondents.

For statistical purposes, responses for the Likert-type questions (questions 1-26) were assigned a number value. After each response was recorded on the Excel spreadsheet, a numerical conversion was made. The numerical values ranged from SA (1), A (2), N (3), D (4), to SD (5) for questions one through 12 and 18 through 26. The numerical values for questions 13 through 17 ranged from At least once an hour during work (1), At least once every day (2), At least once a week (3), At least once a month (4), and Less than once a month (5). Through the use of these numbers, the calculated means revealed a snapshot of the challenges the school-based SLPs feel they face in the RTI process. For questions one through 12 and 18 through 26, a smaller mean represented more agreement and a larger mean represented more disagreement with the Likert-type statements. The mean closer to three revealed a more neutral opinion. The calculated mean for each item showed the average of the number values assigned. The standard deviation (SD) is the average amount of variability of how much the scores differ from the mean. A larger SD indicated that the responses were more spread out and that the feeling toward the challenges within the RTI process varied to a larger degree.

The rank order data was analyzed by the percentage of SLPs recording their level of challenge from most challenging to least challenging in each of the following four categories:

- $\quad$ participating in the RTI model;

- accountability and data collection;

- $\quad$ professional development related to RTI; and 
- caseload versus workload issues related to RTI

An average of the percents reported for service delivery time was employed to assess the amount of time reported for each category of service delivery by the school-based SLPs who participated in this study. The categories included the following areas: direct services providing individual or group therapy in the therapy room (pull-out services), providing therapy services in the classroom (push-in services), consultation with teachers (collaboration), RTI implementation, and other. Each school-based SLP had the opportunity to report their of service delivery by the percent of time allotted for the categories previously explained, for example, $50 \%$ of their time in the therapy room (pull-out services), 30\% in the classroom setting (push-in services), $10 \%$ in consultation (collaboration), and 10\% participating in the RTI model.

Demographic information was obtained in the following areas: gender, highest degree earned current caseload configuration, and years of experience. Demographic information was considered in order to investigate any patterns that may emerge in relation to feelings toward challenges in the RTI process and number of years of experience.

\section{Establishment of Content Validity and Reliability}

Before distribution of the survey, three SLPs were randomly selected to review the survey. Each SLP was contacted by the researcher and agreed to participate. All three were given verbal instructions to rate each response on the questionnaire with either a score of 1 - statement is representative of SLPs' challenges in the RTI process or 2 statement is not representative of SLPs' challenges in the RTI process. The average number of years of employment as a school-based SLP was 12 years of employment for 
the three therapists who participated as experts to give their subjective opinions to help in the establishment of the content validity of the instrument. This reasoning was supported by Huck (2008). These three school-based SLPs were considered “content experts” and contributed to the development of the final draft of the survey (Lynn, 1986). In order to reduce biases, the surveys completed by the three respondents who served as content experts were excluded from the study since they had already seen and been given the questionnaire (Nardi, 2006).

Then, a purposive sample of school-based SLPs was selected from two counties from different Regional Educational Service Agency (RESA) districts in West Virginia to participate in a pilot study. Twenty-eight respondents were from RESA V and twenty respondents were from RESA VII. To further attempt to establish validity of the survey, the respondents were provided a question at the end of the survey that asked for comments of how the respondent felt concerning what the survey intended to measure. According to Huck (2008), a measuring instrument is valid to the "extent that it measures what it purports to measure” (p. 88).

Forty-eight school-based SLPs in two counties were mailed the cover letter and the questionnaire, which included demographic information, Likert-type questions, one question to rank order four categories and a final question, which involved reporting the percentage of their current service delivery practice. The terminology used in the cover letter and the questionnaire was intended to be both common and understandable for the target population. Results from the pilot study indicated that the two groups showed significantly different results on two categories from the Likert-type questions $(\mathrm{p}<.05)$. No outliers were noted in relation to the data collected in the pilot study. 
Reliability of the instrument was validated through Cronbach’s Alpha testing. According to Huck (2008), Cronbach's alpha is versatile and can be used with instruments made up of items like a Likert-type questionnaire where the five response options extend from strongly agree to strongly disagree. Santos (1999) further noted that alpha coefficient ranges in value from 0 to 1 and may be used to describe reliability factors associated with survey scales. The higher the score, the scale can be considered to be reliable. Researchers tend to follow the guideline that alpha should be at least 0.7 $(\alpha>0.7)$

Validity in Relation to Research Questions. The survey was designed to incorporate the concepts of RTI and examine the challenges SLPs feel they face within the RTI model in a measurable manner. Twenty six of the statements on the questionnaire survey were designed to address specific opinions and attitudes concerning the challenges SLPs currently face within the RTI model. According to Page (2002), survey research should consider the objective of building a case for "convergent validity”. Page (2002) noted that information from a variety of sources can be used to support and triangulate research findings. A researcher can have confidence in drawing conclusions and inferences when the data from several different sources indicate the same trends.

Through a review of the literature, several themes emerged that assisted in the development of research questions for this study. The following research questions reflect the challenges that school-based SLPs currently face within the RTI model such as: overall perceptions of school-based SLPs involvement in the RTI process; professional development issues for the school-based SLPs within the RTI model; 
caseload versus workload issues; documentation and accountability for school-based SLPs in the RTI process; and collaboration with other professionals within the RTI model.

Research Question One (RQ1). What do school-based SLPs in West Virginia perceive as challenges in the RTI process? The first research question addressed in this study deals with school-based SLPs’ perceptions of the challenges that they face within the RTI process. Conversations regarding RTI are taking place throughout the field of education. The attention on RTI can be attributed to changes in the field of speechlanguage pathology, including an emphasis on early learning standards and progress for all, a movement toward preventive practices and early intervention of struggling learners, the use of scientifically based practices to recognize and respond to individual needs, the use of scientifically based practices to respond to individual needs, and the promotion of professional competencies to foster learning in the least restrictive environment (Bender \& Shores, 2007). It is important to understand the school-based SLPs' perceptions of the challenges that they feel they face in the RTI process in order to better meet their professional learning needs. Figure 3.2 below lists the survey questions that address RQ1. 


\section{Figure 3.2 Survey Statements That Address RQ1}

Item \# 1 SLPs should play an active role in research-based interventions.

Item \#2 SLPs should monitor progress of struggling learners in the general education setting.

Item \#3 I am comfortable with the components of the RTI model.

Item \#4 My unique experience and knowledge base is respected in the RTI process.

Item \#5 I have the opportunity to voice my concerns about the tiered intervention model.

Item \#6 Participating in the tiered intervention implementation compromises my other responsibilities as an SLP.

Figure 3.2. List of questions from Survey of School-Based SLPs and the RTI Process that address $R Q 1$.

Research Question Two (RQ2). How do school-based SLPs in West Virginia feel about their present levels of training regarding implementation of tiered intervention practices? Justice (2006) noted that the RTI model has significant “implications for the SLP who is invested in promoting reading achievement among the pupils on his or her caseload and in adhering to the current best evidence on approaches to reducing reading difficulties” (p. 286). Implementation of the RTI model calls for an explicit focus on school-based SLPs to continually seek improvement in the quality of their instruction to struggling learners. SLPs must be aware of the need for guidance in creating effective early learning experiences with an emphasis on quality instruction and intervention. It is vital that school-based SLPs be knowledgeable and prepared for the challenges that they 
face in the RTI process in order to provide their students with a strong curriculum framework. Any framework is only as effective as the educators who provide the instruction within the framework. Through understanding how school-based SLPs feel about the level of training they have received within the RTI framework, districts can match the needs of school-based SLPS with appropriate levels of support to ensure that instructional opportunities are effective and foster continued progress. ASHA (2010) noted the importance of professional preparation for school-based SLPs in the RTI process. ASHA (2010) suggested that new or expanded roles for school-based SLPS may require high quality professional development for SLPs who service children in the schools. Figure 3.3 located below lists Item \#18 through Item \#23 that address how school-based SLPs feel about their level of training in the RTI process.

Figure 3.3 Survey Statements That Address RQ2

Item \#18 I have received an appropriate amount of training related to tiered intervention practices.

Item \#19 I am comfortable with the common vocabulary used in the RTI model.

Item \#20 There is an adequate network of support available in my school/s to provide a continuity of services needed for tiered instruction practices.

Item \# 21 I am comfortable implementing the three tiers involved in the RTI model.

Item \#22 I have access to engaged leaders that guide my successful implementation of tiered intervention practices.

Item \#23 I have received adequate training regarding the three tiers involved in the RTI model.

Figure 3.3. List of questions from Survey of School-Based SLPs and the RTI Process that address $R Q 2$. 
Research Question Three (RQ3). How does RTI ultimately impact service delivery on a day-to-day basis for school-based SLPs? Ehren (2007) suggested that school-based SLPs may have to "set the stage" for shifting roles by defining the existing context and conditions in their schools. For example, the existing model of a traditional caseload approach may require examination. The concept of a workload, which has been offered by ASHA since 2002, is essential to the RTI model (Ehren, 2007). Katz et al. (2010) reported that caseload issues continue to be an area of concern for school-based SLPs, and efforts to address this problem must continue in order to prevent long-term struggles with SLPs' dissatisfaction, shortages, and turnover. Katz et al. (2010) also noted "recent changes in federal special education law are now opening up avenues for districts to identify and intervene with children in need of special education services in a more preemptive way” (p. 149). The RTI model holds promise for SLPs, in terms of the extent to which they will be able to use their knowledge and expertise in working with students not only in remediation but also in prevention (Ehren \& Whitmire, 2005). Figure 3.4 located below addresses how school-based SLPs feel about caseload/workload models of service delivery.

\section{Figure 3.4 Survey Statements That Address RQ3}

Item \#24 I am comfortable with an RTI model in general education classrooms that involves more consultation and collaboration than the traditional norm.

Item \#25 School-based SLPs should follow a caseload only model.

Item \#26 School-based SLPs should follow a combination caseload/workload model

Figure 3.4 List of questions from Survey of School-Based SLPs and the RTI Process that address $R Q 3$. 
Research Question Four (RQ4). How willing are SLPs in West Virginia to participate in the documentation process within the RTI model? ASHA (2010) reported that data collection and analysis are critical roles and responsibilities for all school-based SLPs. ASHA (2010) further stated, "SLPs, like all educators, are accountable for student outcomes; therefore, data-based decision making, including gathering and interpreting data with individual students, as well as overall program evaluation are essential responsibilities” (p. 2). How school-based SLPs feel about their role in documentation of information in the RTI process will effect the identification of students who require additional specialized services. Figure 3.5 located below lists questions from the survey that ask the school-based SLPs' opinions on issues involved with documentation within the RTI process.

\section{Figure 3.5 Survey Statements That Address RQ4}

Item \#7 Careful attention to paper-based documentation is crucial to the success of the intervention process.

Item \#8 I am willing to accept responsibility for paperwork and documentation involved in the RTI process.

Item \#9 Individuals other than the SLPs should be responsible for the paperwork and documentation involved in the RTI process.

Item \#10 I understand the accountability and documentation procedures used in the RTI model.

Item \#11 Careful attention to electronic documentation is crucial to the success of the intervention process.

Item \#12 The RTI model uses appropriate monitoring methods

Figure 3.5. List of questions from Survey of School-Based SLPs and the RTI Process that address $R Q 4$. 
Research Question Five (RQ5). How willing are SLPs in West Virginia to adopt collaboration with other professionals in order to participate within the RTI model? ASHA (2002) noted the importance of collaboration, leadership, and research principles for working with others, serving as advocates, and advancing knowledge about evidencebased practices in Knowledge and Skills Needed by Speech-Language Pathologists with Respect to Reading and Writing in Children. ASHA (2002) also suggested school-based SLPS should collaborate with general and special education teachers in a variety of service delivery models to provide inclusive educational experiences that could serve to maximize the potential of all students to progress in the general education curriculum. ASHA’s 2010 Position Statement highlighted the importance of school-based SLPs to work in partnership with others to meet the needs of all students. ASHA (2010) noted that SLPs' unique contributions can serve to complement and augment other professionals who also have unique perspectives and skills. ASHA (2010) further stated that "working collegially with general education teachers who are primarily responsible for curriculum and instruction is essential” (p. 3). Figure 3.6 located below lists questions from the survey that address the area of collaboration. 


\section{Figure 3.6 Survey Statements That Address RQ5}

Item \#13 Accessing recorded data (paper or electronic) to help guide a decision regarding your work as an SLP.

Item \#14 Seeking advice from another SLP colleague to help guide a decision regarding your work as an SLP.

Item \#15 Seeking advice from a School Leader to help guide a decision regarding your work as an SLP.

Item \#16 Seeking advice from a Teacher to help guide a decision regarding your work as an SLP.

Item \#17 Reading a journal article from the SLP literature to help guide a decision regarding your work as an SLP.

Figure 3.6. List of questions from Survey of School-Based SLPs and the RTI Process that address $R Q 5$.

\section{Limitations}

This research study was limited by the number of school-based SLPs in the state of West Virginia who agreed to complete a survey. However, great care was taken to contact school-based SLPs from all RESA Districts in the state of West Virginia. In addition, the use of surveys has basic limitations, which may include a non-response rate - the rate of non-responders to the survey could skew final results. Few respondents can create a result that does not represent the majority of the population surveyed (Groves, Fowler, Couper, Lepkowski, Singer, \& Tourangeau, 2009). Moreover, application of the study may be limited in that the findings may only be useful for SLPs who are schoolbased. Another limitation to consider is that the respondents in this study were schoolbased SLPs from the eight RESA Districts in West Virginia; therefore, the results of this study may not represent the population of school-based SLPs from other states. 
Technical problems may have been another limitation of the study. Only fifteen surveys were completed through the use of SurveyMonkey.com. Several e-mails indicated difficulty with accessing the survey on-line. A new e-mail was sent to those school-based SLPs who could not open the link. However, follow-up responses were not received to indicate successful access to the survey. Another consideration of the low response rate for the on-line survey may have been associated with the time of year that the survey was conducted. The on-line survey was distributed close to the end of the school year, which coincided with the completion of IEPs and end of the year reports for school-based SLPs.

\section{Summary}

The purpose of this study was to obtain information concerning school-based SLPs' challenges in the RTI process. A Likert-type questionnaire was developed for this descriptive study to collect data on challenges school-based SLPs face within the RTI process. School-based SLPs from across the state of West Virginia were surveyed. This population of individuals $(\mathrm{n}=227)$ was asked to participate voluntarily in the study in order to research the challenges school-based SLPs feel they currently face in their dayto-day service delivery to the students on their prospective caseloads.

The questionnaire was administered using a Three Phase process. Initially, a pilot study was completed that involved 48 school-based SLPs from two counties in West Virginia. During Phase Two, the survey was distributed at the 2011 WVSHA Annual Convention to 165 school-based SLPs who represented the eight RESA Districts from the state of West Virginia. Finally, the survey was distributed via access accounts through the use of SurveyMonkey.com to lead therapists or school-based SLP contacts in all 55 
counties by Kathryn Knighton at the West Virginia Department of Education. The last step of this process was initiated to offer the survey to WVSHA members who were unable to attend the annual conference and school-based SLPs from the 55 counties who are not currently members of WVSHA or did not attend the 2011 WVSHA Annual Convention. Content validity was established through the implementation of a pilot study.

This chapter has explained the methodology used to quantitatively survey schoolbased SLPs challenges within the RTI process in West Virginia. The survey questions, rank order question, and service delivery question were created through an investigation of the literature, which addresses early intervening and RTI approaches in many different service delivery formats for school-based SLPs. The data collected from the respondents have been examined through the use of descriptive and inferential statistics. Through the analyzed data, insight has been gained to enhance the understanding of the challenges school-based SLPs in West Virginia feel they face in the RTI process.

In the next chapter, the results of the reported challenges school-based SLPs feel they face in West Virginia will be discussed and summarized through descriptive data as well as through the use of an analysis of variance (ANOVA) to explore relationships among the school-based SLPs from all eight RESA districts. 


\section{CHAPTER 4}

\section{Results}

\section{Introduction}

In the wake of the No Child Left Behind legislation (NCLB. 2002), data-driven decision making has become a central focus of education policy and practice. At the present time, the RTI process appears to be the strongest national movement local education agencies (LEAs) are utilizing to detect academic difficulties and guide the use of research-based interventions. According to Troia (2005) SLPs can play a proactive and substantive part in school wide reading disability prevention and intervention efforts within the RTI framework. In addition, Ehren (2007) noted school-based SLPs have much to offer in their efforts to provide effective, scientifically based instruction and intervention, especially related to literacy.

As stated in the previous Research Methodology chapter, this study was a quantitative design, which utilized a survey questionnaire to investigate the challenges school-based SLPs feel they currently face within the RTI model. Data were collected through the use of a paper survey and an online survey that was sent via SurveyMonkey.com. The survey questionnaire consisted of 26 Likert-type statements, a rank order question, and a service delivery question. It was the intent of this study to investigate the challenges that schoolbased SLPs representing the eight RESA Districts in the state of West Virginia feel they face in the RTI process. Chapter 4 includes results of demographic information and an analysis of survey results for the 26 Likert-type statements, a rank order question, and a service delivery question for the 227 respondents who completed the survey. 
In order to determine the overall response rate, the total number of surveys completed was subtracted from the approximate number of school-based SLPs in West Virginia. The total number of respondents for the three phases of the survey totaled 227. Based on information of the approximate number of school-based SLP positions currently in the state of West Virginia $(N=400)$, the response rate for the survey was $57 \%$. Since an accurate number of currently employed school-based SLPs in West Virginia was unattainable at the time of this study, the response rate may be higher than $57 \%$ due to variables such as unfilled positions, leaves of absences, etc. The minimum sample size, which required at least 162 respondents, was achieved; therefore, the sample size was considered adequate for this study (Raosoft, 2004).

\section{Demographic and Descriptive Statistics}

The sample of school-based SLPs in this study represented the approximately 400 SLPs who provide speech and language services to the children enrolled in both public and private schools across the state of West Virginia. The sample in this study included 227 school-based SLPs from all eight RESA districts.

The first part of the survey afforded the respondents an opportunity to provide basic demographic information. The following sections analyze breakdowns of the demographic information of the respondents. The tables below show both the frequency and the percent of responses in the areas of current caseload configuration, years of experience, gender, and highest degree earned.

Current Caseload Configuration. School-based SLPs serve children from three years of age to 21 years of age in the public and private schools in West Virginia. Caseload configurations may include Primary (Pre-K through second grade), 
Intermediate (third grade through fifth grade), Middle School (sixth grade through eighth grade), High School (ninth grade through twelfth grade), or a combination of schools (Mixed). SLPs assigned to provide services at the primary level clearly dominated caseload configuration with a frequency of 156 respondents (68.7\%) out of the 227 who responded to this question. Table 4.1 located below shows the caseload configuration reported by 225 respondents to the survey. Two respondents did not complete the question regarding caseload configuration on the survey.

\section{Table 4.1}

Frequency and Percent of the Caseload Configuration Reported by School-Based SLPs in the State of West Virginia Who Responded to the Survey

\begin{tabular}{lccccc} 
& \multicolumn{5}{c}{ Caseload Configuration } \\
\cline { 2 - 6 } & $\begin{array}{l}\text { Primary } \\
\text { Pre-K - }\end{array}$ & $\begin{array}{c}\text { Intermediate } \\
\mathbf{3 - 5}\end{array}$ & $\begin{array}{c}\text { Middle School } \\
\mathbf{6 - 8}\end{array}$ & $\begin{array}{c}\text { High School } \\
\mathbf{9 - 1 2}\end{array}$ & Mixed \\
\cline { 2 - 6 } & 156 & 13 & 7 & 3 & 47 \\
Frequency & 68.7 & 5.7 & 3.1 & 1.3 & 20.7 \\
Percent & & & & & \\
\hline
\end{tabular}

Note. $\mathrm{n}=225$ respondents. Two respondents did not report a Caseload Configuration.

Years of Experience. Demographic results for Years of Experience of the respondents are displayed in Table 4.2 below. The highest percent (43.6\%) was in the 21 or more years of experience group ( $n=99$ ), while the lowest percent (10.6\%) noted was in the 16 to 20 years of experience group $(n=24)$. 
Table 4.2

Frequency and Percent of the Years of Experience Breakdown of School-Based SLPs in the State of West Virginia Who Responded to the Survey

\begin{tabular}{llllll}
\hline & \multicolumn{5}{c}{ Years of Experience } \\
\cline { 2 - 6 } & $0-5$ & $6-10$ & $11-15$ & $16-20$ & 21 or more \\
\cline { 2 - 6 } Frequency & 31 & 36 & 37 & 24 & 99 \\
Percentage & $13.7 \%$ & $15.9 \%$ & $16.3 \%$ & $10.6 \%$ & $43.6 \%$ \\
\hline
\end{tabular}

Note. $\mathrm{n}=227$ respondents who completed the survey.

Gender. Table 4.3 located below shows a breakdown by Gender. The sample was clearly dominated by females. As displayed in Table 4.2, 97.4\% of the sample was female. Two point six percent of the sample was male.

Table 4.3

Frequency and Percentage by Gender of School-based SLPs in the State of West Virginia Who Responded to the Survey

Gender

Frequency

6

221

Percentage

2.6

97.4

Note. $\mathrm{n}=227$ respondents who completed the survey.

Highest Degree Earned. Table 4.4 located below shows a breakdown of the 227 respondents by Highest Degree Earned. The sample indicated a clearly defined dominate 
group of respondents. The vast majority of respondents to the survey held master's degrees in speech-language pathology $(n=191,84.1 \%)$. As Table 4.4 below indicates, 34 respondents (15\%) noted completion of a speech-language degree at the bachelor's level.

Table 4.4

Frequency and Percent by Highest Degree Earned of School-based SLPs in the State of West Virginia Who Responded to the Survey

Highest Degree Earned

Frequency

20

191

14

Percentage

$8.8 \%$

$84.1 \%$

$6.2 \%$

Note. $\mathrm{n}=225$ respondents who completed the survey. Two respondents did not report Highest Degree Earned

Breakdown of Respondents by RESA District. All of the eight RESA Districts in the state of West Virginia were represented by the 227 respondents. The largest number of respondents represented RESA VII. The smallest number of respondents represented RESA VI. Two respondents did not identify a RESA District on their survey. Table 4.5 located below shows the frequency and percent by each RESA District of the respondents. 
Table 4.5

Frequency and Percent by RESA District of School-based SLPs in the State of West Virginia Who Responded to the Survey

RESA 1 RESA 2 RESA 3 RESA 4 RESA 5 RESA 6 RESA 7 RESA 8

$\begin{array}{lllllllll}\text { Frequency } & 19 & 28 & 18 & 25 & 42 & 12 & 55 & 26\end{array}$

$\begin{array}{lllllllll}\text { Percent } & 8.4 & 12.3 & 7.9 & 11 & 18.5 & 5.3 & 24.2 & 11.5\end{array}$

Note. $\mathrm{n}=225$ respondents who identified a RESA District on their completed the survey.

\section{Data Analysis for Research Questions}

The mean score, standard deviation, frequency, and percent were examined for the 26 Likert-type items on the survey. The following sections will examine results of the five research questions.

Research Question One (RQ1). Statements \#1 through \#6 addressed RQ1 - What do school-based SLPs in West Virginia perceive as challenges in the RTI process?

Statements \#1 through \#6 examined how the respondents perceived the challenges they felt school-based SLPs face in the RTI process. A summary of the scores by frequency and percent are shown in Table 4.6 below. On statement $\# 1,66.1 \%(n=150)$ of the respondents responded that they disagree or strongly disagree that SLPs should play an active role in research-based interventions. On statements \#2, \#3, \#4, and \#5, the respondents' largest percent of responses were in the Neutral (N) category. On statement \#6 (Participating in the tiered intervention implementation compromises my other responsibilities as an SLP), 56\% ( $n=127)$, responded that they disagree or strongly disagree. 
Table 4.6

Reported Frequency and Percent for Questions \#1 through \#6

\begin{tabular}{llllll}
\hline Survey Item & SA & A & N & D & SD
\end{tabular}

1. SLPs should play an active

Frequency

$\begin{array}{lllll}7 & 28 & 42 & 95 & 55\end{array}$

role in research-based

Percent

$\begin{array}{lllll}3.1 & 12.3 & 18.5 & 41.9 & 24.2\end{array}$

interventions.

2. SLPs should monitor

Frequency

$\begin{array}{lllll}20 & 49 & 80 & 67 & 11\end{array}$

progress of struggling

Percent

$\begin{array}{lllll}8.8 & 21.6 & 35.2 & 29.5 & 4.8\end{array}$

learners in the general

education setting.

3. I am comfortable with the components of the RTI model.

Frequency

Percent

Frequency

Percent

Frequency

Percent

to voice my concerns

about the tiered

intervention model.

6. Participating in the

tiered intervention

implementation

compromises my

other responsibilities

as an SLP.

Note. Frequency and percent based on $n=227$ respondents. Strongly Agree (SA), Agree (A), Neutral (N), Disagree (D), and Strongly Disagree (SD).

Research Question Two (RQ2). Statements \#18 through \#23 addressed RQ2 - How do school-based SLPs in West Virginia feel about their present levels of training for implementation of tiered intervention practices? This question probed SLPs' feelings toward their present levels of training for implementation of RTI practices. Statements 
\#18, \#19, and \#20 revealed the largest frequency of respondents in the Disagree (D) category. Statement \#18 addressed school-based SLPs receiving an appropriate amount of training, statement \#19 addressed SLPs familiarity with the common vocabulary used in the RTI process, and statement \#20 addressed the support services available to schoolbased SLPs to provide a continuity of services needed for RTI practices. Table 4.7 below provides a summary of the frequency and percent of the responses for the survey items regarding present levels of training for implementation of RTI practices.

Table 4.7

Reported Frequency and Percent for Questions \#18 through \#23

\begin{tabular}{|c|c|c|c|c|c|c|}
\hline Survey Item & & SA & A & $\mathrm{N}$ & $\mathrm{D}$ & SD \\
\hline $\begin{array}{l}\text { 18. I have received an } \\
\text { appropriate amount of } \\
\text { training related to tiered } \\
\text { intervention practices }\end{array}$ & $\begin{array}{l}\text { Frequency } \\
\text { Percent }\end{array}$ & $\begin{array}{l}36 \\
15.9\end{array}$ & $\begin{array}{l}53 \\
23.3\end{array}$ & $\begin{array}{l}59 \\
26\end{array}$ & $\begin{array}{l}73 \\
32.2\end{array}$ & $\begin{array}{l}6 \\
2.6\end{array}$ \\
\hline $\begin{array}{l}\text { 19. I am comfortable with } \\
\text { the common vocabulary } \\
\text { used in the RTI model. }\end{array}$ & $\begin{array}{l}\text { Frequency } \\
\text { Percent }\end{array}$ & $\begin{array}{l}19 \\
8.4\end{array}$ & $\begin{array}{l}46 \\
20.3\end{array}$ & $\begin{array}{l}74 \\
32.6\end{array}$ & $\begin{array}{l}76 \\
33.5\end{array}$ & $\begin{array}{l}12 \\
5.3\end{array}$ \\
\hline $\begin{array}{l}\text { 20. There is an adequate } \\
\text { network of support } \\
\text { available in my school/s } \\
\text { to provide a continuity of services } \\
\text { needed for tiered instruction } \\
\text { practices. }\end{array}$ & $\begin{array}{l}\text { Frequency } \\
\text { Percent }\end{array}$ & $\begin{array}{l}14 \\
6.2\end{array}$ & $\begin{array}{l}47 \\
20.7\end{array}$ & $\begin{array}{l}69 \\
30.4\end{array}$ & $\begin{array}{l}82 \\
36.1\end{array}$ & $\begin{array}{l}15 \\
6.6\end{array}$ \\
\hline $\begin{array}{l}\text { 21. I am comfortable } \\
\text { implementing the three } \\
\text { tiers involved in the RTI model. }\end{array}$ & $\begin{array}{l}\text { Frequency } \\
\text { Percent }\end{array}$ & $\begin{array}{c}52 \\
22.9\end{array}$ & $\begin{array}{c}67 \\
29.5\end{array}$ & $\begin{array}{l}56 \\
24.7\end{array}$ & $\begin{array}{l}48 \\
21.1\end{array}$ & $\begin{array}{l}4 \\
1.8\end{array}$ \\
\hline $\begin{array}{l}\text { 22. I have access to engaged } \\
\text { leaders that guide my } \\
\text { my successful implementation } \\
\text { of tiered intervention practices. }\end{array}$ & $\begin{array}{l}\text { Frequency } \\
\text { Percent }\end{array}$ & $\begin{array}{l}21 \\
9.3\end{array}$ & $\begin{array}{l}43 \\
18.9\end{array}$ & $\begin{array}{l}92 \\
40.5\end{array}$ & $\begin{array}{l}63 \\
27.8\end{array}$ & $\begin{array}{l}8 \\
3.5\end{array}$ \\
\hline 23. I have received adequate & Frequency & 41 & 52 & 65 & 64 & 5 \\
\hline
\end{tabular}


training regarding the three

Note. Frequency and percent based on $n=227$ respondents. Strongly Agree (SA), Agree (A), Neutral (N), Disagree (D), and Strongly Disagree (SD).

Research Questions Three (RQ3). Statements \#24 through \#26 addressed RQ3 What are the challenges of RTI within the service delivery on a day-to-day basis for school-based SLPs in West Virginia? The third research question addressed the issue of caseload/workload models for school-based SLPs. Table 4.8 located below indicates that the school-based SLPs responded with a total of $40.9 \%(n=93)$ in the Strongly Disagree (SD) and Disagree (D) categories when asked if school-based SLPs should follow a caseload/workload model (question \#26). When asked if school-based SLPs should follow a caseload-only model, 34.8\% $(n=79)$ responded in the Strongly Agree (SA) and Agree (A) categories (question \#25). In addition, the respondents responded with the highest percent at 36.6\% $(n=83)$ in the Neutral $(\mathrm{N})$ category when asked if school-based SLPs were comfortable with an RTI model in general education that involves more consultation and collaboration than the traditional norm (question \#24).

Table 4.8

Reported Frequency and Percent for Questions \#24 through \#26

\begin{tabular}{|c|c|c|c|c|c|c|}
\hline Survey Item & & $\mathrm{SA}$ & $\mathrm{A}$ & $\mathrm{N}$ & $\mathrm{D}$ & SD \\
\hline $\begin{array}{l}\text { 24. I am comfortable with } \\
\text { an RTI model in general } \\
\text { education classrooms } \\
\text { that involves more } \\
\text { consultation and collaboration } \\
\text { than the traditional norm. }\end{array}$ & $\begin{array}{l}\text { Frequency } \\
\text { Percent }\end{array}$ & $\begin{array}{l}20 \\
8.8\end{array}$ & $\begin{array}{l}56 \\
24.7\end{array}$ & $\begin{array}{l}83 \\
36.6\end{array}$ & $\begin{array}{l}63 \\
27.8\end{array}$ & $\begin{array}{l}5 \\
2.2\end{array}$ \\
\hline $\begin{array}{l}\text { 25. School-based SLPs } \\
\text { should follow a }\end{array}$ & $\begin{array}{l}\text { Frequency } \\
\text { Percent }\end{array}$ & $\begin{array}{l}12 \\
5.3\end{array}$ & $\begin{array}{c}67 \\
29.5\end{array}$ & $\begin{array}{c}67 \\
29.5\end{array}$ & $\begin{array}{r}45 \\
19.8\end{array}$ & $\begin{array}{c}36 \\
15.9\end{array}$ \\
\hline
\end{tabular}


caseload-only model.

26. School-based SLPs

Frequency

21

$\begin{array}{llll}42 & 71 & 77 & 16\end{array}$

should follow a combination

Percent

9.3

$18.5 \quad 31.3 \quad 33.9$

7

caseload/workload model.

Note. Frequency and percent based on $n=227$ respondents. Strongly Agree (SA), Agree (A), Neutral (N), Disagree (D), and Strongly Disagree (SD).

Research Question Four (RQ4). Statements \# 7 through \#12 addressed RQ4 - How willing are SLPs in West Virginia to participate in the documentation process within the RTI model? Table 4.9 located below indicates respondents responded with a total of $66.5 \%(n=151)$ in the Strongly Disagree (SD) and Disagree (D) categories when asked if careful attention to paper-based documentation is crucial to the success of the intervention process. Also, respondents responded in the Neutral $(\mathrm{N})$ category on statements \#11 and \#12, which addressed electronic documentation and appropriate monitoring methods.

Table 4.9

Reported Frequency and Percent for Questions \#7 through \#12

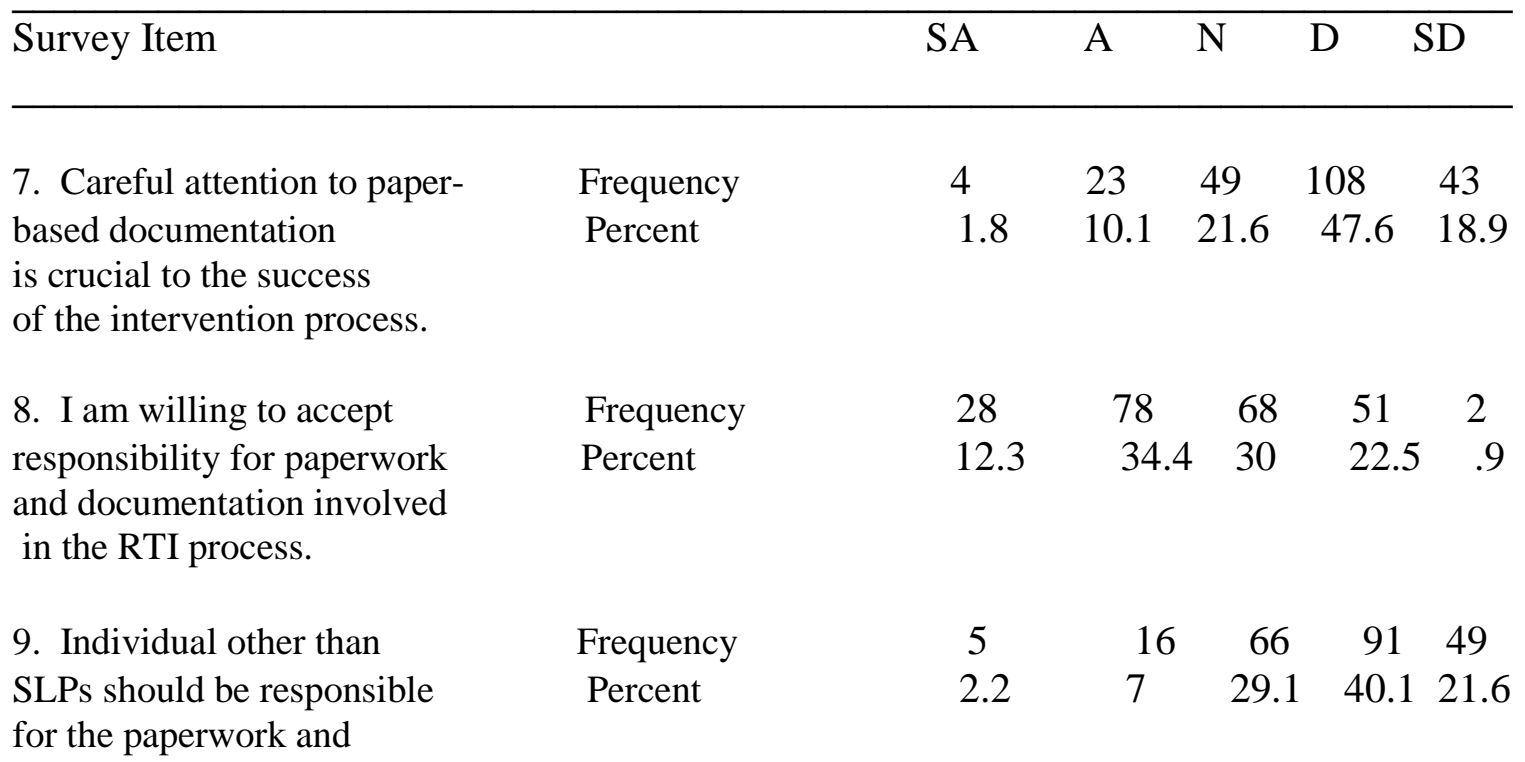


documentation involved in

the RTI process.

10. I understand the accountability $\quad$ Frequency $\quad \begin{array}{llllll}15 & 59 & 68 & 73 & 12\end{array}$ and documentation procedures Percent used in the RTI model.

$\begin{array}{lllll}6.6 & 26 & 30 & 32.2 & 5.3\end{array}$

$\begin{array}{lllllll}\text { 11. Careful attention to electronic } & \text { Frequency } & 2 & 19 & 101 & 89 & 16\end{array}$ $\begin{array}{lllllll}\text { documentation is crucial to the } & \text { Percent } & .9 & 8.4 & 44.5 & 39.2 & 7\end{array}$ success of the intervention process.

$\begin{array}{lllllll}\text { 12. The RTI model uses } & \text { Frequency } & 1 & 25 & 133 & 62 & 6\end{array}$

$\begin{array}{lllllll}\text { appropriate monitoring methods. } & \text { Percent } & .4 & 11 & 58.6 & 27.3 & 2.6\end{array}$

Note. Frequency and percent based on $n=227$ respondents. Strongly Agree (SA), Agree (A), Neutral (N), Disagree (D), and Strongly Disagree (SD).

Research Question Five (RQ5). Statements \#13 through \#17 addressed RQ5 - How willing are SLPs in West Virginia to adopt collaboration techniques with other professionals in order to participate within the RTI model? Table 4.10 located below shows the results of the frequency and percent for statements \#13 through \#17. The following scale was used to obtain scores: At least once an hour during work (1); At least once every day (2); At least once a week (3), At least once a month (4); and Less than once a month (5). Forty-one percent $(n=94)$ of the respondents reported that they are willing to seek advice from another SLP colleague to help guide a decision regarding their work as an SLP at least once a month. Sixty-one percent $(n=138)$ of the respondents reported that they were willing to seek advice from a Teacher to help guide a decision regarding their work as an SLP at least once a month or less than once a month; while eight percent $(n=19)$ reported a willingness to seek advice from a Teacher at least once every day. Seventy percent $(n=158)$ of the respondents reported that they are willing to seek advice from a School Leader to help guide a decision regarding their work as an 
SLP either at least once a month or less than once a month with five percent $(n=12)$

willing to seek advice from a School Leader at least once every day.

Table 4.10

Reported Frequency and Percent for Questions \#13 through \#17

\begin{tabular}{|c|c|c|c|c|c|c|}
\hline Survey Item & & $\begin{array}{l}\text { At least } \\
\text { once } \\
\text { an hour } \\
\text { during } \\
\text { work }\end{array}$ & $\begin{array}{l}\text { At least } \\
\text { once } \\
\text { every } \\
\text { day }\end{array}$ & $\begin{array}{l}\text { At least } \\
\text { once } \\
\text { a week }\end{array}$ & $\begin{array}{l}\text { At least } \\
\text { once } \\
\text { a month }\end{array}$ & $\begin{array}{l}\text { Less } \\
\text { than } \\
\text { once } \\
\text { a month }\end{array}$ \\
\hline $\begin{array}{l}\text { 13. Accessing recorded } \\
\text { data (paper or electronic) } \\
\text { to help guide a decision } \\
\text { regarding your work as an } \\
\text { SLP. }\end{array}$ & $\begin{array}{l}\text { Frequency } \\
\text { Percent }\end{array}$ & $\begin{array}{l}61 \\
26.9\end{array}$ & $\begin{array}{l}71 \\
31.3\end{array}$ & $\begin{array}{l}52 \\
22.9\end{array}$ & $\begin{array}{l}25 \\
11\end{array}$ & $\begin{array}{r}18 \\
7.9\end{array}$ \\
\hline $\begin{array}{l}\text { 14. Seeking advice from } \\
\text { another SLP colleague } \\
\text { to help guide a decision } \\
\text { regarding your work as } \\
\text { an SLP. }\end{array}$ & $\begin{array}{l}\text { Frequency } \\
\text { Percent }\end{array}$ & $\begin{array}{l}6 \\
2.6\end{array}$ & $\begin{array}{l}21 \\
9.3\end{array}$ & $\begin{array}{l}69 \\
30.4\end{array}$ & $\begin{array}{l}94 \\
41.4\end{array}$ & $\begin{array}{l}37 \\
16.3\end{array}$ \\
\hline $\begin{array}{l}\text { 15. Seeking advice from } \\
\text { a School Leader to help } \\
\text { guide a decision regarding } \\
\text { your work as an SLP. }\end{array}$ & $\begin{array}{l}\text { Frequency } \\
\text { Percent }\end{array}$ & $\begin{array}{l}9 \\
4\end{array}$ & $\begin{array}{r}12 \\
5.3\end{array}$ & $\begin{array}{l}48 \\
21.1\end{array}$ & $\begin{array}{l}60 \\
26.4\end{array}$ & $\begin{array}{l}98 \\
43.2\end{array}$ \\
\hline $\begin{array}{l}\text { 16. Seeking advice from } \\
\text { a Teacher to help guide } \\
\text { a decision regarding } \\
\text { your work as an SLP. }\end{array}$ & $\begin{array}{l}\text { Frequency } \\
\text { Percent }\end{array}$ & $\begin{array}{l}4 \\
1.8\end{array}$ & $\begin{array}{c}19 \\
8.4\end{array}$ & $\begin{array}{l}66 \\
29.1\end{array}$ & $\begin{array}{l}74 \\
32.6\end{array}$ & $\begin{array}{l}64 \\
28.2\end{array}$ \\
\hline $\begin{array}{l}\text { 17. Reading a journal } \\
\text { article from the SLP } \\
\text { literature to help guide } \\
\text { a decision regarding } \\
\text { your work as an SLP. }\end{array}$ & $\begin{array}{l}\text { Frequency } \\
\text { Percent }\end{array}$ & $\begin{array}{l}7 \\
3.1\end{array}$ & $\begin{array}{l}7 \\
3.1\end{array}$ & $\begin{array}{l}26 \\
11.5\end{array}$ & $\begin{array}{l}86 \\
37.9\end{array}$ & $\begin{array}{l}101 \\
44.5\end{array}$ \\
\hline
\end{tabular}

Note. Frequency and percent based on $n=227$ respondents. Strongly Agree (SA), Agree (A), Neutral (N), Disagree (D), and Strongly Disagree (SD). 
Null Hypotheses. Research questions RQ1 through RQ5 were addressed in the 26 Likert-type survey statements as SLPs selected their responses on statements about the challenges SLPs face in the RTI process. SLPs selected one of five values ranging from Strongly Agree (SA), Agree (A), Neutral (N), Disagree (D), or Strongly Disagree (SD) on research questions $R Q 1$ through $R Q 4$. SLPs selected one of five statements, which included the following: at least once an hour during work; at least once every day; at least once a week; at least once a month; and less than once a month. Significant differences regarding the challenges school-based SLPs in West Virginia feel they face in the RTI process were examined in relation to the demographic information collected in this study. The null hypotheses for this study included the following:

- Null Hypothesis One (NH1). There will be no difference in the perceptions of the challenges of the RTI model for school-based SLPs;

- Null Hypothesis Two (NH2). There will be no difference in the challenges associated with the levels of professional development for the implementation of the RTI model for school-based SLPs from the eight Regional Education Service Agency (RESA) Districts in West Virginia.

- Null Hypothesis Three (NH3). There will be no difference in the challenges associated with service delivery of the RTI model on a day-to-day basis for school-based SLPs from the eight Regional Education Service Agency (RESA) Districts in West Virginia.

- Null Hypothesis Four (NH4). There will be no difference in the willingness of SLPs in West Virginia to participate in the documentation process within the RTI model. 
- Null Hypothesis Five (NH5). There will be no difference in the willingness of SLPs in West Virginia to adopt collaboration techniques with other professionals in order to participate within the RTI model.

Analysis of Variance (ANOVA). A one-way Analysis of Variance test was used to examine the difference between groups. Analysis of variance looks for the differences between the means of more than two groups. The $F$ tests for an overall difference between means were examined to show a ratio of variability between groups to variability within groups. The demographics section of the survey (with the exception of gender) contained categories of more that two independent variables. An ANOVA was conducted for each research question using demographics that included the following areas: current caseload configuration (i.e. primary, intermediate, middle school, high school, mixed), years of experience (i.e. 0-5, 6-10, 11-15, 16-20, 21+ years), highest degree earned (i.e. B.S., M.S., other), and RESA District (RESA I, RESA II, RESA III, RESA IV, RESA V, RESA VI, RESA VII, RESA VIII). The level of significance or Type 1 error was $.05(p<.05)$. Gender was not considered in the statistical analysis due to the overwhelming number of females over males.

Post Hoc analysis using Bonferroni and Scheffe tests were utilized to determine differences between the subgroups.

Current Caseload Configuration. A one-way between groups ANOVA was conducted to compare the effect current caseload configuration had on school-based SLPs' feelings toward the challenges they face in the RTI process, professional development in the RTI process, service delivery models, documentation process in the 
RTI model, and adoption of collaboration techniques. According to the ANOVA results, the null hypothesis was rejected only for Null Hypothesis Five (NH5) -There will be no difference in the willingness of SLPs in West Virginia to adopt collaboration techniques with other professionals in order to participate within the RTI model. The area of collaboration differed significantly for current caseload configuration, $F(5,221)=3.06$, $p=.011$.

Years of Experience. A one-way between groups ANOVA was used to test for the effect years of experience had on school-based SLPs' feelings toward the challenges they face in the RTI process, professional development in the RTI process, service delivery models, documentation process in the RTI model, and adoption of collaboration techniques. According to the ANOVA results, no significant differences were found.

Highest Degree Earned. A one-way between groups ANOVA was used to test the effect the highest degree earned had on school-based SLPs' feelings toward the challenges they face in the RTI process, professional development in the RTI process, service delivery models, documentation process in the RTI model, and adoption of collaboration techniques. According to the ANOVA results, the null hypothesis was rejected only for Null Hypothesis Five (NH5) -There will be no difference in the willingness of SLPs in West Virginia to adopt collaboration techniques with other professionals in order to participate within the RTI model. The area of collaboration revealed a significant difference, $F(3,223)=3.77, p=.011$.

RESA Districts. A one-way between groups ANOVA was conducted to compare the effect RESA Districts had on school-based SLPs' feelings toward the challenges they 
face in the RTI process, professional development in the RTI process, service delivery models, documentation process in the RTI model, and adoption of collaboration techniques. According to the ANOVA results, all five null hypotheses were rejected at the significance level of $p<.05$. There was a difference in the challenges of schoolbased SLPs regarding the RTI process based on RESA Districts (Challenges $-F(8,218)$ $=3.53, p=.001$; Professional Development $-F(8,218)=5.15, p=.000$; Service Delivery $-F(8,218)=2.94, p=.004$; Collaboration $-F(8,218)=3.078, p=.003$; Documentation $-F(8,218)=3.26, p=.002)$.

Ranking of Major Issues for SLPs in the RTI Process. The respondents were asked to rank four statements from Most Challenging, to Least Challenging. The statements were meant to serve as possible indicators of the challenges school-based SLPs may face in the RTI process. The following four statements were used in the survey: Participating in the Tiered Intervention Model of RTI, Accountability and Data Collection, Professional Development Related to RTI, and Caseload versus Workload Issues Related to RTI. Thirty-seven respondents (16.3\%) who participated by paper survey did not complete the rank order question. Of the 37 respondents who made the decision not to answer the rank order question, 25 responded by drawing a line through the question and writing “I do not participate in RTI”.

The bar graph located below in Figure 4.1 shows the frequency of the number of respondents that ranked one of the four statements as Most Challenging. Caseload versus workload issues related to RTI received the largest number of responses (65 responses or 28.5\%). Professional development related to RTI received the lowest number of responses (31 responses/13.7\%). 
Figure 4.1. Results of the Reported Frequency Responses to the Rank Order Question for the Category of Most Challenging

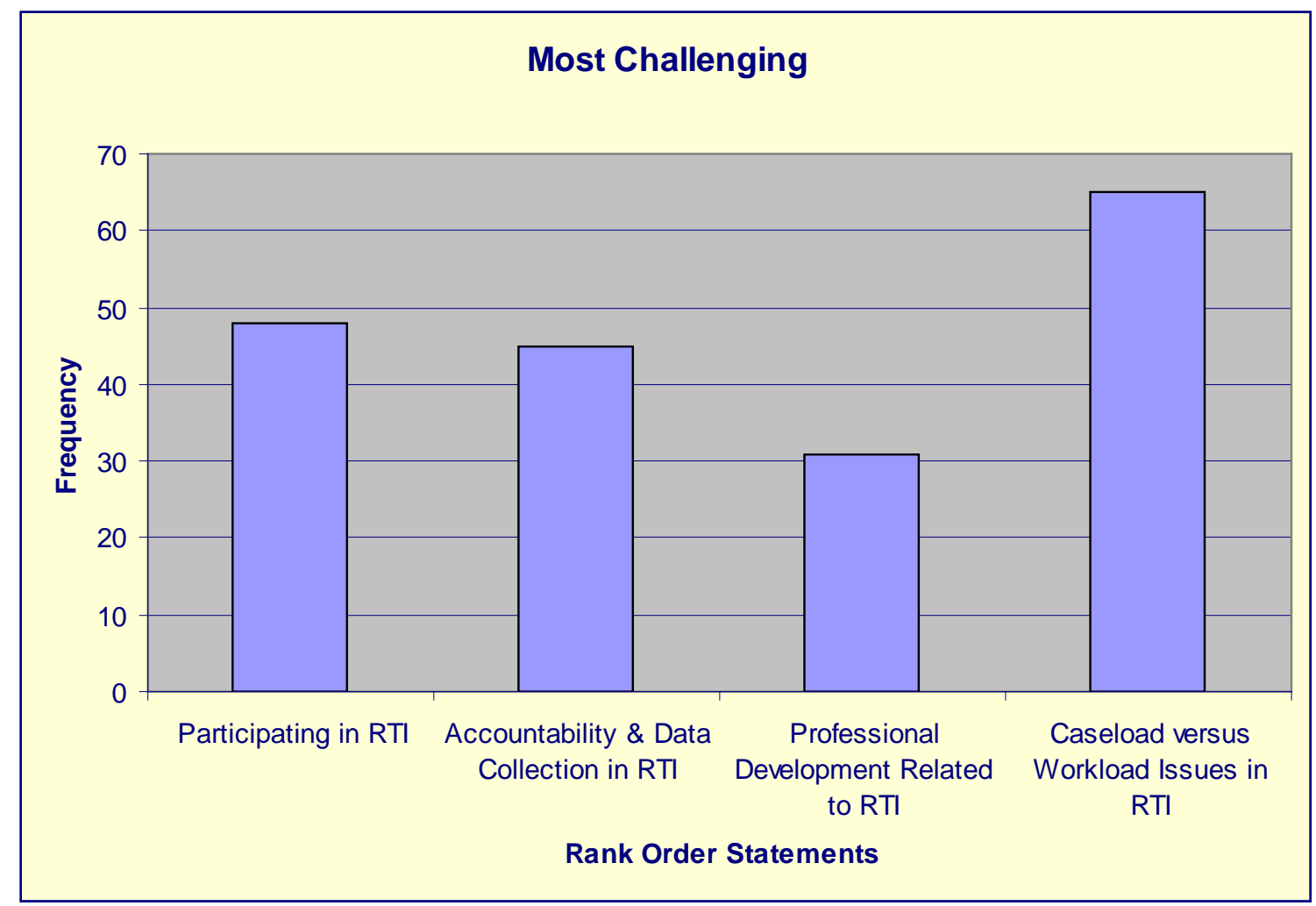

Figure 4.1. $\mathrm{n}=190$ respondents.

Figure 4.2, located below, shows the frequency of the number of respondents that ranked one of the four statements as Least Challenging. The results indicate that professional development related to RTI was the least challenging of the four statements for the school-based SLPs who responded to the rank order question. Sixty-two schoolbased SLPs (27.3\%) ranked professional development related to RTI as the least challenging statement. 
Figure 4.2. Results of the Reported Frequency Responses to the Rank Order Question for the Category of Least Challenging

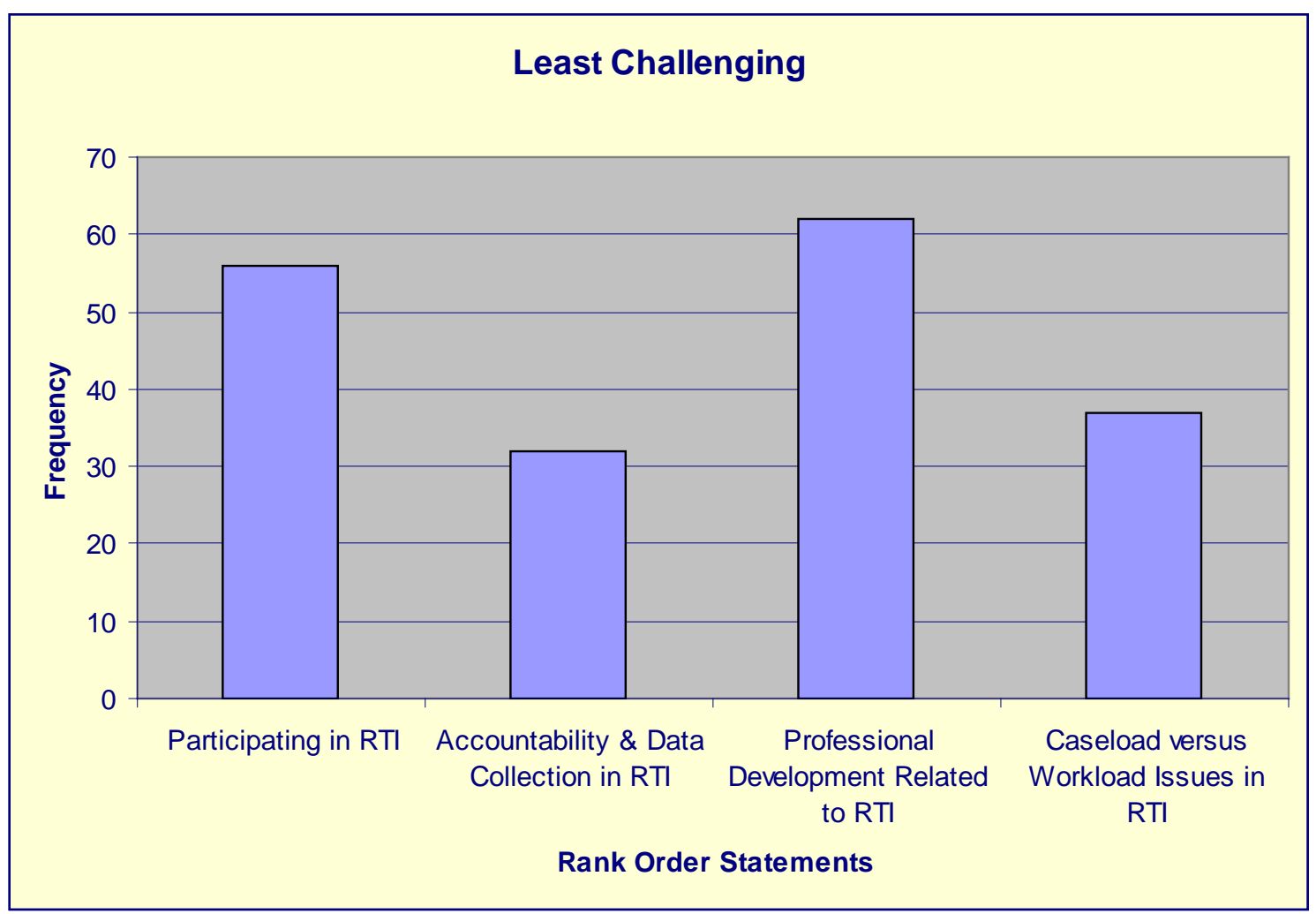

Figure 4.1. $\mathrm{n}=190$ respondents.

Service Delivery. The respondents were asked to report their current service delivery model by estimating the breakdown of their services by percentage for the following categories: Direct Therapy (pull-out), Classroom (push-in), Consultation (collaboration), Participation in RTI, and Other. The highest mean percentage was reported for direct 
therapy (pull-out) at $85.85 \%$ for the respondents. The lowest mean percentage was reported for other at $1.66 \%$. Table 4.11 located below shows the mean percentage and standard deviation for the five categories of service delivery.

In addition to the reporting by percent of the delivery of services by school-based SLPs, the respondents were asked to describe the approach they utilize in their schools on a day-to-day basis. Results indicated that respondents reported 96.5\% ( $n=219)$ utilize a caseload only model or a caseload/workload emphasis on caseload in their day-to-day delivery of services. Respondents indicated a $2.6 \%$ ( $n=6)$ use of a caseload/workload emphasis on workload. A workload only model was reported by one respondent, which accounted for .4\%. One respondent did not complete this question.

Table 4.11

Reported Service Delivery by SLPs in West Virginia

\begin{tabular}{lllllr}
\hline & $\begin{array}{l}\text { Direct Therapy } \\
\text { (Pull-out) }\end{array}$ & $\begin{array}{l}\text { Classroom } \\
\text { (Push-in) }\end{array}$ & $\begin{array}{l}\text { Consultation } \\
\text { (Collaboration) }\end{array}$ & $\begin{array}{l}\text { Participation } \\
\text { in RTI }\end{array}$ & Other \\
\hline & & & & & \\
Mean & 85.85 & 5.62 & 3.91 & 2.64 & 1.66 \\
SD & 15.42 & 9.22 & 4.44 & 5.07 & 5.38 \\
\hline
\end{tabular}

Note. Mean and SD based on $\mathrm{n}=226$ respondents. SD=standard deviation.

Additional Information by RESA District Regarding Participation in RTI. A further breakdown of participation in the RTI process by RESA District was conducted to provide additional information regarding the specific RESA Districts in West Virginia that reported involvement in the RTI process. The RESA District with the highest participation percent reported was RESA II with 21 out of 28 respondents (75\%). The 
RESA District with the lowest participation percent reported was RESA VII with five out of 55 respondents (9\%). A total frequency of 70 respondents reported participation in the RTI process during their day-to-day delivery of services. Table 4.12 below shows the breakdown of the number and percentage of respondents who reported participating in RTI by RESA District.

Table 4.12

Frequency and Percent of Respondents Who Reported Participation in RTI by RESA District

RESA I RESA II RESA III RESA IV RESA V RESA VI RESA VII RESA VIII

\begin{tabular}{lcccccccc}
$\begin{array}{l}\text { Total } \\
\text { Number }\end{array}$ & 19 & 28 & 18 & 25 & 42 & 12 & 55 & 26 \\
$\begin{array}{l}\text { Number } \\
\text { Participating } \\
\text { in RTI }\end{array}$ & 10 & 21 & 10 & 6 & 8 & 2 & 5 & 8 \\
$\begin{array}{l}\text { Percentage } \\
\text { Participating } \\
\text { in RTI }\end{array}$ & 52 & 75 & 55 & 24 & 19 & 16 & 9 & 31 \\
\hline
\end{tabular}

Note. Based on $\mathrm{n}=225$. Two respondents did not identify a RESA District.

Figure 4.3 below shows the percent of participation in RTI reported by RESA

Districts. RESA II reported the highest participation rate at 75\%. Only the three RESA Districts located in the south western portion of West Virginia (RESA I, RESA II, RESA III) reported a greater than $50 \%$ participation rate in this federally mandated intervention. RESA VII, which surprisingly includes Monongalia, Marion, and Harrison counties, reported the lowest participation rate at nine percent. 
Figure 4.3 Percentages of Reported Participation by RESA Districts

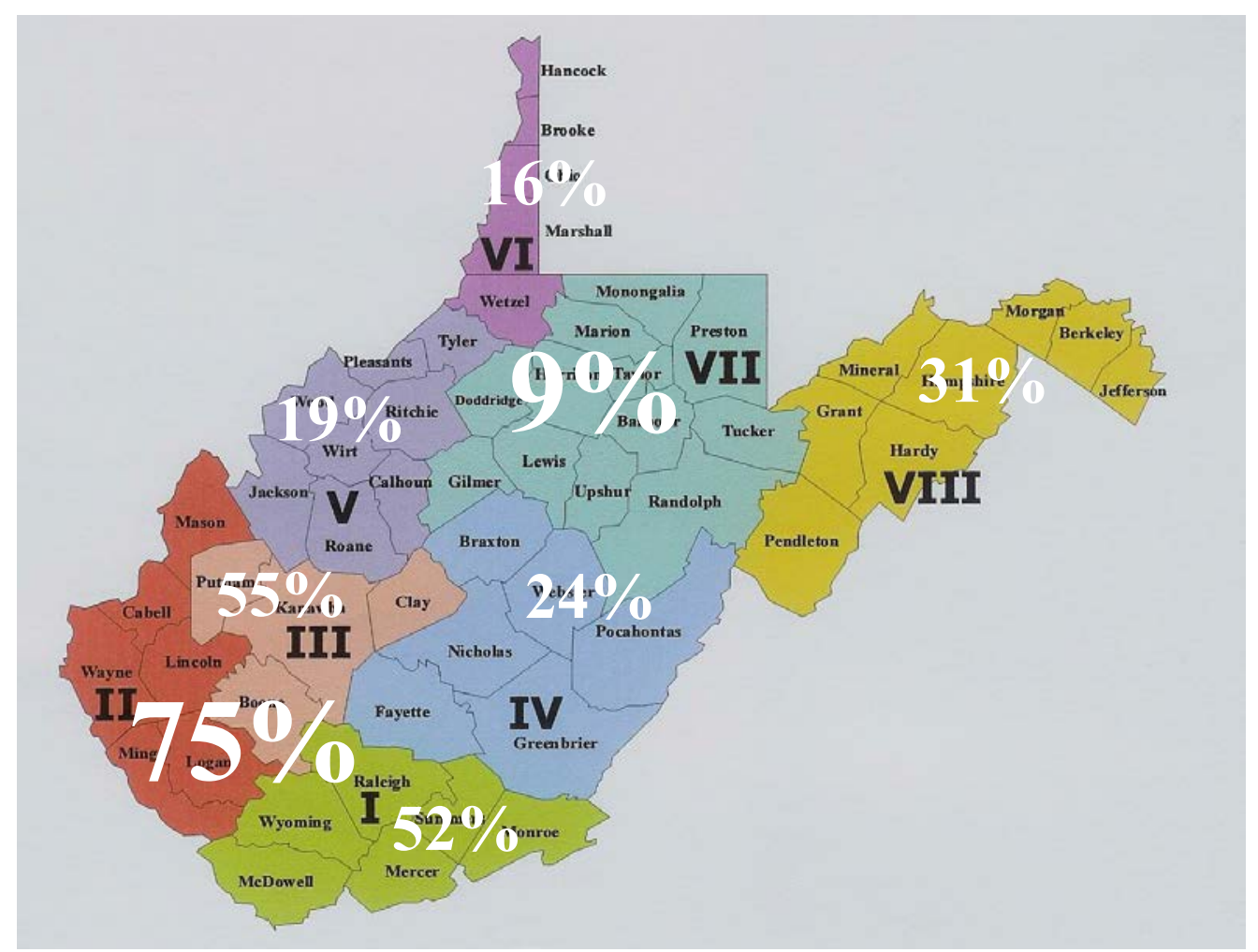

Figure 4.3. n=225. Two respondents did not identify a RESA District.

Internal Reliability. A Cronbach's coefficient alpha was selected to measure the internal consistency of the current survey (Nardi, 2006; Creswell, 2003). According to Cronbach’s alpha, the current survey possessed adequate internal reliability for the 26 Likert-type questions on the survey (Cronbach’s $\alpha=.757)$. This Cronbach's alpha value deems the survey reliable due to researchers following the guideline that alpha should be at least $0.7(\alpha>0.7)$. 


\section{Summary}

The current survey was divided into four distinct sections: demographics of the respondents, 26 Likert-type statements, a rank order question, and a service delivery question. Overall, the descriptive statistics associated with the Likert-type questions revealed the areas of challenges school-based SLPs feel toward the RTI process. The rank order question indicated that school-based SLPs feel that caseload/workload issues are a major concern. Moreover, the current survey revealed that school-based SLPs in West Virginia show an overwhelming support for a traditional pull-out model of delivery of services to their students in order to deliver day-to-day speech therapy services.

The purpose of this study sought to investigate the challenges school-based SLPs feel they are currently facing in light of federal mandates such as IDEA. Demographic facts were collected as well as information on how the respondents felt toward the challenges in the RTI process school-based SLPs face through Likert-type survey statements in the areas of perceptions of challenges, professional development, service delivery, documentation in the RTI process, and collaboration in the RTI process.

This chapter reviewed the analysis of descriptive and inferential statistics including frequency, percent, mean, standard deviation, and ANOVA. Results indicated that collaboration in the RTI process was a significant predictor of work practices that could impact successful implementation of the RTI model for school-based SLPs. In addition, percentages obtained for service delivery to students on the caseloads of the respondents suggested that the majority of school-based SLPs in the eight RESA Districts continue to provide the majority of their services through a traditional pull-out model. 
The next chapter contains a discussion of the findings, conclusions, implications, recommendations for future research, and limitations. 


\section{CHAPTER 5}

\section{Discussion}

\section{Introduction}

School-based SLPs have been encouraged to broaden their intervention approaches when working with children and adolescents to include an increased emphasis on addressing difficulties with emergent, early, and conventional literacy skills (ASHA, 2001). School-based SLPs can play a number of important roles in using the RTI process to identify children with disabilities and provide needed instruction to struggling students in both general education and special education settings (Ehren, 2000). However, RTI requires practice changes by school-based SLPs in terms of assessment approaches as well as models of intervention and instructional support. Staskowski and Rivera (2005) noted increasing curriculum-relevant practices for school-based SLPs can lead to, and make it easier to, participate in the school's RTI initiative.

Response to Intervention (RTI) is a process that provides an academic support system matched to student needs. Since it has been suggested that school-based SLPs should play an integral part of the team in the general education setting that addresses appropriate inventions for struggling students, it was essential to determine the challenges school-based SLPs feel they face in the RTI process.

Chapter 5 provides a review of the study and discusses three themes that emerged as a result of the study. Chapter 5 also presents conclusions, implications, recommendations for future research, and limitations. 


\section{Emergent Themes}

After analyzing the data, the overall finding revealed that school-based SLPs had difficulty with a paradigm shift and the nature of their role within the RTI model. This was evident in three different yet related areas - collaboration, caseload/workload configuration, and ownership of new responsibilities involved in the RTI process.

\section{Difficulty Embracing Collaboration within the RTI model. The current study} indicated school-based SLPs from the eight RESA Districts share similar feelings concerning the challenges involved in the RTI process. It has been noted that SLPs have much to offer in the effort to improve reading and written language within the RTI process. According to Ehren (2002), SLPs have the background to understand the language foundation of reading problems. However, to be effective in the RTI process, SLPs must work collaboratively with others such as classroom teachers and school leaders to implement the RTI model.

The current study indicated that there was a significant difference found among SLPs in the area of collaboration. This difference was noted both within the profession (between an SLP and another SLP) and within the wider scope of the educator population (e. g. an SLP and a classroom teacher, an SLP and a school leader, and an SLP and the State Department of Education). In addition, this finding addressed the differences in the percentage of participation in the RESA Districts located in southwestern West Virginia, which reported a larger participation rate in RTI than the other RESA Districts across the state. Although SLPs may possess the knowledge and expertise in speech and language development, planning and implementation of the RTI model relies on involvement from all stakeholders. Moreover, the current study indicated school-based SLPs are willing to 
collaborate with other school-based SLPs, but revealed resistance to collaborating on a regular basis with teachers or school leaders.

A lack of collaboration for school-based SLPs is a major concern for ASHA due to the fact that the national organization places such a high value on collaborative activities such as involvement in the RTI process for school-based SLPs (ASHA, 2010). ASHA encourages school-based SLPs to work in partnership with others in the school setting to meet the needs of students. In addition, ASHA (2010) noted that working collegially with general education teachers who are primarily responsible for curriculum and instruction is essential to provide the services needed in the schools.

A lack of willingness to collaborate with teachers and school leaders does not fulfill to the federal mandates outlined in the re-authorization of IDEA (2004). IDEA (2004) defined the services of school-based SLPs within the RTI model as habilitation or prevention. IDEA (2004) also emphasized collaboration, consultation, and teaming as the responsibilities of school-based SLPs within the RTI model. The results from the current study indicated that school-based SLPs in West Virginia were willing to collaborate with their speech colleagues, but were reluctant to collaborate with teachers and school leaders. This lack of compliance with federal mandates indicated that schoolbased SLPs in West Virginia are not interested in modifying their established patterns, and practices which that deter participation in the RTI process within their day-to-day service delivery to students.

Difficulty Embracing Changes within Service Delivery Models. Traditionally, a school-based SLP's day-to-day delivery of services to children with IEPs has been conceptualized as being almost exclusively synonymous with caseload as Frequenz 
(2003) noted in her study of workload versus caseload issues. This is a practice that has been in place since the early days of what was referred to as speech correction services that delivered speech practice to students in a separate room within the educational environment.

The results from the current study supported the findings of the ASHA Schools Survey Report (2010) that reported West Virginia as the only state with school-based SLPs who continue to provide speech services through a caseload only model. West Virginia SLPs who responded to the survey reported a 100\% caseload approach. At the other end of the continuum was New Hampshire's SLPs who reported a balance within their day-to-day service delivery model of 56\% through a caseload model and $44 \%$ through a workload model. Embedded within this caseload only model is the traditional pull-out therapy model, which the current study indicated was the preference for the majority of school-based SLPs in West Virginia for delivery of speech services on a dayto-day basis. Ehren (2007) noted that if traditional roles continue it would be difficult for school-based SLPs to expand service delivery to include RTI practices.

The current study revealed the majority of school-based SLPs from the eight RESA Districts continue to follow a model of service delivery that involved individual or smallgroup "pull-out” therapy. Results from the current study also indicated that school-based SLPs in West Virginia are not willing to change their attitude toward a workload concept of service delivery. A workload approach would involve implementation embedded in a systems approach that is dynamic rather than static in order to facilitate student outcomes. In addition, the rank order question indicated caseload/workload issues were at the forefront of topics that concerned school-based SLPs. This is in line with the current 
debate taking place in the field of speech-language pathology within the literature. Ehren (2007) noted that it is difficult to become involved in RTI within a traditional caseload approach. The concept of workload is not in-line with traditional speech therapy practices. Ehren (2007) further suggested that the concept of workload is essential to make the concept of RTI work and school-based SLPs must consider the restructuring of service delivery models in order to participate in RTI practices. ASHA (2002) has acknowledged the importance of workload activities to "ensure that students receive the services they need" (p.89).

Difficulty Embracing Ownership of the RTI Model. In order to adopt the RTI model, school-based SLPs are challenged to embrace shifting roles and responsibilities to meet the diverse needs of students. Results from the current study indicated that the majority of school-based SLPs were not willing to take ownership of the changing roles and responsibilities.

Over half of the school-based SLPs who responded to the survey reported they disagree or strongly disagree that SLPs should play an active role in research-based intervention. This finding indicated that the majority of school-based SLPs in West Virginia are unwilling to embrace the RTI model and incorporate it in their daily service delivery to students who receive speech and language services. Despite the Guidelines for Best Practices from the West Virginia Office of Special Programs (2011) encouraging school-based SLPs to become involved in the delivery of RTI intervention practices, the lack of ownership within the RTI model is a deterrent to the implementation of RTI within the realm of speech services. 
An interesting result that was noted from the data associated with the rank order question on the survey included the 37 school-based SLPs who did not answer this question. The 37 school-based SLPs that did not provide a response to this particular question on the survey sent a definite message that they were not interested in participation in the RTI process in their day-to-day service delivery. Upon closer examination of the raw data reported for the rank order question, it was noted that 25 of the 37 school-based SLPs who put a slash through this question provided the same explanation: “I do not participate in RTI”. All 25 of the school-based SLPs that made the decision to mark this particular question with a slash mark had 21 or more years of experience. This data indicated that school-based SLPs with 21 or more years of experience are not willing to adopt new models within their established patterns of service delivery.

\section{Conclusions}

The purpose of this study was to investigate the challenges school-based SLPs feel they face in the RTI process. According to Blosser and Neidecker (2002) the future of school-based SLPs involves the development of strategies that embrace change within their day-to day practices. In addition, Blosser and Neidecker (2002) noted the role of the school-based SLPs will be greatly expanded in the areas of collaborator and consultant. School-based SLPs will need to expand their role within the school environment to meet the communicative needs of reading, writing, and spelling as well as in speaking and listening (ASHA, 2010; ASHA, 2001). Most school-based SLPs who completed the survey indicated minimal contact with the RTI process in their daily schedules. 
In addition to the paradigm shift difficulties with collaboration, day-to-day service delivery models, and ownership of the RTI model, the current study confirmed the need for professional development for school-based SLPs in order to encourage the implementation of RTI strategies in their daily work practices. Findings from this study indicated that a problematic area for the implementation of RTI for school-based SLPs in West Virginia involved the area of professional development. Even though the schoolbased SLPs reported that they did not find professional development a challenging issue, they still reported feelings of not receiving adequate training in the RTI process. In addition, the majority of school-based SLPs reported they did not feel an adequate network of RTI support services were available within their respective schools.

\section{Implications}

Another area of consideration to encourage successful implementation of the RTI process among school-based SLPs is engagement in collaborative practices in the general education setting. ASHA (2010) noted the importance of work within the "larger context of education, such as literacy, curriculum, and RTI, requires close collaboration with other educators” (p. 13). It is critical for school-based SLPs to understand the importance of placing an emphasis on developing collaborative relationships. Even though the school-based SLPs in this study noted they were willing to collaborate with each other, there was clearly a lack of interest shown to collaborate with teachers and school leaders. A lack of willingness to collaborate with other professionals within the general education setting is in direct conflict with ASHA's position that school-based SLPs need to work in partnership with others to meet the needs of students (ASHA, 2010). School-based SLPs have been encouraged to provide services in the classroom and work collaboratively with 
teachers (Whitmire, 2002; Ehren \& Ehren, 2001; ASHA, 1995). Several important factors necessary for effective collaboration that should be encouraged among schoolbased SLPs in West Virginia include the following: shared responsibility among team members, awareness of each student's curriculum, time to meet outside of classroom duties, cooperation, and willingness to pool areas of expertise (Ehren \& Ehren, 2001; Ehren, 2000; ASHA, 1991).

Findings from this study also suggested that the majority of school-based SLPs who completed surveys continue to provide primarily traditional pull-out services to students. If school-based SLPs continue to use this method of service delivery exclusively, federal regulations, specifically least restrictive environment (LRE), are being ignored (ASHA, 2010). Moreover, ASHA (2010) noted that some of the biggest changes brought on by evolving practices such as literary and RTI require a redefinition of service delivery. In order to address the changing roles and responsibilities of school-based SLPs and ensure appropriate services to students, a paradigm shift must occur among the school-based SLPs in West Virginia.

The findings of the challenges associated with RTI for school-based SLPs in West Virginia could possibly be used in a general way for all school-based SLPs. My goal in the development of this study was to investigate the challenges school-based SLPs are currently facing in West Virginia in order to broaden the understanding of these challenges for others who might read this study and who might have had similar situations, experiences, and encounters.

The current ASHA Position Statement (2010), which was driven by educational reform, legal mandates, and evolving professional practices, recognized that school-based 
SLPs may face a realignment of their existing roles and responsibilities in the context of a reasonable workload with appropriate professional preparation and lifelong learning. Moreover, Ehren et al. (2007) highlighted four areas that will need consideration from SLPs if they are to meet the challenge of participation in the RTI process. The four areas include:

- SLPs will need to be open to change;

- SLPs will need to be open to professional development;

- SLPs will need to be willing to adapt to a less traditional service delivery; and

- SLPs must be willing to educate others on the unique contributions that they can make to the RTI process.

Understanding how school-based SLPs perceive the challenges they face in the RTI process may guide districts and counties in the effective use of resources. This information may also help guide decisions for continuing education programs offered through the Office of Special Programs at the state level. Professional development is critical to the success of RTI implementation. Darling-Hammond and McLaughlin (2011) noted that effective professional development involves stakeholders both as learners and as teachers and allows them to struggle with the different stages of uncertainty encountered within each step of the professional development. Moreover, school-based SLPs in West Virginia could possibly take the advice of Darling-Hammond and McLaughlin (2011) who suggested addressing effective professional development by creating settings where a novice becomes mentored by an educator with experience in a particular area such as in this case, RTI practices. Through sharing of knowledge, 
school-based SLPs may begin to focus on changing their belief systems in regard to implementing RTI practices.

Movement of school-based SLPs within caseload configurations must be a consideration in order to ensure school-based SLPs are trained in research-based interventions and progress monitoring procedures. Counties and districts may consider offering incentives or recognition for school-based SLPs who implement research based practices and progress monitoring procedures within the RTI model to improve the achievement of struggling students.

In addition, college and university programs that provide "pre-service” training in Speech-Language Pathology may have an impact on future school-based SLPs' attitudes through the addition of courses that place an emphasis on literacy as well as the importance of collaboration activities with other school personnel. The current study confirmed the need of support from institutions of higher education. Without more informed courses relating to federal mandates such as RTI, delivery of services by school-based SLPs will remain limited to the traditional practices, which will continue the controversy surrounding providing adequate support to struggling students. Additionally, SLP graduate students could explore various problem-solving strategies that could be used in the schools as well as investigate ways to advocate for appropriate service delivery models for students.

Information from the surveys in this study could be provided to WVSHA as well as ASHA. The results from the current study could possibly provide feedback about the challenges school-based SLPs feel they are facing as their roles and responsibilities change in the school setting in order to guide WVSHA and ASHA with decisions 
concerning future professional development sessions. More specifically, programs could be provided through WVSHA and ASHA to show the advantages and disadvantages of various service delivery models (e.g. traditional pull-out therapy, push-in, collaborative consultation) and flexible scheduling models.

\section{Recommendations for Future Research}

I feel that the results from this study have raised many issues that warrant further investigation. Even though the literature revealed that ASHA clearly supports the schoolbased SLPs' role in RTI, previous studies have not highlighted the challenges schoolbased SLPs feel they face in the RTI process (ASHA, 2010; ASHA, 2001).

Nine of the responses on the Likert-type statements produced levels of neutrality (statements 2, 3, 4, 5, 10, 18, 19, 22, and 24). The mean scores that were considered for the nine statements included scores from 2.9 to 3.1, which accounted for $58 \%$ of the 26 statements. It was possible that this neutrality was due to poorly written statements. If this study would be replicated, it is recommended that these statements be reworded to determine if the wording had an impact on the response frequencies.

In addition, a qualitative study of the RESA Districts with the highest percent reported participation in the RTI process (RESA II with a reported 75\% participation rate among the respondents) and the lowest percent reported participation in the RTI process (RESA VII with a 9\% participation rate among the respondents) could be considered. The Likert-type statements did not allow respondents to expand on their responses or clarify positions that they took on any particular statement. Additional information on the challenges that school-based SLPs feel they face in the RTI process might be better understood during face-to-face interviews. RESA II is located in the southern part of 
West Virginia. RESA VII is located in the northern part of West Virginia. Damico and Simmons-Mackie (2003) suggested qualitative research provides information concerning delivery of services "through a variety of analytic procedures designed to systematically collect and describe authentic, contextualized social phenomena with the goal of interpretive adequacy” (p. 132). In addition, Damico and Simmons-Mackie (2003) noted qualitative study provides the researcher with an avenue to employ more "open and flexible research approaches that can sustain empirical rigor in more authentic settings” (p. 140). An in-depth qualitative study may provide further insight into how schoolbased SLPs approach the challenges they face in the RTI process.

A future possibility for this survey could be a more national dispersion. It would be of great importance to see if the results from school-based SLPs in West Virginia would hold true for the country as a whole.

Camp (2009) suggested that in order for an individual to be able to combine representational thoughts involving a particular concept, an individual must first recombine their thoughts "within the states of affairs being represented" (p. 275). Camp (2009) further stated that such Systematicity or "representational thoughts support a cognitive engagement with the world that is flexible, abstract, and active” (p. 275). Cummins, Blackmon, Byrd, Poirier, Roth, and Schwartz (2001) noted that Systematicity involved a mental representation with a language-like combination of syntax and associated semantics, which may serve to explain the reluctance of school-based SLPs to embrace a paradigm shift within the RTI model and adopt a new Systematicity of thought in relation to participation in the RTI model. I have included the concept of Systematicity for future research recommendations to suggest that an in-depth 
examination of school-based SLPs' willingness to acknowledge new models within therapy approaches that focus on prevention rather than identification is warranted. This notion would involve a change in representational thoughts of traditional service delivery models. By approaching research through the lens of Systematicity, an investigation would be able to assess school-based SLPs' willingness to participate in a problemsolving framework through the change in cognitive states involving a change in service delivery models to achieve participation in the RTI process.

School-based SLPs rely on the pull-out method of service delivery as the traditional delivery of services to students. Results from this study indicated that approximately $86 \%$ of the respondents reported a pull-out method of service delivery as their primary model of service delivery. Through the continued use of a traditional service delivery model, school-based SLPs continue to ignore federal regulations that specifically call for least restrictive environment (LRE) considerations for all students. A study conducted by Cirrin and Gillam (2008) suggested that pull-out services did not provide significant evidence of superiority over other service delivery methods. A study of the Systematicity of service delivery mindset of school-based SLPs may provide a better picture of how willing school-based SLPs are to break out of their systematic patterns of constancy of the traditional therapy pull-out model.

\section{Limitations}

Many of the survey respondents are assigned to caseloads within the same schools within their respective counties. The possibility that the respondents discussed the survey prior to completion may possibly have affected their final responses on the surveys. If so, responses to the survey may have been impacted by these discussions. This issue may 
have influenced external validity that in turn may have placed the results of this study in jeopardy due to an interaction effect. In addition, a few school-based SLPs indicated that they were unable to access the survey on-line due to the limitations of their software at their school site.

A closed question format was utilized that did not allow the respondents to expand on their responses. Moreover, no attempt was made to follow up with survey respondents in order to gain more information on their perceptions of the challenges school-based SLPs feel they face in the RTI process. Some SLPs may have had experiences with the RTI process and the closed nature of the Likert-type statements did not allow the respondents to account for these experiences.

These findings should not be generalized to all school-based SLPs from other states. The data were only collected from SLPs who were employed in the public and private school settings in West Virginia. Finally, since all school-based SLPs in West Virginia are not employed to work under the same conditions (e.g. geographic area, socioeconomic level, percentage of minorities), it would be wrong to assume that each district had the same district policies regarding RTI, number of staff to provide RTI services, and finances available to provide in-service training in the RTI process.

\section{Summary}

There are major changes taking place in the field of education that impact the delivery of services provided by school-based SLPs. RTI has the potential to affect regular education, special education, eligibility, and the "interface between the two" (Ukrainetz, 2006, p. 298). Chapter Five has reiterated the lack of interest in RTI participation for school-based SLPs in West Virginia that influenced me to study in-depth the challenges 
school-based SLPs in West Virginia feel they face in the RTI process. In addition, this chapter has reviewed the methods used for research, offered results from the survey, discussed the implications for future practice, exposed the limitations of the findings, and offered suggestions for future practice and recommendations for future research. The recommendations for SLPs employed in school districts and pre-service SLPs completing graduate level courses are both practical and realistic to prepare SLPs for work in the schools in West Virginia.

The educational changes brought about by RTI provide opportunities as well as challenges for school-based SLPs to make fundamental changes in their methods of service delivery. This study attempted to understand how the perceptions of the challenges encountered within the RTI process impact the day- to-day delivery of services to children by school-based SLPs. Successful implementation of tiered intervention practices by school-based SLPs requires not only active participation in the RTI process, but the development of collaboration among a team of professionals as well. The Roles and Responsibilities of Speech-Language Pathologists (2001) noted "The critical contributions of literacy competence to academic and social success and lifetime opportunities make it not only appropriate but essential that SLPs assume these roles and responsibilities." (ASHA, 2001, p. 34). Moore-Brown, Montgomery, Bielinski, and Shubin (2005) indicated that the field of speech-language pathology is constantly evolving. It is imperative that school-based SLPs engage in meaningful professional growth experiences and seek more effective ways to help students communicate.

In summation, school-based SLPs now have many creative opportunities to adapt their service delivery to the unique needs of children. It is my hope the data obtained 
from this survey will reveal the challenges school-based SLPs in West Virginia feel they face within the general knowledge of the RTI process and how the RTI process impacts their day-to-day service delivery model. Also, I anticipate that the information obtained in this study will provide insight into any differences that exist between the school-based SLPs among the eight RESA districts in relation to delivery of services within the RTI model. It is my sincere wish that school-based SLPs in West Virginia will begin to embrace a process that provides an academic support system for all students. It is my belief that the challenges school-based SLPs in West Virginia feel they face due to their changing roles and responsibilities warrant further study. In addition, challenges for school-based SLPs within the RTI model should be investigated further because no other study is available to validate these findings. Overall, the data obtained from this survey is significant due to the fact it demonstrated many school-based SLPs in West Virginia have not implemented educational reform, legal mandates, and evolving professional practices. 


\section{References}

Abbott, M., Walton, C., Tapia, Y., \& Greenwood, C. R. (1999). Research to practice: A “blueprint” for closing the gap in local schools. Exceptional Children, 65, 339-352.

American Educational Research Association. (2005). Teaching teachers: Professional development to improve student achievement. Research Points: Essential Information for Education Policy, 3(1), 1-4.

American Speech-Language-Hearing Association. (1991). A model for collaborative service delivery for students with language-learning disorders in public schools. www.asha.org/policy

American Speech-Language-Hearing Association. (1995). Beyond inclusion: Making the system work for children with a language learning disability. Division 1 Newsletter, Language Learning and Education 2(1).

American Speech-Language-Hearing Association. (2001). Roles and Responsibilities of Speech-Language Pathologists With Respect to Reading and Writing in Children and Adolescents [Guidelines]. doi: 10.1044/policy.GL2001-00062

American Speech-Language-Hearing Association. (2002). A Workload Analysis Approach for Establishing Speech-Language Caseload Standards in the School: Position Statement [Position Statement]. Available from www.asha.org/policy. American Speech-Language-Hearing Association. (2002). Knowledge and skills needed by speech-language pathologists with respect to reading and writing in children and adolescents. [Knowledge and Skills]. doi: 10.1044/policy.KS2002-00082 American Speech-Language-Hearing Association. (2007). Scope of practice in speechlanguage pathology [Scope of Practice]. doi: 10.1044/policy.SP2007-00283 
American Speech-Language-Hearing Association. (2010). Roles and responsibilities of speech-language pathologists in schools [Position Statement]. doi: 10.1044/policy PS2010-00318

American Speech-Language-Hearing Association. (2010). Schools survey report: SLP caseload characteristics. Retrieved from www.asha.org/research/memberdata/ SchoolsSurvey.htm

Babbie, E. (1990). Survey research methods (2nd ed.). Belmont, CA: Wadsworth.

Barnes, A. C., \& Harlacher, J. E. (2008). Clearing the confusion: Response-tointervention as a set of principles. Education \& Treatment of Children, 31, 417-431.

Batsche, G., Elliot, J., Graden, J. L., Grimes, J., Kovaleski, J. F., Prasse, D. (2006). Response to Intervention: Policy considerations and implementation. Alexandria, VA: National Association of State Directors of Special Education, Inc.

Bean, R.M. \& Morewood, A.L. (2007). Best practices in professional development for improving literacy instruction. In L.B. Gambrell, L. Mandel Morrow \& M. Pressley (Eds.), Best practices in Literacy Instruction Vol. III. New York, NY: Guilford Publications, Inc.

Bender, W. N. \& Shores, C. (2007). Response to intervention: A practical guide for every teacher. Thousand Oaks, CA: Corwin Press.

Berkley, S., Bender, W. N., Peaster, L. G., \& Saunders, L. (2009). Implementation of response to intervention: A snapshot of progress. Journal of Learning Disabilities, 42, 85-95.

Blood, G. W., Ridenour, J. S. Thomas, E. A. \& Qualls, C. D. (2002). Predicting job satisfaction among speech-language pathologists working in public schools. 
Language, Speech, and Hearing Services in School, 33, 282-290.

Blosser, J. and Kratcoski, A. (2002). PACS: A framework for determining appropriate service delivery options. Language, Speech, and Hearing Services in the Schools, 28, 99-107.

Blosser, J. and Neidecker, E. (2002). School programs in speech-language pathology: Organization and service delivery (4th ed.). Boston: Allyn and Bacon.

Boscardin, M. L. (2007). What is special about special education administration? Considerations for school leadership. Exceptionality, 15(3), 189-200.

Boswell, S. (2005). Prevention model takes off in schools. The ASHA Leader. Retrieved from http://www.asha.org/Publications/leader/2005/050322/05322b. htm

Brown-Chidsey, R., \& Steege, Mark W. (2005). Response to intervention: Principles and strategies for effective practice. New York, NY: The Guilford Press.

Camp, E. (2009). Putting thoughts to work: Concepts, Systematicity, and stimulus dependence. Philosophy and Phenomenological Research, 78(2), 275-311.

Catts, H. (1997). The early identification of language-based reading difficulties. Language, Speech, and Hearing Services in the Schools, 28, 86-87.

Catts, H., Fey, M., Zhang, X., \& Tomblin, B. (2001). Estimating the risk of future reading difficulties in kindergarten children: A research-based model and its clinical implementation. Language, Speech, and Hearing Services in Schools, 32, 32-50.

Chard, D., \& Dickson, S. (1999). Phonological awareness: Instructional and assessment guidelines. Intervention in School and Clinic, 34, 261-270.

Ciampaglio, S. (2008). Teamwork helps struggling readers: Response-to-intervention 
program pairs SLP, reading teachers. The ASHA Leader. Retrieved from http:// www.asha.org/publications/leader/2008/080923/080923c/

Cirrin, F. M. \& Gillam, R. B. (2008). Language intervention practices for school-age children with spoken language disorders: A systematic review. Language, Speech, and Hearing Services in Schools, 39, 110-137.

Crane, T. (2009). Synthese. Philosophy Department of Rutgers University, 170, 211215. doi: 10.1007/s11229-009-9579-8.

Creswell, J. W. (2003). Research design: Qualitative, quantitative, and mixed methods approaches (2nd ed.). Thousand Oaks, CA: Sage.

Cummins, R., Blackmon, J., Byrd, D., Poirier, P., Roth, M. \& Schwartz, G. (2001). Systematicity and the cognition of structured domains. Journal of Philosphy, 98, 167-185.

Damico, J. S. and Simmons-Mackie, N. N. (2003). Qualitative research and speechlanguage pathology: A tutorial for the clinical realm. American Journal of SpeechLanguage Pathology 12, 131-143.

Dana, N. F. \& Yendol-Hoppey, D. (2008). The refelective educator's guide to professional development: Coaching inquiry-oriented learning communities. Thousand Oaks, CA: Corwin Press.

Daniel, M. \& Reynolds, M.E. (2007). Phonological awareness instruction: Opinions and practices of educators and speech-language pathologists. Contemporary Issues in Communication Science and Disorders 34, 106-117. Danielson, L., Doolittle, J., \& Bradley, R. (2007). Professional development, capacity building, and research needs: Critical issues for response to intervention 
implementation. School Psychology Review, 36, (4), 632-637.

Darling-Hammond, L., \& McLaughlin, M. W. (2011). Policies that support development in an era of reform. Phi Delta Kappan 92, 81-92.

Desimone, L. (2011). A primer on effective professional development. Phi DeltaKappan 92, 68-71.

Desimone, L., Porter, A. C., Garet, M., Yoon, K. S., \& Birman, B. (2002). Does professional development change teacher's instruction? Results from a three-year study. Educational Evaluation and Policy Analysis 24, (2), 81-112.

Ehren, B. (2000). Maintaining a therapeutic focus and sharing responsibility for student success: Keys to in-classroom speech language services. Language, Speech, and Hearing Services in Schools, 31, 219-229.

Ehren, B. (2002). Speech-language pathologists contributing significantly to the academic success of high school students: A vision for professional growth. Topics in Language Disorder, 22(2), 60-80.

Ehren, B. (2007). Responsiveness to intervention: An opportunity to reinvent speechlanguage services schools. The ASHA Leader, 12, 10-15.

Ehren, B. (2009). Response-to-intervention: SLPs as linchpins in secondary schools. The ASHA Leader, 14, 10-13.

Ehren, B , \& Ehren, T. C. (2001). New or expanded literacy roles for speech-language pathologists: Making it happen in the schools. Seminars in Speech and Language, 22(3), 234-243.

Ehren, B., Montgomery, J., Rudebusch, J., \& Whitmire, K. (2006). Responsiveness 
to intervention: New roles for speech, language pathologists. Retrieved from http://www.asha.org/slp/schools/prof-consult/NewRolesSLP.htm

Ehren, B. J. \& Whitmire, K. A. (2005). Leadership opportunities in the context of responsiveness to intervention activities. Topics in Language Disorders, 25(2), 168-179.

Elksnin, L. K., \& Gilson J. C. (1994). Speech-language pathologists' perceptions of integrated service delivery in school settings. Language, Speech, and Hearing Services in Schools, 25, 258-267.

Fink, A. 2009. How to conduct surveys: A step-by-step guide (4 ${ }^{\text {th }}$ ed.). Los Angeles: Sage.

Fuchs, D., \& Deshler, D. D. (2007). What we need to know about responsiveness to intervention (and shouldn't be afraid to ask). Learning Disabilities Research \& Practice, 22, 129-136.

Fuchs, D., Fuchs, L. S., Compton, D. L., Bouton, B., Caffrey, E., \& Hill, L. (2007). Dynamic assessment as Responsiveness to Intervention: A scripted protocol to identify young at-risk readers. Teaching Exceptional Children, 39(5), 58-63.

Fuchs, D., Mock, D., Morgan, P. L., \& Young, C. L. (2003). Responsiveness-tointervention: Definitions, evidence, and implications for the learning disabilities construct. Learning Disabilities Research \& Practice, 18(3), 157-171.

Gersten, R. \& Hitchcock, J. H. (2008). What is credible evidence in education? The role of the What Works Clearinghouse in informing the process. In S.I. Donaldson, C. A. Christie \& M. A. Marks (Eds.). What counts as credible evidence in education? (pp. 78-95). Thousand Oaks, CA: Sage. 
Gillam, S. (2008). What is RTI and how do I fit in? The Communicator, Utah Speech Language Hearing Association, 47 (4), 7. Retrieved from http://digitalcommons. usu.edu/comd facpub/6

Gresham, F. M. (2001). Responsiveness to intervention: An alternative approach to the identification of learning disabilities. Paper presented at the Learning Disabilities Summit, Washington, DC.

Groves, R. M., Fowler, F. J., Couper, M. P., Lepkowski, J. M., Singer, E. \& Tourangeau, R. (2009). Survey Methodology. Hoboken, NJ: John Wiley and Sons.

Hollenbeck, A. F. (2007). From IDEA to implementation: A discussion of foundational and future responsiveness-to-intervention research. Learning Disabilities Research and Practice, 22, 137-146.

Huck, S. W. (2008). Reading statistics and research. Boston: Pearson.

Idol, L., Nevin, A., \& Paolucci-Whitcomb, P. (1994). Collaborative consultation (2nd ed.). Austin, TX: PRO-ED.

Individuals with Disabilities Education Improvement Act, Public Law 108-446. (2004). Retrieved from http://frwebgate.access.gpo.gov/cgi-bin/getdoc.cgi?dbname=108_ cong_public_laws\&docid=f:publ446.108

Justice, L. M. (2006). Evidence-based practice, response to intervention and the prevention of reading disabilities. Language, Speech, and Hearing Services in ૫Schools, 37, 284-297.

Justice, L. M., \& Ezell, H. (2004). Print referencing: An emergent literacy enhancement strategy and its clinical applications. Language, Speech, and Hearing Services in Schools, 35, 185-193. 
Kaderavek, J., \& Justice, L. (2004). Shared storybook reading as an intervention context: Practices and potential pitfalls. American Journal of Speech-Language Pathology, 11 395-407.

Katz, L. A., Maag, A., Fallon, K. A., Blenkarn, K., Smith, M. (2010). What makes a caseload (un)manageable? School-based speech-language pathologists speak. Language, Speech, and Hearing Services in Schools, 41, 139-151.

Kavale, K. A., Holdnack, J. A., \& Mostert, M. P. (2005). Responsiveness to intervention and the identification of specific learning disability: A critique and alternative proposal. Learning Disability Quarterly, 28, 2-16.

Koutsoftas, S. D., Harmon, M. T. \& Gray, S. (2009). The effect of tier 2 intervention for phonemic awareness in a response-to intervention model in low-income preschool classrooms. Language, Speech, and Hearing Services in Schools, 40, 116-130.

Knighton, Kathryn. (2011). An oral interview with Kathryn Knighton, Coordinator from the Office of Special Programs for the West Virginia Department of

Education/Interviewer: J. Simmerman. West Virginia Speech-Language and Hearing 2011 Annual Convention, Flatwoods, West Virginia.

Kovaleski, J. F. (2003, December). The three tier model of identifying learning disabilities: Critical program features and system issues. Paper presented at the National Research Center on Learning Disabilities Responsiveness-to-Intervention Symposium, Kansas City, MO. Retrieved from http://www.nrcld.org/symposium 2003/kovalski/kovaleski.pdf

Kratochwill, T. R., Volpiansky, P., Clements, M., \& Ball, C. (2007). Professional development in implementing and sustaining multitier prevention models: 
Implications for response to intervention. School Psychology Review, 36, 618-631.

Lynn, M. (1986). Determination and quantification of content validity. Nursing Research, 35, 382-385.

Martella, R. C., Nelson, R., \& Marchand-Martella, N. E. (1999). Research methods: Learning to become a critical research consumer. Boston: Allyn \& Bacon.

Matzke, L., \& Neumiller, T. L. (2008). RtI in Title 1: Tools and guidance to get it right. Horsham, Pennsylvania: LRP Publications.

Means, J. (2006). The impact of IDEA 04 and NCLB on speech and language services: How do we meet the challenges? Retrieved from Forum on Public Policy Website: http://www.forumonpublicpolicy.com/archive06/means.pdf

Merritt, D. D. \& Culatta, B. (1998). Language intervention in the classroom. San Diego, CA: Singular Publishing Group.

Moore-Brown, B. (2004). Becoming proficient in the lesions of No Child Left Behind. Perspectives on School Based Issues, Vol. 5 (1), 7-10.

Moore-Brown, B. J., Montgomery, J. K., Bielinski, J., \& Shubin, J. (2005).

Responsiveness to intervention; Teaching before testing helps avoid labeling. Topics in Language Disorders, 25(2), 148-167.

Nancollis, A., Lawrie, B. A., \& Dodd, B. (2005). Phonological awareness intervention and the acquisition of literacy skills in children from deprived social backgrounds. Language, Speech, and Hearing Service in Schools, 36, 325-335.

Nardi, P. M. (2006). Doing survey research: A guide to quantitative methods (2nd ed.). Boston: Pearson Education.

National Association of State Directors of Special Education (NASDE). (2005). 
Response to intervention: Policy, Considerations, and Implementation. Alexandria, VA: NASDE.

National Institute of Child Health and Human Development (2000). Report of the National Reading Panel. Teaching children to read: An evidence-based assessment of the scientific research literature on reading and its implications for reading instruction (NIH Publication No. 00-4769.) Washington, DC: U.S. Government Printing Office.

No Child Left Behind Act of 2002. Title IX, section 9101(23). Public Law 107-110 North Central Regional Educational Laboratory. (n.d.). Professional Development for Teachers. Retrieved from http://www.ncrel.org/sdrs/areas/issues/educatrs/ profdevl/pd2prof.htm

O’Connor, R. E., Harty, K. R., \& Fulmer, D. (2005). Tiers of intervention in kindergarten through third grade. Journal of Learning Disabilities, 38, 532-538.

Olsen, J. (2008). RTI: Speech sound intervention. Advance. Retrieved from http:// speech-language-pathology-audiology.advance.com/

Page, R. A. (2002). Taking surveys to the next level: When external validation is a good thing. Retrieved from http://www.performancedimensions.com/article02.htm

Pullen, P., \& Justice, L. (2003). Enhancing phonological awareness, print awareness, and oral language skills in preschool children. Intervention in School and Clinic, 39, 87-98.

Raosoft, Inc. (2004). Retrieved from http://www.raosoft.com/samplesize.html

Reed, Brian. (2011). An oral interview with Brian Reed/Interviewer: J. Simmerman. West Virginia Speech-Language and Hearing 2011 Annual Convention, Flatwoods, West Virginia. 
Rigney, S. (2004). No child left behind: Implications for ASHA professionals.

Perspectives on School-Based Issues, vol. 5 (1), 4-6.

Ritter, M. J. (2009). The speech-language pathologist and reading: Opportunities to extend services for the children we serve. Perspectives on School-Based Issues, 10, $38-44$.

Santos, J. R. A. (1999). Cronbach’s Alpha: A tool for assessing reliability of scales. Journal of Extension, 37 (2). Retrieved from http://www.joe.org/joe/1999april/ tt3php

Schuele, D. M. \& Boudreau, D. (2008). Phonological awareness intervention: Beyond the basics. Language, Speech, and Hearing Services in Schools, 39, 3-20.

Shulman, L.S. (1986). Those who understand: Knowledge growth in teaching. Educational Researcher, 15, 4-14.

Staskowski, M., \& Rivera, E. A. (2005). Speech-language pathologists’ involvement in responsiveness to intervention activities; A complement to curriculum-relevant practices. Topics in Language Disorders, 25(2), 132-147.

Troia, G. A. (2005). Responsiveness to intervention: Roles for speech-language pathologists in the prevention and identification of learning disabilities. Topics in Language Disorders, 25, (2), 106-119.

Ukrainetz, T. (2006). “The implications of RTI and EBP for SLPs: Commentary on L. M. Justice. Language, Speech, and Hearing Services in Schools, 37, 298-303.

Ukrainetz, T. A., \& Fresquez, E. F. (2003). “What isn’t language?”: A qualitative study of the role of the school speech-language pathologist. Language, Speech, and Hearing Services in Schools, 34, 284-298. 
U.S. Department of Education Office of Special Education and Rehabilitative Services, A new era: Revitalizing special education for children and their families. Washington, DC. 2002, 1-96.

Walker, H. M. (2004). Use of evidence-based interventions in schools: Where we’ve been, where we are, and where we need to go. School Psychology Review, 33, 398407.

Werts, M. G., Lambert, M., \& Carpenter, E. (2009). What special education directors say about RtI. Learning Disability Quarterly, 32, 245-254.

West Virginia Department of Education. (2011). Guidelines for best practices: Speechlanguage pathology services in WV schools. Office of Special Programs.

West Virginia Department of Education. (2008). Understanding the response to intervention process. Office of Special Programs, Extended and Early Learning.

West Virginia Code, West Virginia School Laws Ann. West Virginia Code§18-2-26 (2009).

Whitmire, K. (2002). The evolution of school-based speech-language services: A half century of change and a new century of practice. Communication Disorders Quarterly, 23(2), 68-76.

Wiersma, W. (2000). Research methods in education: An introduction (7th ed.). Boston: Allyn \& Bacon.

Wold, C. (2010). Response to intervention: A study of the implementation of Response to Intervention in North Dakota Schools (Doctoral Dissertation). Available from ProQuest Dissertations and Theses database. (UMI No. 3391784) 
Appendix A

SURVEY OF SCHOOL-BASED SLPS AND THE RTI PROCESS

This survey is designed to measure Speech Language Pathologists' perspectives of the RTI process. We value your input, and therefore ask that you please complete this survey. We know your time is valuable, therefore this survey is designed to be completed in 15 minutes or less.

1. Please indicate your gender.

- Female

Male

2. What is the highest level degree you have earned in Speech, Language Pathology?

Bachelor of Science

- Master of Science

Ed.D.

- Ph.D.

Other (please specify)

3. Which of the following best describes your current caseload configuration?

- Primary

- Intermediate

Middle School

- High School

4. How many years experience have you gained as a Speech, Language Pathologist?

0-5 Years

6-10 Years

- 11-15 Years

16-20 Years

21 or More Years

5. How many pairs of shoes do you own that each cost at least $\$ 75$ retail?

25-50 pairs

- 51-100 pairs

- 101 or More pairs 
Just checking to see if you're paying attention

6. Please identify your RESA District.

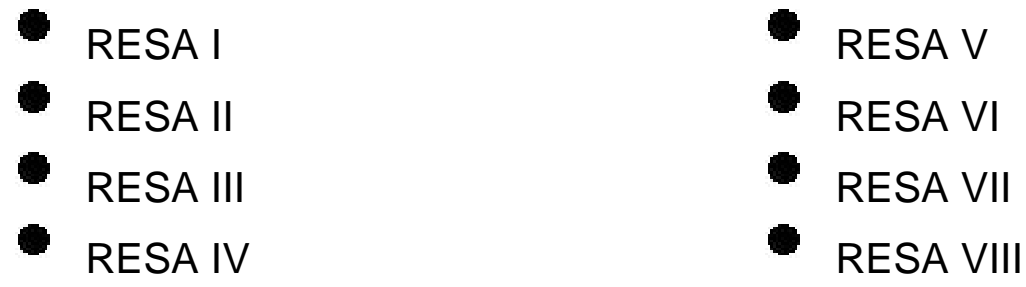

7. For each of the following items, please select the response that best matches your level of agreement.

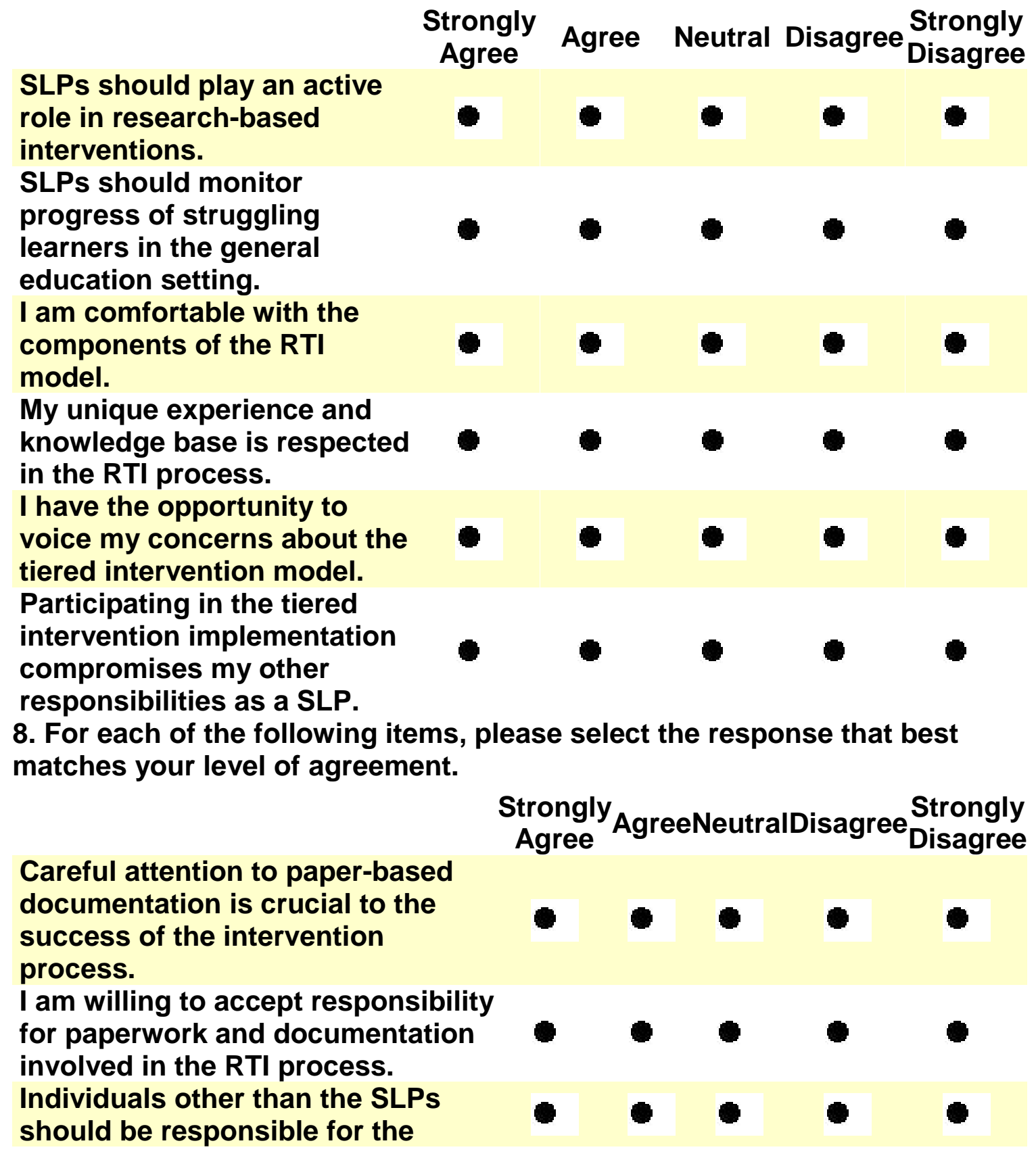


paperwork and documentation

$$
\begin{gathered}
\text { Strongly } \\
\text { Agree }
\end{gathered} \text { AgreeNeutralDisagree }_{\text {Disagree }}^{\text {Strongly }}
$$

involved in the RTI process.

I understand the accountability and documentation procedures used in the RTI model.

Careful attention to electronic documentation is crucial to the success of the intervention process.

The RTI model uses appropriate monitoring methods.

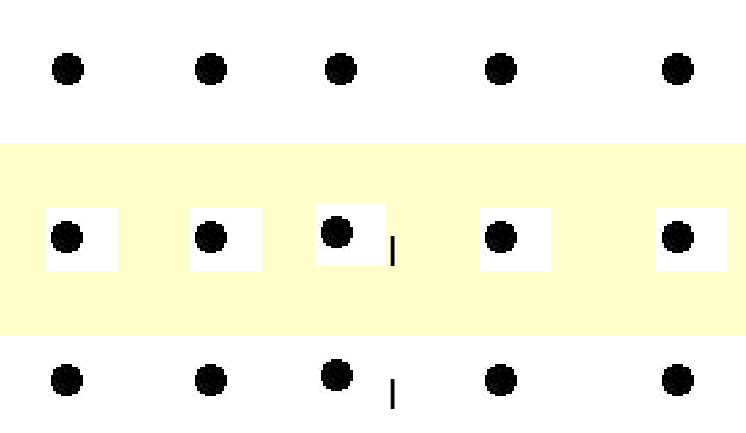

9. Please select the item that best describes the frequency with which you engage in the following activities in your work as a SLP.

Accessing recorded data (paper or electronic) to help guide a decision regarding your work as a SLP.

Seeking advice from another SLP colleague to help guide a decision regarding your work as a SLP.

Seeking advice from a

School Leader to help guide a decision regarding your work as a SLP.

Seeking advice from a Teacher to help guide a decision regarding your work as a SLP.

Reading a journal article from the SLP literature to help guide a decision regarding your work as a SLP.

$\begin{array}{ccccc}\begin{array}{c}\text { At least } \\ \text { once an } \\ \text { hour }\end{array} & \begin{array}{c}\text { At least } \\ \text { once }\end{array} & \begin{array}{c}\text { At least } \\ \text { ence At least } \\ \text { during } \\ \text { every } \\ \text { work }\end{array} & \begin{array}{c}\text { once a } \\ \text { day }\end{array} & \begin{array}{c}\text { than } \\ \text { week } \\ \text { month }\end{array} \\ \begin{array}{c}\text { once a } \\ \text { month }\end{array}\end{array}$

10. For each of the following items, please select the response that best matches your level of agreement.

I have received an appropriate amount of training related to tiered

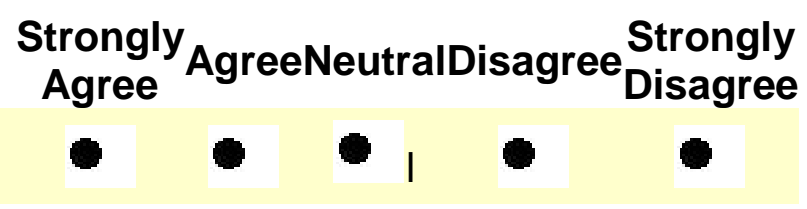


intervention practices.

Strongly
Agree

I am comfortable with the common vocabulary used in the RTI model. There is an adequate network of support available in my school/s to provide a continuity of services needed for tiered instruction practices. I am comfortable implementing the three tiers involved in the RTI model.

I have access to engaged leaders that guide my successful implementation of tiered intervention practices.

I have received adequate training regarding the three tiers involved in the RTI model.

11. Which of the following best describes the approach you utilize in your school(s)?

- I practice a caseload model only.

- I practice a combination caseload/workload model, with a higher emphasis towards caseload.

- I practice a combination caseload/workload model, with a higher emphasis towards workload.

I practice a workload model only.

12. For each of the following items, please select the response that best matches your level of agreement.

I am comfortable with an RTI model Strongly
Agree in general education classrooms that involves more consultation and collaboration than the traditional norm.

School-based SLPs should follow a caseload-only model.

School-based SLPs should follow a combination caseload/workload model. 
13. Listed below are 4 major issues related to the RTI process. Please rank order these in terms of how challenging they are to you as an SLP working with the RTI process (1=most challenging; 4=least challenging).

$$
\begin{aligned}
& 1=\text { Most } \quad 2=2 \text { nd } \quad 3=3 r d \quad 4=\text { Least } \\
& \text { Challenging } \begin{array}{c}
\text { Most MallengingChallenging } \\
\text { Challenging }
\end{array}
\end{aligned}
$$

Participating in the Tiered Intervention Model of RTI Accountability and Data Collection in the RTI Process

Professional Development related to $\mathrm{RTI}$

Caseload versus Workload Issues Related to RTI

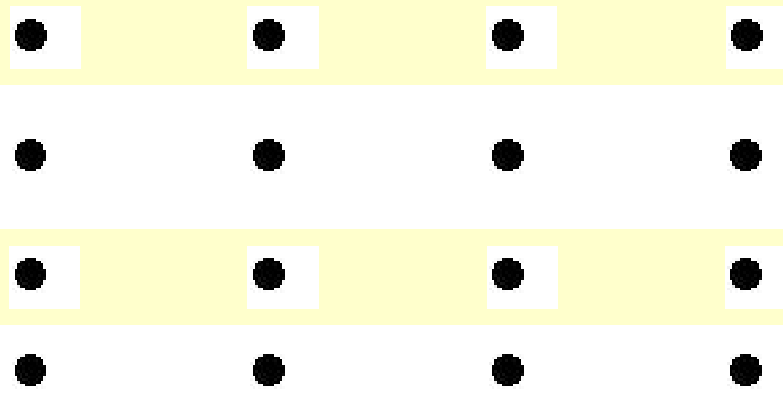

14. Please estimate the current breakdown of your current service delivery within your school(s). Enter a percentage amount in each box (without the "\%" symbol). Your total percentage must equal 100.

Please estimate the current breakdown of your current service delivery within your school(s). Enter a percentage amount in each box (without the "\%" symbol). Your total percentage must equal 100. Direct Therapy (Pull-out)

Classroom (Push-in)

Consultation

(Collaboration)

Participation in RTI

Other
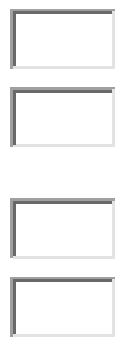


\title{
Appendix B
}

\section{Example of the Invitation Letter for the Paper Survey}

\author{
Department of Curriculum \& Instruction/Literacy Studies \\ WestVirginiaUniversity. \\ College of Human Resources and Education
}

\section{Dear School-Based SLP:}

Thank you for agreeing to participate in a research study for my dissertation for my doctoral program in Curriculum and Instruction at West Virginia University of "Survey of Response-toIntervention's (RTI) Challenges for School-Based Speech-Language Pathologists”. I am conducting this research study under the supervision of Allison Swan-Dagen, Ph.D., an Associate Professor in the College of Human Resources at West Virginia University. The purpose of this study is to investigate school-based SLPs' challenges in the specific framework of their applicable roles and responsibilities within the RTI model. It is very important to examine the perceptions and opinions of school-based SLPs from around the state of West Virginia. These perceptions and opinions can help to guide future positions in issues that address implementation of the RTI model for school-based SLPs. Before you begin the survey, I would like to make sure that you understand the following:

- You must be 18 years of age or older to participate in this study;

- Your participation is entirely voluntary;

- Your responses will be kept as confidential as legally possible. You do not have to answer all questions and may quit at any time;

- Your job status will not be affected if you decide either not to participate or withdraw; and

- West Virginia University’s Institutional Review Board (IRB) has acknowledgement of this study on file.

This survey will use the following terms for consistency purposes:

- Response to Intervention: Research-based interventions over time while progress monitoring the student's response to interventions. The state of West Virginia recommends both duration and increased intensity of interventions to meet the needs of struggling students in the general education environment in order to decide if a student needs further evaluation by a psychologist and/or individualized education plan;

- Tiered intervention: Struggling students are provided research-based interventions with graduating levels of intensity based on data collected over time;

- Caseload: For this survey, a caseload is defined as being one based only on the number of students served who have a current Individualized Educational Plan (IEP) that addresses communication issues; and

- Workload: For this survey, a workload is defined as being one based on the number of students with an IEP that addresses communication issues served plus additional duties performed by the school-based SLP (such as implementation of RTI practices). 
Sincerely,

Jane D. Simmerman, SLP, MS

AUD

304-622-7834

jsimmerm@mix.wvu.edu

602 Allen Hall PO Box 6122 Morgantown, WV 26506-6122

Phone: 304-293-3441 Fax: 304-293-3802

Equal Opportunity / Affirmative Action Institution 
Appendix C

\section{Example of the Invitation Letter for Survey Monkey}

\section{Department of Curriculum \& Instruction/Literacy Studies WestVirginiaUniversity. \\ College of Human Resources and Education}

Dear School-Based SLP: (If you completed this survey in paper form, please do not complete a second time. Your prior participation was greatly appreciated.)

Thank you for agreeing to participate in a research study for my dissertation for my doctoral program in Curriculum and Instruction at West Virginia University of "Survey of Response-toIntervention's (RTI) Challenges for School-Based Speech-Language Pathologists”. I am conducting this research study under the supervision of Allison Swan-Dagen, Ph.D., an Associate Professor in the College of Human Resources at West Virginia University. The purpose of this study is to investigate school-based SLPs' challenges in the specific framework of their applicable roles and responsibilities within the RTI model. It is very important to examine the perceptions and opinions of school-based SLPs from around the state of West Virginia. These perceptions and opinions can help to guide future positions in issues that address implementation of the RTI model for school-based SLPs. Before you begin the survey, I would like to make sure that you understand the following:

- You must be 18 years of age or older to participate in this study;

- Your participation is entirely voluntary;

- Your responses will be kept as confidential as legally possible. You do not have to answer all the questions and may quit the study at any time;

- Your job status will not be affected if you decide either not to participate or withdraw; and

- West Virginia University’s Institutional Review Board (IRB) has acknowledgement of this study on file.

This survey will use the following terms for consistency purposes:

- Response to Intervention: Research-based interventions over time while progress monitoring the student's response to interventions. The state of West Virginia recommends both duration and increased intensity of interventions to meet the needs of struggling students in the general education environment in order to decide if a student needs further evaluation by a psychologist and/or individualized education plan;

- Tiered intervention: Struggling students are provided research-based interventions with graduating levels of intensity based on data collected over time;

- Caseload: For this survey, a caseload is defined as being one based only on the number of students served who have a current Individualized Educational Plan (IEP) that addresses communication issues; and

- Workload: For this survey, a workload is defined as being one based on the number of students with an IEP that addresses communication issues served plus additional duties performed by the school-based SLP (such as implementation of RTI practices). 
Thank you for your willingness to participate in this research study.

The following link, http://www.surveymonkey.com/s/XFPJJ2Z, will take you to the survey, which is located on SurveyMonkey.com.

Sincerely,

Jane D. Simmerman, SLP, MS

AUD

304-622-7834

jsimmerm@mix.wvu.edu

602 Allen Hall PO Box 6122 Morgantown, WV 26506-6122

Phone: 304-293-3441 Fax: 304-293-3802

Equal Opportunity / Affirmative Action Institution 


\section{Appendix D}

\section{Permission to Conduct Pilot Study}

\section{West Virginia University Internal Review Board}

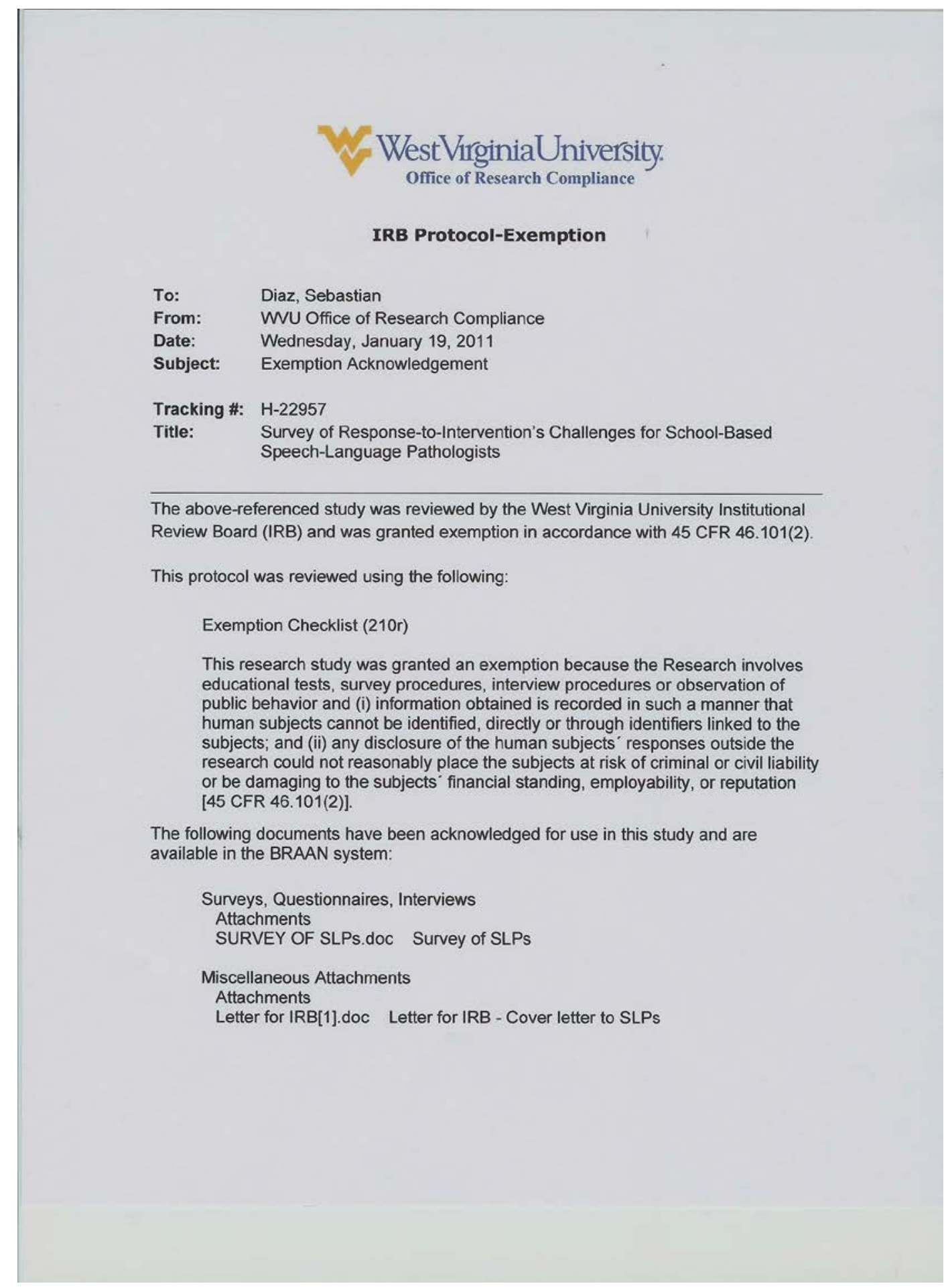




\section{Appendix E}

\section{Permission to Include Pre-Existing Data}

\section{West Virginia University Internal Review Board}

\section{West VurginiaUniversity. \\ Office of Research Compliance}

IRB Protocol-Exemption

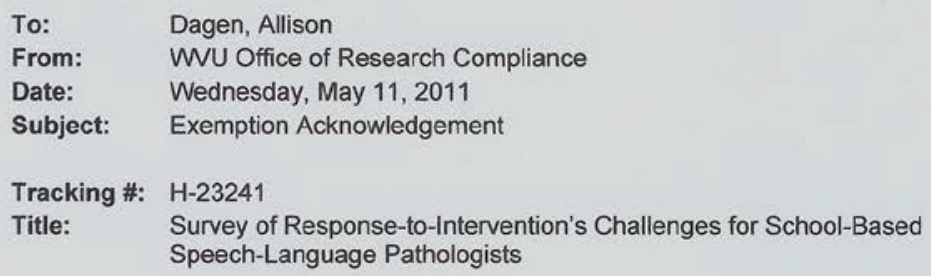

The above-referenced study was reviewed by the West Virginia University Institutional Review Board (IRB) and was granted exemption in accordance with 45 CFR 46.101(4).

This protocol was reviewed using the following:

\section{Exemption Checklist (210r)}

This research study was granted an exemption in accordance with Research on existing data, documents, records, pathological specimens, or diagnostic specimens [45 CFR 46.101(4)].

All exemptions are only good for three years. If this research extends more than three years beyond the approved date, then the researcher will have to request another exemption.

The following documents have been acknowledged for use in this study and are available in the BRAAN system:

\section{Thank you}

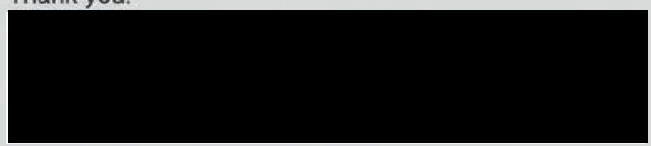

Board Designee: White, Barbara

Letter Sent By: White, Barbara, 5/11/2011 3:04 PM 


\section{Appendix F}

\section{Permission to Collect Data via SurveyMonkey.com}

\section{West Virginia University Internal Review Board}

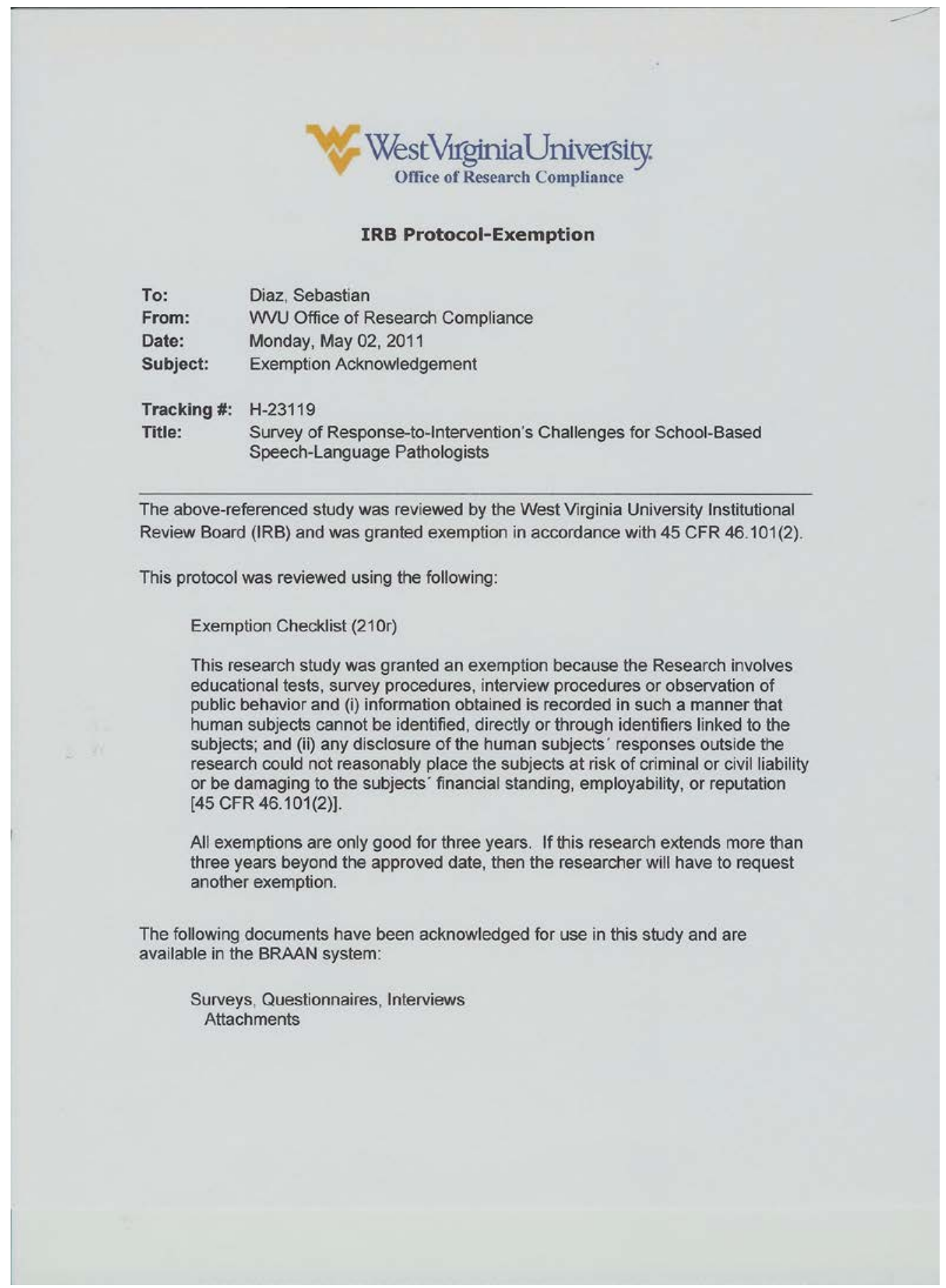


Survey_17752661.pdf

Miscellaneous Attachments

Attachments

LETTER FOR PAPER SURVEY.doc Informational Cover Letter for the Paper Survey

LETTER FOR SURVEYMONKEY SURVEY.doc Informational Cover Letter for SurveyMonkey Survey

Tag for Surveys.doc Tag for "lottery-type" drawing for completed surveys

Miscellaneous Attachments

Attachments

Verbal Script for Distribution of Paper Survey.doc Verbal Script for Paper Survey

Thank you.

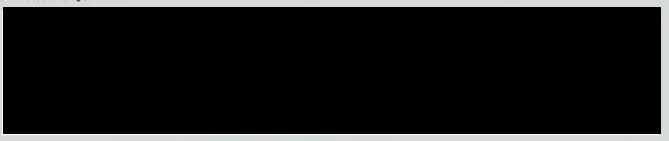

Board Designee: White, Barbara

Letter Sent By: White, Barbara, 5/2/2011 9:14 AM

Once you begin your human subject research, the following regulations apply:

1. Any modifications to the study protocol must be reviewed and acknowledged by the IRB prior to implementation.

2. You may not use a modified form until it has been acknowledged by the IRB.

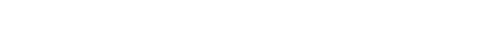

$\mathrm{DN}: \mathrm{cn}=J$ ohn H. Hagen, $\mathrm{o}=$ We

Virginia University Libraries,
ou=Acquisitions Department 